\title{
The Economic Underpinnings of the Drug Epidemic
}

\author{
Nathan Seltzer*, University of California, Berkeley
}

Draft: $10 / 8 / 2020$

\begin{abstract}
U.S. labor markets have experienced transformative change over the past half century. Spurred on by global economic change, robotization, and the decline of labor unions, state labor markets have shifted away from an occupational regime dominated by the production of goods to one characterized by the provision of services. Prior studies have proposed that the deterioration of employment opportunities may be associated with the rise of substance use disorders and drug overdose deaths, yet no clear link between changes in labor market dynamics in the U.S. manufacturing sector and drug overdose deaths has been established. Using restricted-use vital registration records between 1999-2017 that comprise over 700,000 drug deaths, I test two questions: First, what is the association between manufacturing decline and drug and opioid overdose mortality rates? Second, how much of the increase in these drug-related outcomes can be predicted by manufacturing decline? The findings provide strong evidence that the restructuring of the U.S. labor market has played an important upstream role in the current drug crisis. Up to 92,000 overdose deaths for men and up to 44,000 overdose deaths for women are attributable to the decline of state-level manufacturing over this nearly two-decade period. These results persist in models that adjust for other social, economic, and policy trends changing at the same time. Critically, the findings signal the value of policy interventions that aim to reduce persistent economic precarity experienced by individuals and communities, especially the economic strain placed upon the middle class.
\end{abstract}

\section{Keywords}

Drug Overdose Deaths, Opioid Crisis, Deindustrialization, Social Determinants of Health, Economic Conditions

* Nathan Seltzer, Department of Demography, Berkeley Population Center, University of California, Berkeley. Email: nseltzer@berkeley.edu.

The author is grateful for feedback from Jenna Nobles, Rourke O’Brien, Myra Marx Ferree, Christine Schwartz, Jim Raymo, Jessica Polos, and Ariane Ophir as well as from conference participants at the NBER Retirement Research Center Conference on the Determinants of Life Expectancy by Income \& Geography in April 2018. This research was supported by the U.S. Social Security Administration through grant \#RRC08098400-09 to the National Bureau of Economic Research as part of the SSA Retirement Research Consortium. The findings and conclusions expressed are solely those of the author and do not represent the views of SSA, any agency of the Federal Government, or the NBER. This research also received support from the grant [T32 AG00129], awarded to the Center for Demography of Health and Aging at UWMadison by the National Institute on Aging, and grant [T32 HD007014] awarded to the Center for Demography and Ecology at the University of Wisconsin-Madison by the Eunice Kennedy Shriver National Institute of Child Health \& Human Development. All errors are the author's own. The author declares no conflicts of interest. 


\section{The Economic Underpinnings of the Drug Epidemic}

Nathan Seltzer, University of California, Berkeley

\section{Introduction}

The ongoing drug epidemic is one of the most consequential public health issues in the United States right now. Drug overdose deaths in the United States continued to rise through 2017, reducing overall life expectancy for the third year in a row - a trend in life expectancy that has not occurred in over a century (Hedegaard, Warner, and Miniño 2018; Murphy et al. 2018; Woolf and Schoomaker 2020). Nationally, drug overdose death rates increased from 6.1 deaths per 100,000 population in 1999 to 21.7 deaths per 100,000 population in 2017 (Murphy et al. 2018). Despite a slight decline to 20.7 deaths per 100,000 in 2018 (Hedegaard, Miniño, and Warner 2020), preliminary counts of overdose deaths from 2019 indicate a resurgence to 2017 levels (Ahmad, Rossen, and Sutton 2020).

Researchers have debated the extent to which social and economic determinants of health are meaningful explanations of the U.S. drug and opioid epidemic, with a particular emphasis on the opioid epidemic (Case and Deaton 2015, 2018; Dasgupta, Beletsky, and Ciccarone 2018; Ruhm 2019). While some emphasize the importance of pharmaceutical companies in increasing the legal supply of prescription opioids (e.g. Ruhm 2019), others emphasize the role of structural economic change and economic despair as demand-side drivers of rising rates of substance use (e.g. Case and Deaton 2015a, 2017; Monnat 2019). Yet, this framing of dueling supply-side and demand-side explanations overlooks the endogenous interrelationship between both the supply and demand. Analyses of the geospatial patterning of the opioid epidemic indicate that areas with higher economic precarity - higher rates of poverty, higher rates of unemployment, and lower median home values, for instance - also had higher rates of filled opioid prescriptions, opioid- 
related hospital visits, and ultimately, opioid overdose deaths (Ghertner and Groves 2018;

Monnat 2019; Schoenfeld et al. 2019). Moreover, counties that received more pharmaceutical company opioid marketing to physicians also had higher rates of opioid prescribing and opioid overdose deaths (Hadland et al. 2019). A full accounting of the origins of the opioid epidemic therefore necessitate a broader examination of how contextual economic conditions are associated with the rise of opioid deaths.

Prior studies have proposed that long-term changes in economic conditions, including the deterioration of employment opportunities in U.S. labor markets and the rise of economic insecurity for families, may be associated with the rise of substance use disorders and drug overdose mortality rates more generally (Betz and Jones 2018; Case and Deaton 2017; Ghertner and Groves 2018; Hederos et al. 2017; McLean 2016; Monnat 2018; Nosrati et al. 2017). Understanding this relationship is necessary for multiple reasons. Establishing whether drugrelated overdose deaths are attributable to upstream social and economic factors opens additional avenues of clinical, public health, and public policy intervention to stem the ongoing rise of drug overdose deaths. It may also shed light on regional variation in epidemic intensity and facilitate prediction of trends in these rates. Many of the hardest hit regions of the ongoing drug and opioid crisis have also endured decades of deteriorating economic conditions (Dasgupta et al. 2018; Ezzati et al. 2008; Zoorob and Salemi 2020). Investigating this relationship informs social scientists about the scope conditions under which social and economic contexts are salient predictors of population-level health outcomes.

The present study considers how structural economic change - specifically, the decline of employment opportunities in the manufacturing sector - are associated with the rise of drug deaths since the late 1990s. Over the past half century, the United States labor market has 
experienced an industrial restructuring that has fundamentally reshaped the employment opportunities available to American workers, particularly for those with only a high school degree (Acemoglu and Autor 2011; Autor and Dorn 2013; Autor, Katz, and Kearney 2006; Kalleberg 2009). Spurred on by global economic change, robotization, and the decline of labor unions, U.S. labor markets have shifted away from an occupational regime dominated by the production of manufactured goods to one characterized by the provision of services. This new occupational structure has prompted the job polarization of U.S. labor markets, wherein the decline of largely middle-wage employment in manufacturing sectors has been accompanied by the rise of employment growth in low-wage and high-wage service sectors (Autor et al. 2006).

Although this structural transformation of U.S. labor markets began in the 1970s, the decline of employment opportunities in the manufacturing sector accelerated rapidly during the 2000s with the loss of nearly 5.4 million jobs (Atkinson et al. 2012). In comparison to the 1980s and the 1990 s, when manufacturing employment decreased on average by about $0.5 \%$ per year, manufacturing employment decreased on average by $3.7 \%$ per year in the 2000s (Figure 1). And although the manufacturing sector experienced a resurgence of employment growth following the Great Recession throughout the 2010s, only about 1.3 million manufacturing jobs were regained out of the initial 5.4 million that were lost since the early 2000s. Additionally, these new manufacturing jobs were less likely to pay as well as manufacturing jobs created in past decades (Jacobs et al. 2016). Overall, the decline of manufacturing jobs has resulted in the stagnation of wage growth and the depletion of financial resources for the American middle class (Kalleberg 2009; Kalleberg and von Wachter 2017). Middle-income households held 62\% of aggregate household income at the start of the 1970s. They now hold less than $43 \%$ of aggregate household income, largely the result of declining middle-wage jobs (Pew Research Center 2015). 
Recent research in the social and biomedical sciences has raised important questions about the implications of these and other structural economic changes on the mental health and emotional well-being of the middle class. Scholars theorize that the restructuring of labor markets, the rise of precarious work arrangements, and an overall stagnation of economic opportunity for many, has stimulated the rise of economic anxiety (Brand 2015; Case and Deaton 2015; Kalleberg 2018; Kirsch and Ryff 2016; Lim 2017; McCall et al. 2017; Thiede and Monnat 2016). Job loss, economic disinvestment, and out-migration from local labor markets and communities influence perceptions of economic opportunity, which in turn are associated with several indicators of worsened physical and mental health (Burgard, Brand, and House 2009; Catalano 1991; Charles and DeCicca 2008; McLean 2016; Zivin, Paczkowski, and Galea 2011). One of the clearest manifestations of this hypothesized process is the recent intensification of diagnoses of substances use disorders (SUDs) and drug overdose deaths (Gaydosh et al. 2019; Murphy et al. 2018). Both quantitative and qualitative research accounts suggest that local risk environments characterized by dampened economic opportunity can influence substance use (McLean 2016; Monnat 2019; Venkataramani et al. 2020). In this sense, drug deaths may represent a particularly extreme version of individual-level responses to societal pressures.

The present study contributes a sociological perspective to literature on the ongoing drug and opioid epidemic by emphasizing the role of institutions in shaping both social and economic contexts that impact health outcomes. Legislative and regulatory strategies for spurring industrial growth and addressing the oversupply of prescription opioids vary considerably across state borders, which motivates the importance of state-level comparisons that account for heterogenous social, economic, and political contexts. 
Using this state-level framework, I combine economic and business activity data from multiple sources with annual drug and opioid overdose mortality data from the National Center for Health Statistics to answer two questions. First, what is the association between manufacturing decline and drug and opioid overdose mortality rates? Second, how much of the increase in these overdose mortality outcomes can be predicted by manufacturing decline? I use a research design that leverages variation both within states and within time periods to sidestep endogeneity concerns that complicate identification. I use data from the Census Bureau's County Business Patterns program to examine how the decline in the relative share of state-level employment and earnings in manufacturing industries impacts drug and opioid mortality, net of factors that shape the supply of opioids and changes in other state-level contextual and compositional processes. This analysis is augmented by the estimation of a series of alternate specifications, including county-level models, to further evaluate the robustness of the results. The findings suggest strong evidence that the industrial restructuring of the U.S. labor market - the decline of manufacturing, in particular - has likely played an important upstream role in the current drug and opioid crisis. Up to 92,000 overdose deaths for men and up to 44,000 overdose deaths for women are predicted by the decline of state-level manufacturing over this nearly two-decade period.

\section{Background}

\subsection{Economic Deterioration and Negative Health Outcomes}

Social scientists have increasingly turned their attention towards the link between macroeconomic conditions, individual-level experiences of the labor market, and physical and mental health outcomes. Prior individual-level analyses on job displacement and plant closures in the U.S. and in European countries have demonstrated that involuntary job loss is associated with an array of negative health related outcomes, including decreased mental and physical 
health functioning (Riumallo-Herl et al. 2014; Schaller and Stevens 2015), decreased selfreported health (Huijts et al. 2015; Strully 2009), increased cigarette smoking and alcohol consumption (Black, Devereux, and Salvanes 2015; Gallo et al. 2001), and short-term and longterm increased risks of all-cause mortality (Browning and Heinesen 2012; Sullivan and von Wachter 2009). Studies have documented how increased economic strain (Schaller and Stevens 2015; Strully 2009; Sullivan and von Wachter 2009), decreased employment prospects and precarious employment situations (Janoski, assistant) Luke, and Oliver 2014; Strully 2009), and reduced access to health insurance and reduced health care use (Jolly and Phelan 2017; Schaller and Stevens 2015; Sullivan and von Wachter 2009) increase the likelihood of experiencing adverse health outcomes and behaviors, including alcohol and cigarette usage.

Population substance use, including opioid use, may increase during periods of economic deterioration through multiple pathways. This may occur directly through the heightened stress of job displacement on individuals and their families, or indirectly through population health impacts initiated by dampened economic opportunity and increased economic insecurity within labor markets. The individual-level experience of job displacement, and the resultant economic strain and reduction of resources, fosters a risk-environment that increases the likelihood of substance abuse (Mclean 2018; Merline et al. 2004; Rhodes 2009; Rolfs et al. 2012).

Yet, the direct experience of job displacement for laid off workers does not fully account for the massive growth of substance use disorders and drug overdose deaths in communities that have experienced economic deterioration over the past several decades. Several pathways operate outside of individual-level effects. For example, the economic consequences of job loss and business disinvestment from labor markets extend beyond displaced workers to their families and to the broader community; these effects appear to have spillover health costs (Adda and Fawaz 
2019; Broman, Hamilton, and Hoffman 1990; Colantone, Crinò, and Ogliari 2019; Lang, McManus, and Schaur 2019). Long-term economic change like manufacturing decline alters the opportunity structures of labor markets and influences perceptions of economic uncertainty, which in turn increases physical and mental health issues (Colantone et al. 2019; Lang et al. 2019).

Indeed, several recent studies have suggested a link between economic deterioration in labor markets and increased opioid deaths. Monnat (2018), found a cross-sectional association between manufacturing dependence and average drug-related mortality rates across U.S. counties. In a separate analysis, Monnat (2019) found that drug mortality rates for non-Hispanic whites are larger in counties designated as service sector-dependent in comparison to counties designated as non-specialized. Likewise, Pierce and Schott (2016), examining the impact of U.S. trade policy on cause-specific mortality from three categories of deaths of despair, found that the implementation of trade liberalization policies predicted increased mortality rates from accidental poisonings for white men and women, but not for other racial/ethnic groups. In contrast to these findings, Ruhm (2018), examining changes in county-level drug mortality rates between 1999-2015, reported a positive, albeit non-significant, association between Chinese import penetration and overall increased drug mortality rates; but overall, he concludes that economic conditions (including other economic measures besides import penetration) explain less than $10 \%$ of the drug epidemic. Finally, Venkataramani and colleagues' (2020) research on the relationship between automotive plant closures in local communities and opioid overdose mortality suggests that discrete economic shocks within commuting zone labor markets are associated with county-level increases in opioid overdose deaths. 
The present study builds on and contributes to this literature by using an identification strategy that supports attribution of drug and opioid deaths to upstream economic change- and the shift from manufacturing to service employment in particular. I leverage annual variation in statelevel manufacturing change to estimate drug and opioid overdose mortality. The panel design models a data generating process in which yearly fluctuations in employment conditions have immediate impacts on substance use and drug overdose deaths.

Though past findings have asserted that the rise of drug deaths throughout this time period are mostly concentrated among middle-age white men (e.g. Case and Deaton 2015), recent studies have documented a counter-narrative: deaths of despair have substantially increased for a more expansive set of racial/ethnic groups, as well as for women (Alexander, Kiang, and Barbieri 2018; Gaydosh et al. 2019; Woolf et al. 2018). In light of these findings, I further investigate whether structural economic changes have differentially influenced drug deaths across racial/ethnic and gender subgroups by estimating a set of sensitivity models that predict age-, sex-, and race/ethnicity-specific drug mortality rates.

\subsection{State-Level Heterogeneity in Socio-Political Policy Regimes}

Rising differentiation in state-level health and economic policies have contributed to an increasingly common practice of conceptualizing the state as a laboratory to study population welfare (Montez et al. 2020; Montez, Hayward, and Zajacova 2019). Indeed, state-level contexts and policies are important determinants of population health outcomes, specifically (Bradley et al. 2016; Kim and Jennings 2009; Montez et al. 2019). State legislative and regulatory decisions influence population health outcomes directly through health policies such as tobacco control and Medicaid expansion, but also indirectly through social and economic policies in domains such as education and the criminal justice system (Massoglia and Remster 2019; Miller et al. 
2019; Montez et al. 2020), which stratify health outcomes within and across state populations.

Policies concerning economic development and the rise of opioid prescriptions vary dramatically across states, and rather than being viewed as distinct, separate state policies, are better conceptualized as components of broader socio-political policy regimes that influence the daily lives of residents. As noted by Montez et al. (2019), state-level authority has increasingly taken precedence over both federal- and local-level authority over the past several decades.

Additionally, the pace and character of industrial change over the past three decades has differed markedly across states. These differences arise in part because of differences across state labor markets in the routinizability and offshoreability of occupational tasks in certain manufacturing sectors (Acemoglu and Autor 2011; Autor and Dorn 2013), ${ }^{1}$ but also because of state-level policies that create incentives for manufacturers to stay put or to relocate plants. That is, states actively contend with one another as well as with international competitors to retain and attract manufacturing jobs. In order to promote economic development and industrial growth, policy approaches used by states have included financial incentives, corporate tax subsidies, labor deregulation, and the softening of environmental regulations, among others (Eisenger 1988; Eisneger 1995; Grant and Wallace 1994; Bartik 1988; Gray and Lowery 1990; Brace 2002; Giroud and Rauh 2015). Variation in the legislation and implementation of these state-level industrial policies and labor contexts as well as the outcomes of these policies further motivate the importance of state-level comparisons and the usage of state fixed effects. Nationally, the share of jobs in manufacturing industries declined by an average of 5.8 percentage points between 1998-2016, from 15.2\% in 1998 to $9.4 \%$ in 2016 (Figure 2A, data and measurement

\footnotetext{
${ }^{1}$ For instance, manufacturing employment in the automobile industry decreased for midwestern states while increasing for southern states (Cutcher-Gershenfeld, Brooks, and Mulloy 2015).
} 
described below). In this same time period, the share of total annual payroll in manufacturing industries declined by an average of 7.2 percentage points, from $18.6 \%$ in 1998 to $11.4 \%$ in 2016 (Figure 2B). This average national decline masks substantial state-level variation. Arkansas, Rhode Island, Tennessee, North Carolina, and South Carolina experienced large declines in manufacturing employment of over 8 percentage points, while states such as Nevada, Wyoming, and Hawaii experienced declines of less than 2 percentage points.

An analysis examining the effects of state-level economic change on health and mortality must also be attentive to other contemporaneous social, economic, and compositional changes that might confound estimation. To address this concern, the models adjust for a set of theoretically relevant, time-varying compositional and contextual population-level characteristics, including educational attainment, race/ethnicity, nativity, marital status, population age structure, and selfreported health (Chetty et al. 2016; Schoenfeld et al. 2019). Based on prior literature that documents how companies move production operations to labor markets with cheaper labor costs and labor protections (Grant and Wallace 1994), I adjust for state-level trends in the percentage of workers represented by labor unions..$^{2}$ I adjust for state-level trends in labor force participation rates because shifts in labor force participation are associated with changes in population health outcomes and cause-specific mortality rates, including deaths from drugs and alcohol (Case and Deaton 2017). The labor force participation rate is conceptually distinct from the relative share of manufacturing employment since it quantifies attachment to the labor force rather than the industrial characteristics or qualities of jobs in a labor market.

\footnotetext{
${ }^{2}$ I also tested for the percentage of workers in a state labor force who were members of labor unions rather than those covered/represented by labor unions. The results are approximately the same.
} 
For the study of opioids specifically, there is also relevant state-level variation in policies that have facilitated the local supply of opioids. State governments have enacted an array of policy strategies to address the opioid epidemic. For instance, the creation of Prescription Drug Monitoring Program's (PDMPs), state-run electronic databases that allow prescribers, dispensers, and other health authorities to track the prescription patterns of controlled substances for individual patients, has become a widely adopted policy intervention used by states to reduce the amount of opioid painkillers prescribed to patients (Bao et al. 2017; Cerdá et al. 2020; Fink et al. 2018). States have also enacted other policy interventions such as laws that aim to regulate pain management clinics, increase access to naloxone, and improve legal protections for bystanders who report drug overdoses as they are occurring. The outcomes of these policies, whether effective in reducing substance use and opioid deaths or not, has varied (e.g. Doleac and Mukherjee 2018). I adjust for the implementation of PDMPs, naloxone access laws, and Good Samaritan laws, to account for these major drug policy interventions. Given data availability limitations for the full 19-year time period, I adjust for state-level trends in the supply of legally dispensed opioid prescriptions in sensitivity analyses that span the years 2007-2017, thereby netting out the supply of legal opioids. As an alternative strategy, I additionally test for differences across states that had implemented "triplicate" programs - early versions of PDMPs - in the 1990s. States with triplicate policies have experienced slower growth in opioid overdose deaths over the past two decades, largely the result of receiving a smaller supply of prescription opioids than non-triplicate states (Alpert et al. 2019).

Situating the present analysis at the state-level therefore facilitates modeling how regional variation in ecological risk environments contributes to variation in the concentration of a pressing public health concern, specifically, drug and opioid overdose mortality. It also 
facilitates an opportunity to address the implementation of several important state-level policy changes that are widely considered relevant to the unfolding of the U.S. opioid epidemic. Capturing annual variation in these processes both increases the precision of identification and advances a theoretical model of how labor market dynamics shape contexts of substance use and drug overdose.

\section{Data and Methods}

\subsection{Drug Overdose Mortality Rates}

Rates of annual state-level, drug and opioid overdose mortality between 1999-2017 were calculated using the restricted-use multiple cause of death file from the National Center for Health Statistics (NCHS) in combination with bridged-race population estimates from the NCHS. Mortality data used in this study are based on approximately 47.7 million death certificate records of U.S. residents reported to the National Vital Statistics System (NVSS) between 1999-2017. For drug overdose mortality rates, this data represents approximately 260,000 deaths to women and 440,000 deaths to men, among which 326,000 of those male deaths are for non-Hispanic white men ages 15-64. For opioid mortality rates, this data represents approximately 134,000 deaths to women and 262,000 deaths to men.

Drug overdose mortality rates were constructed and defined using the International Statistical Classification of Diseases and Related Health Problems $10^{\text {th }}$ Revision (ICD10) underlying cause of death codes X40-44, X60-64, X85, and Y10-14 (Hedegaard et al. 2018). These classifications include drug deaths recorded as unintentional, suicide, homicide, or of undetermined intent, although nearly $90 \%$ are recorded as unintentional. Opioid overdose mortality rates were constructed using the previous ICD10 underlying cause of death codes in conjunction with any of the following ICD10 multiple cause of death codes T40.0 (Opium), T40.1 (Heroin), T40.2 
(Other Opioids), T40.3 (Methadone), T40.4 (Other Synthetic Narcotics), or T40.6 (Other

Unspecified Narcotics). Appendix Table S1 presents the full description of all ICD10 codes used to define drug and opioid mortality rates.

Between 1999-2017, 21\% of drug overdose deaths in the NCHS multiple cause of death file were coded as involving a single unspecified drug, medicament, or biological substance (ICD10 code T50.9). The high proportion of unclassified drug overdoses on death certificates has likely resulted in an undercount of opioid involved overdoses (Boslett, Denham, and Hill 2020; Buchanich et al. 2018; Ruhm 2017; Warner et al. 2013). Using correction techniques, researchers estimate that nearly $3 / 4$ of these unclassified drug overdose deaths were likely to involve opioids, with substantial variation across states and time (Boslett et al. 2020; Ruhm 2017). To address the undercount, I implemented a correction procedure that predicted opioid involvement in unclassified drug overdose deaths using logistic regression models and a parsimonious set of decedent characteristics as predictors (Boslett et al. 2020). The full methodology for this correction procedure is described in Appendix Note S1. For analyses in the present study that test for the association between manufacturing decline and opioid deaths, I present estimates for both the non-corrected opioid mortality rates and the corrected opioid mortality rates.

I calculated age-adjusted mortality rates to account for shifts in the age distribution of state populations over time as well as differences in the age distribution of populations across states. I then log-transformed the age-adjusted mortality rates because the non-transformed mortality rates are right-skewed and nonnormal (Figure S1). Since there were only a couple of state-year observations with drug or opioid death rates of zero, I allowed the log transformation to render these values as undefined and excluded them from my analysis. I used the "direct" method of age standardization to derive age-adjusted death rates based on the weighted age distribution of the 
total U.S. population in the year 2000 as the standard (Anderson and Rosenberg 1998). I accessed bridged-race population estimates from the NCHS for population denominators. I then evaluated the accuracy of the calculated age-adjusted mortality rates by comparing equivalent non-suppressed, publicly available age-adjusted mortality rates for state-year observations that had more than 9 deaths through the CDC Wonder database. The correlation between the rates I calculated and those accessed through CDC Wonder ranged from $r=.9998$ to $r=.9999$, indicating that the calculations were performed correctly. The advantage of using the restricted-use multiple cause of death file is that the present analysis includes non-zero, state-year observations that would otherwise be suppressed in the public-use file.

\subsection{Measures}

\subsubsection{Manufacturing decline}

The decline of the U.S. manufacturing sector in state labor markets was assessed using relative measures of the total number of employees and total annual payroll concentrated in the manufacturing sector. Both measures were lagged one-year to achieve appropriate temporal ordering. I obtained state-level data on annual employment and payroll between 1998-2016 from the U.S. Census Bureau's County Business Patterns program (CBP) which compiles subnational business establishment data according to 6-digit North American Industry Classification System (NAICS) codes (U.S. Census Bureau 2018). CBP relies primarily on business establishment data from the Census Bureau's Business Register (BR) which contains a complete list of all business establishments in the United States with paid employees. The relative share of annual employment and payroll was calculated by dividing the number of employees and payroll in the manufacturing sector (NAICS 2-digit codes 31-33) by the number of employees and payroll in all business sectors. 


\subsubsection{Covariates}

I included a set of theoretically relevant, time-varying covariates in the models which might plausibly confound the direct association between manufacturing decline and mortality rates. Based on extant literature on the economic and geographic determinants of mortality and life expectancy (e.g. Chetty et al. 2016; Elo et al. 2019; Woolf and Schoomaker 2020), the models adjust for state-level compositional and contextual characteristics including the labor force participation rate, the percentage of workers covered by labor unions, the percentage of the population with a college degree, the percentage of the population ever married, the percentage of the population who are Hispanic, the percentage of the population who are Black, the age structure of the population, the percentage of the population living in metropolitan area counties, and scores of self-reported health.

The findings of several recent studies (Currie, Jin, and Schnell 2019; Krueger 2017) have suggested a reverse causal direction between economic conditions and the opioid epidemic: that is, substance use might causally impact rates of unemployment and labor force participation. I use an estimation strategy that lags all predictors by one year to achieve well-defined temporal ordering, but I additionally test specifications that adjust for a set of state-specific drug regulatory policies that might plausibly be associated with both growth or contraction in manufacturing industries (or labor markets more broadly) and drug use. These policies include annual binary indicators for the initial and ongoing implementation of Prescription Drug Monitoring Programs (PDMPs), naloxone access laws, and Good Samaritan laws. The outcomes of these policies, whether effective in reducing substance use and opioid deaths, has varied (for Naloxone access laws, see Doleac and Mukherjee 2018; for PDMPs, see Fink et al. 2018, Finley 
et al. 2017, or Grecu et al. 2019); yet, they represent the implementation of extensive state-level interventions that might explain trends in drug and opioid deaths.

Data on state-level labor force participation rates were accessed from the U.S. Census Bureau's Local Area Unemployment Statistics program (LAUS) (Bureau of Labor Statistics 2018). Data on annual state-level union coverage come from the Union Membership and Coverage Database (Hirsch and Macpherson 2003) which estimates statistics on union membership using the Current Population Survey (CPS). Data used to calculate the percentage of the state population living in metropolitan counties were accessed from the USDA Economic Research Service's 2013 ruralurban continuum codes dataset (United States Department of Agriculture 2019). Data used to calculate compositional racial/ethnic and age structure covariates were accessed from the NCHS bridged-race population estimates. Data on other state-level social, economic, health, and compositional characteristics between 1999-2017 were calculated using micro-data from the U.S. Census Bureau's CPS Annual Social and Economic Supplement accessed through the Integrated Public Use Microdata System (IPUMS) at the University of Minnesota (Flood et al. 2020). I applied person-level weights when generating these state-level characteristics. Finally, data on the implementation of state-level drug policies were acquired from the Prescription Drug Abuse

Policy System (PDAPS) (Bao et al. 2017). Table 1 displays the means and standard deviations of the entire sample for the full period of the study, 1999-2017.

\subsection{Analytic Approach and Model Specification}

This study leverages annual variation within state labor markets over nearly two decades to evaluate how declining shares of manufacturing jobs and earnings contribute to changes in drug and opioid overdose mortality. I estimated a set of two-way, state-level fixed effects regression equations predicting log-transformed age-adjusted rates of drug and opioid overdose deaths, for 
women and men separately. The first specification adjusted for state and year fixed effects as well as contextual and economic characteristics. I then introduced measures of several state-level time-varying policies that might plausibly confound the association between manufacturing decline and overdose mortality. To test the robustness of the results to measurement choices, I operationalized the decline of manufacturing in two separate ways: first, as the percentage of workers employed in the manufacturing sector, and second, as the percentage of total annual payroll concentrated in the manufacturing sector. Parameter estimates and clustered standard errors at the state-level are reported for all estimated regression models. In the main analyses, I omit state-level population weights because states are conceptualized here as distinct administrative entities with different sets of social, economic, and health policies. Nevertheless, I present supplementary analyses that weight for population size to test whether the results hold up under a different set of assumptions. The models are specified as follows:

Eq. 1

$$
\log \left(M_{s t}\right)=\boldsymbol{\beta} \boldsymbol{x}_{s t}+\boldsymbol{\alpha}_{s}+\boldsymbol{\mu}_{s t}
$$

where $\log \left(M_{s t}\right)$ refers to the log-transformed age-adjusted mortality rate for state $s$ during year $t$; $\boldsymbol{\beta}$ refers to a vector of estimated coefficients; $\boldsymbol{x}_{s t}$ refers to a vector that measures the relative share of state-level manufacturing, either the percentage of employment or annual payroll concentrated in manufacturing industries, and vectors of state-level compositional and contextual characteristics as well as additional state-level policies, in addition to binary-coded year vectors; $\boldsymbol{\alpha}_{s}$ refers to a vector of state-specific intercepts; and $\boldsymbol{\mu}_{s t}$ refers to state- and year-specific error terms.

\subsection{Subgroup and Sensitivity Analyses}

I conducted several additional analyses to (1) further investigate subgroup heterogeneity, (2) test for differences across states with and without "triplicate" programs, and, alternatively, explicitly 
adjust for the state-level supply of prescription opioids, (3) evaluate whether the results persist when predicting county-level drug and opioid overdose mortality rates, (4) assess whether the results persist when using negative binomial regression equations as an alternative modeling strategy, (5) include population weights in the model estimation, (6) adjust for multiple potential sources of omitted variable bias and gauge the extent to which unobserved omitted variables might influence the results, and, (7) test whether the results persist when using non-fatal outcomes of substance use: opioid-related inpatient hospitalizations and emergency department visits.

First, I constructed models that predicted age-specific counts of drug deaths, binned across 10year age intervals between the ages 25-64, for non-Hispanic whites and blacks separately by sex. ${ }^{3}$ To account for an excess of state-year observations with zero deaths for these racial/ethnic and age subgroups as well as overdispersion, I estimated negative binomial models predicting counts of drug and opioid overdose deaths instead of logged rates as in Eq. 1.

Second, recent findings by Alpert and colleagues (2019) document how states with "triplicate" programs - early versions of prescription drug monitoring programs - in place when OxyContin was initially introduced in 1996 experienced fewer opioid deaths over the following two decades. Alpert and colleagues (2019) argue that these state-level drug policies reduced the intensity of predatory marketing of prescription opioids by pharmaceutical companies, leading to lower longterm opioid prescribing rates. To evaluate whether the findings of the present study are robust to this important supply-side predictor of the opioid crisis, I estimated models that tested for differences in the association between manufacturing decline and opioid/drug overdose mortality

\footnotetext{
${ }^{3}$ In the age-, sex-, and race/ethnicity-specific set of sensitivity models, I include whites and Blacks, but not other racial/ethnic groups because most state-year values for other racial/ethnic groups are below 10 deaths and unreliable.
} 
according to whether states had implemented triplicate programs prior to OxyContin's introduction. I accomplished this by fully interacting the predictors in the main model with a binary indicator of whether a state had implemented a triplicate program in the years prior to the introduction of OxyContin. ${ }^{4}$ The interaction coefficient between measures of manufacturing decline and triplicate status tests for differences across triplicate states and non-triplicate states.

More broadly, the relationship between economic conditions and drug-related mortality and hospitalizations might be confounded by issues of drug supply (Monnat 2019; Ruhm 2019). Several recent studies have argued that the supply of prescription opioids is negatively associated with labor force outcomes, including unemployment rates and labor force participation (Currie et al. 2019; Hollingsworth, Ruhm, and Simon 2017; Krueger 2017). State-level opioid supply might therefore confound the identification in Eq. 1 that models the relationship between lagged manufacturing decline and drug overdose mortality rates and opioid-related hospitalizations. Therefore, I conducted sensitivity tests that adjusted for the state-level rate of retail opioid prescriptions dispensed per 100 population, which accounts for the full supply of legally dispensed prescription pills. ${ }^{5}$ These sensitivity models only cover the years 2007-2017 because of data availability. Data on the prescription opioid rate were accessed from the CDC which acquired prescription data from IQVIA, a health information technology and clinical research company (Centers for Disease Control and Prevention 2019; Guy et al. 2020). Unfortunately, there is no comparable dataset which measures the supply of illegal drugs.

\footnotetext{
${ }^{4}$ Triplicate states include California, Idaho, Illinois, New York, and Texas. I also include Indiana and Michigan which had triplicate programs that were discontinued in 1994, two years prior to the introduction of OxyContin. These former triplicate states had long-term trends in OxyContin supply and promotional payments to physicians by Purdue Pharma that more closely resembled states with triplicate programs than states that never had triplicate programs (Alpert et al. 2019).

${ }^{5}$ This is a measure of pill quantity and not prescription strength (i.e. morphine milligram equivalents).
} 
To evaluate whether the results persist when accounting for within-state variation, I estimated models predicting logged county-level drug and opioid overdose mortality rates with measures of manufacturing employment and annual payroll at three different levels of aggregation: the county-level, commuting zone-level, and state-level. For all specifications, I include county-level fixed effects and year fixed effects to maintain the two-way fixed effects modeling strategy. I incorporate county-level population weights, measured at the beginning of the time period (1999), to downweight counties with small populations that are likely to yield less stable annual mortality rates, and upweight counties with large populations that are likely to yield more stable annual mortality rates. I address the issue of substantial nonrandom data suppression of employment values in the county-level Census Bureau CBP dataset by estimating specifications that include manufacturing employment measures calculated from (a) the original CBP dataset, and (b) an imputed CBP dataset (Eckert et al. 2020) that relies on data suppression flags and the hierarchical structure of the Census CBP database to impute missing values using a linear programing algorithm. ${ }^{6}$

The commuting zone- and state-levels of aggregation for the manufacturing employment and annual payroll measures are preferable to counties because they account for relevant geographic spillovers of labor market conditions - that is, employment opportunities extend beyond one's county of residence (Venkataramani et al. 2020). Commuting zones identify clusters of contiguous counties, not bounded by state borders, where people both live and work based on commuter flows (Tolbert and Sizer 1996). Aggregating measures of manufacturing employment and earnings at these higher geographic levels capture pertinent information that would not necessarily be detectable at a lower level of geographic scale, such as the county-level (Lindo

\footnotetext{
${ }^{6}$ Unfortunately, there are no equivalent imputed datasets for annual payroll.
} 
2015). For all county-level models, I adjust for county-level compositional covariates (\% nonHispanic Black, \% Hispanic, and detailed population age structure in 5-year age bins), countylevel level labor force participation rates (for residents of the county), state-level characteristics (\% college educated, $\%$ ever-married, $\%$ of state living in metropolitan area counties, $\%$ foreign born) and policy variables (naloxone access law implementation, PDMP implementation, Good Samaritan law implementation, and \% workers covered by labor unions).

I next evaluated whether the results from the main specifications were sensitive to several important methodological decisions: modeling strategy, weighting procedure, over-adjustment, and potential omitted variable bias. I first estimated negative binomial regression models to predict counts of drug and opioid overdose deaths. I then re-estimated the main specifications with state-level population weights to address the concern that states with smaller populations might be biasing the results. I next removed the labor force participation rate from the set of covariates to address the potential issue that the process of deindustrialization might also alter the relative size of the labor force and therefore including this covariate might suppress the full effect. Finally, I tested for three potential sources of confounding: the detailed age structure of state populations, the percentage of the state population born outside of the U.S., and state-byyear linear time trends. Following these tests, I additionally implemented a formal bounds analysis (Oster 2019) to assess the sensitivity of the parameter estimates to unobservable variables.

Mortality is the most dismal consequence of drug and opioid misuse; however, the drug epidemic has also devastated individuals and communities through an array of negative physical and mental health outcomes that require medical interventions. In a final sensitivity analysis, I consider whether structural changes in manufacturing employment and annual payroll are 
associated with two types of medical utilization: opioid-related emergency department visits and inpatient hospitalization stays. I accessed data on these outcomes through the Healthcare Cost and Utilization Project (HCUP) database from the Agency for Healthcare Research and Quality (AHRQ) at the U.S. Department of Health and Human Services. AHRQ draws on an annual sample of treat-and-release visits to emergency departments from the State Emergency Department Databases (SEDD) and a sample of short-term inpatient stays at community hospitals from the State Inpatient Databases (SID). Opioid-related emergency department visits and inpatient stays are coded according to ICD-9-CM codes (Weiss et al. 2017). These samples cover $98 \%$ of all inpatient discharges and $98.5 \%$ of all emergency department visits in the states that partner with AHRQ. For both measures, data are only available from 2005-2017, and the maximum number of states participating in the databases are 36 for the emergency department visits and 47 for the inpatient stays.

\section{Results}

\subsection{Manufacturing Decline and Logged Mortality from Drug Overdoses}

Figure 3 presents a series of maps of the U.S. that display the variation in age-adjusted drug overdose mortality rates across states in 1999, 2008, and 2017. For both men and women, rates of overdose mortality increased throughout the time period and were highest in West Virginia, Virginia, Ohio, and Washington, D.C. at the end of the period in 2017.

Table 2, Panel A presents the regression results predicting state-level logged mortality rates from drug overdoses for women and men using both measures of manufacturing decline (Full model output is presented in Appendix Table S2A). For the full age-adjusted log-transformed drug mortality rate models, Model 2, a one percentage point increase in the share of workers employed in manufacturing is associated with a $-3.4 \%$ decrease in drug mortality rates for 
women and a $-4.9 \%$ decrease in drug mortality rates for men. ${ }^{7}$ This is equivalent to a decrease of -0.32 deaths per 100,000 population in the drug mortality rate for women and a decrease of -0.77 deaths per 100,000 population in the drug mortality rate for men. Using the annual payroll measure, a one percentage point increase in the share of overall annual payroll in manufacturing is associated with a $-3.1 \%$ decrease in drug mortality rates for women and a $-3.8 \%$ decrease in drug mortality rates for men. This is equivalent to a reduction of -0.29 in the drug mortality rate for women and a decrease of -0.61 in the drug mortality rate for men. For both measures, the results are statistically significant below the $\mathrm{p}<.001$ threshold for men and below the $\mathrm{p}<.01$ level for women. Manufacturing jobs, as a share of all jobs in state labor markets, declined by an average of 5.8 percentage points throughout the entire 1999-2017 period. Accordingly, changes in manufacturing employment accounted on average for an additional 1.8 drug deaths per 100,000 for women and 4.5 drug deaths per 100,000 for men based on the point estimates between the start and end of this period. Similarly, the average decline of manufacturing annual payroll by 7.2 percentage points accounts for an additional 2.3 drug deaths per 100,000 for women and 5.5 drug deaths per 100,000 for men between the start and end of this period.

The point estimates indicate that manufacturing decline between 1999-2017 predicts an additional 90,309 (annual payroll) to 92,511 (employment) drug overdose deaths for men and an additional 39,402 (annual payroll) to 44,710 (employment) drug overdose deaths for women over this 19-year period, had the share of manufacturing employment and annual payroll remained at 1999 levels during each year of the present analysis. This means that manufacturing decline can

\footnotetext{
${ }^{7}$ For women, $(\exp (-0.034)-1) * 100=-3.343$; for men, $(\exp (-0.050)-1) * 100=-4.877$.
} 
explain approximately $21 \%$ of all overdose deaths for men and $15.2 \%$ to $17.2 \%$ of all overdose deaths for women between the start and end of this period.

Figure 4 displays the percentage of deaths between 1999-2017 attributable to changes in statespecific decreases in manufacturing employment and annual payroll for both women and men between 1999-2017. For states such as South Dakota, North Carolina, Mississippi, Nebraska, and Iowa, manufacturing decline predicts $40 \%$ or more of all overdose deaths for men and approximately $20 \%$ of all overdose deaths for women. Meanwhile, manufacturing decline predicts less than $5 \%$ of all overdose deaths for men and less than $2.5 \%$ of all overdose deaths for women in the District of Columbia and states such as Wyoming, Nevada, Hawaii, Alaska, and New Mexico. This map demonstrates the substantial and meaningful variation in the statelevel association between manufacturing decline and drug overdose death rates - a range of over 50 percentage points for men and roughly 30 percentage points for women. Appendix Table S3 presents the predicted number of deaths in each state attributable to manufacturing decline based on the employment and annual payroll point estimates.

\subsection{Manufacturing Decline and Mortality from Opioid Overdoses}

Out of the 700,000 drug overdose deaths over the 1999-2017 period, approximately 400,000 deaths involved the specified use of opioids, including prescription opioids, heroin, and synthetic opioids such as fentanyl and fentanyl analogs. To investigate the role of manufacturing decline on the opioid crisis specifically, Table 2, Panel B presents regression results predicting statelevel logged opioid mortality for women and men using both measures of manufacturing decline (Full model output is presented in Appendix Table S2B). For the full age-adjusted opioid mortality rate models, Model 2, a one percentage point increase in the share of workers employed in the manufacturing sector is associated with a $-5.4 \%$ decrease in opioid mortality for 
women and a $-6.9 \%$ decrease in opioid mortality for men. Using the annual payroll measure yields similar results: a one percentage point increase in the share of overall annual payroll in manufacturing is associated with a $-4.8 \%$ reduction in opioid mortality for women and an $-5.2 \%$ reduction in opioid mortality for men. The results are similar, although slightly larger in magnitude, when estimating models that use logged opioid mortality rates that have been corrected for death certificate records that undercount opioid involvement (Table 2, Panel C; Full model output is presented in Appendix Table S2C).

Throughout the entire 1999-2017 period, changes in manufacturing employment on average predict an additional 1.6 opioid deaths per 100,000 for women and 3.9 opioid deaths per 100,000 for men based on the point estimates. Changes in manufacturing annual payroll on average predict an additional 2.0 opioid deaths per 100,000 for women and 4.9 opioid deaths per 100,000 for men.

\subsection{Subgroup Analysis: Manufacturing Decline and Overdose Mortality across Racial/Ethnic-} Specific 10-Year Age Groups

Researchers have documented how the rise of drug deaths - particularly opioid drug deaths - is concentrated among middle-age, non-Hispanic white males (Case and Deaton 2015). The third column of Figure 3 presents a set of maps which display the rapid and widespread increase in overdose deaths among non-Hispanic white males ages 45-54 in 1999, 2008, and 2017.

Table 3A estimates negative binomial regression models predicting state-level counts of drug overdose deaths for non-Hispanic white females and males between the age of 25 to 64, binned at 10-year intervals. Regardless of the measure of manufacturing decline, the results for all age groups are substantively large and statistically significant for white males, with the effect size largest for white men ages 45-54. For the female age-specific models, the results are 
substantively large and statistically significant for both manufacturing measures in all age groups with the exception of the oldest 55-64 age group. In contrast to whites, manufacturing decline is generally not significantly associated with the rise of drug deaths for non-Hispanic Black females and males (Table 3B), but the association is largest and most precisely estimated for Black females ages 45-54 and Black males in the 35-44 and 55-54 age groups. ${ }^{8}$

\subsection{Triplicate Programs and Prescription Drug Supply}

Alpert et al. (2019) find extensive state-level variation in the growth of opioid overdose deaths according to whether state triplicate policies had been adopted prior to the introduction of OxyContin by Purdue Pharma in 1996. To evaluate whether the association between manufacturing decline and the rise of opioid overdose deaths persists regardless of state-level policies that limited the widescale prescribing of opioid medication, I estimated models that tested for differences across triplicate and non-triplicate states (Table 4). The results show that there is no statistically significant difference below the $p<.05$ level in the effect size of manufacturing decline on overdose deaths between triplicate and non-triplicate states. This suggests that the ecological, demand-side influence of structural economic change remains a salient predictor of rising opioid and drug overdose deaths even in states that had adopted strict drug control policies in the 1990s which would ultimately reduce the supply of legal prescription opioids over the next two decades.

To further assess the importance of drug supply on the main results, I estimated a set of models (Appendix Table S4, first column) that adjusted specifically for the legal supply of opioid prescriptions per 100 population using data accessed from the CDC. For models estimating log-

\footnotetext{
${ }^{8}$ The number of drug and opioid deaths for other racial/ethnic groups at the state level are too small to generate enough reliable annual mortality estimates for analysis.
} 
transformed age-adjusted rates of drug deaths, the results do not substantively change for men the magnitude of both manufacturing measures remains, but is less precisely estimated for the annual payroll measure - but the coefficient for percentage of annual payroll concentrated in manufacturing slightly attenuates and both measures lose precision for women. In contrast, the inclusion of this additional covariate into the models predicting log-transformed age-adjusted rates of opioid and corrected opioid deaths increases the standard errors in the male models as well as the female models. While caution should be used to interpret these models (they only cover the years 2007-2017, have a reduced number of state-year observations, and are not directly comparable to the main specifications), they indicate that the role of manufacturing decline on the broader drug epidemic cannot be simply explained away by state-level trends in the legal supply of opioid pain prescriptions; however, there is evidence that this might be the case for deaths specifically from opioids.

\subsection{County-Level Analyses}

Table 5 presents a set of models predicting county-level logged drug and opioid mortality rates, which separately test measures of manufacturing employment and annual payroll at the county-, commuting zone, and state-level. For the most part, the coefficients are sizable, precisely estimated, and increase in magnitude at higher levels of aggregation, for both the drug and opioid mortality rate models. The pattern of these results is consistent with prior research on geographic scale and effect sensitivity (i.e. Lindo 2015) that finds that coefficient estimates of economic conditions on mortality are downwardly biased at lower levels of aggregation. In the models that use commuting zone-level manufacturing measures - which consider across-county spillover effects of local labor markets - a one percentage point increase in manufacturing employment is associated with a $-1.6 \%$ reduction in drug overdose mortality rates for women and a $-2.0 \%$ 
reduction in drug overdose mortality rates for men. ${ }^{9}$ County population-weighted, commuting zone-level manufacturing employment decreased on average by 5.9 percentage points between 1999-2017. This indicates that reductions in commuting zone-level manufacturing employment between 1999-2017 can explain on average roughly $7.4 \%$ of the rise in county-level drug deaths for women and $8.3 \%$ of the rise in county-level drug deaths for men over this period. For the models that expand the definition of spillovers to include the entirety of state-level labor markets, a one percentage point increase in manufacturing employment is associated with a $3.2 \%$ reduction in drug overdose rates for women and a $-4.7 \%$ reduction in drug overdose mortality rates for men. These effects explain on average roughly $16.6 \%$ of the total rise in drug mortality rates for women and $21.1 \%$ of the total rise in drug mortality rates for men. Overall, these county-level results largely correspond to the main state-level findings, which demonstrates that the association between manufacturing decline and the rise of drug and opioid overdose deaths persists when accounting for within-state variation.

\subsection{Additional Sensitivity Analyses}

In a first set of additional sensitivity analyses, I evaluated whether the results were sensitive to the modeling strategy used. I re-estimated the main specifications using negative binomial regression models and a dependent measure of drug and opioid overdose death counts. The results, presented in the second column of Appendix Table S4, are similar in size and magnitude as those estimated from Eq. 1. I then re-estimated the main specifications with state-level population weights (third column, Appendix Table S4). These weighted models alter the theoretical interpretation of the main models because they give precedence to population size

\footnotetext{
${ }^{9}$ These calculations are based on the results from the CBP Imputed models. For women, $(\exp (-0.0158)-1)^{*} 100=-$ 1.57 ; for men, $(\exp (-0.0204)-1) * 100=-2.02$.
} 
rather than treating each state as a comparable administrative unit. Nevertheless, the inclusion of population weights does not substantively alter the effect size or significance level of the results. Next, in the fourth column of Appendix Table S4, I considered whether the inclusion of the labor force participation rate covariate was obscuring the full relationship between manufacturing decline and drug and opioid overdose deaths. In comparison to the main specifications, little changes with removal of this covariate.

Appendix Table S5 presents models that adjust for three additional potential sources of confounding: detailed population age structure, the percentage of the population who were born outside of the U.S., and state-by-year linear time trends. For the specifications that adjust for the first two covariates, the substantive results do not change. For the specification that adjusts for state-by-year linear time trends, the estimates lose statistical significance below the $\mathrm{p}<.05$ level and become positive. It is likely that the state-specific time trends are sweeping out part of the estimate of interest. Prior studies on the appropriateness of location-specific time trends (e.g. Wolfers 2006) have documented how their inclusion can confound estimation, particularly in the context of analyzing dynamic, evolving processes over time. Since changes in manufacturing employment and payroll commence immediately at the beginning of the 1999-2017 period, these state-specific time trends are not adjusting for pre-existing differences in overdose mortality rates across states prior to the treatment, but rather are likely in part adjusting for trends in overdose mortality rates that are responding in part to changes in manufacturing employment and annual payroll after treatment. As a result, this specification risks over-controlling and confounding estimation.

I further investigated the role of omitted variable bias by conducting a formal bounds analysis (Oster 2019). The results of this analysis, presented in Appendix Note S2, suggest that selection 
on unobserved omitted variables would have to be extreme to reduce the coefficient estimates from the main results down to zero.

Finally, I estimated models that predicted non-fatal outcome of substance use: opioid-related emergency department visits and inpatient hospitalizations. Data on these outcomes are only available between 2005-2017 and most states do not have observations spanning those entire 13 years. The estimates, presented in Appendix Table S6, are consistent in direction and substantive magnitude as the primary findings presented above, particularly for emergency department visits, though the estimate precision varies by the years of the study. Overall, this series of additional sensitivity analyses indicates that the findings from the main analysis generally hold up under different methodological decisions, different theoretical assumptions, different levels of geographic aggregation, and different outcomes of opioid use.

\section{Discussion}

The drug epidemic continues to disrupt the lives of individuals, families, and communities throughout the country. Since 1999 , over 700,000 people in the U.S. have died from drug overdoses (including over 400,000 from opioid overdoses), and according to the most recent estimates, 2.1 million people suffered from an opioid use disorder in 2017 (Center for Behavioral Health Statistics and Quality 2018). This study documents a large and substantively important state-level relationship between annual declines in the U.S. manufacturing sector and increases in drug and opioid overdose mortality rates between 1999-2017. These findings demonstrate how the ongoing transformation of U.S. labor markets has altered ecological-level risk environments that shape population health outcomes. 
Manufacturing decline, measured either as the share of manufacturing jobs in a state labor market or the share of total annual payroll concentrated in the manufacturing sector, accounts for approximately $21 \%$ of all overdose deaths for men and $15.2 \%$ to $17.2 \%$ of all overdose deaths for women between the start and end of the time period studied, 1999-2017. This represents an upward bound of an excess 92,000 male and 44,000 female drug overdose deaths that would otherwise have been avoided if the share of manufacturing employment and annual payroll had remained at 1999 levels. These results persist in models that adjust for a set of state-level contextual, compositional, and labor and drug policy characteristics as well as sensitivity models that estimate this relationship at the county-level and test for differences across states that had triplicate drug monitoring programs prior to the introduction of OxyContin. The effect size of the coefficient was also substantively larger when looking at racial/ethnic and age subgroups, especially for non-Hispanic white males between the ages of 45-54, a demographic group that has been particularly hard-hit by the rise in drug deaths (Case and Deaton 2015, 2017; Okie 2010).

Many explanations of the rise of the overdose epidemic emphasize the important, mechanistic role of pharmaceutical companies and pill mills in deluging communities with inexpensive opioid pain relievers (Kolodny et al. 2015). The results presented here do not conflict with this supply-side explanation since it is likely that workers in manufacturing industries, already more likely to experience workplace-related pain ailments such as repetitive strain injuries (van Tulder, Malmivaara, and Koes 2007), were at higher risk to becoming addicted to prescription painkillers upon job loss and financial hardship (Dasgupta et al. 2018; Nagelhout et al. 2017). Economically depressed regions were also more likely to be targeted by pharmaceutical companies pushing opioid medications (Hadland et al. 2019). In fact, the results suggest that 
state-level differences in manufacturing decline represent a substantial amount of variation in drug and opioid overdose deaths. Future research would benefit from moving beyond the current scholarly debate about the opioid and broader drug epidemic that sets in opposition social/economic explanations and drug supply explanations.

The modeling strategy used in the present study - two-way fixed effects - is well suited for evaluating the relationship between manufacturing decline and overdose mortality since it adjusts for all observed and unobserved time-invariant, state-specific confounders as well as for aggregate time trends (Allison 2009). In addition, the models adjust for time-varying characteristics - state-level contextual, compositional, and drug and labor policy- that might potentially confound the relationship between manufacturing decline and drug mortality/opioidrelated overdoses. Equivalent county-level models that include county-level fixed effects further indicate that the results are robust when examining this process in local communities specifically. This evidence indicates strong support for the labor market explanation that has been widely theorized, but until now, not well supported empirically (Case and Deaton 2015; Monnat 2018; Ruhm 2019). Nevertheless, the results presented here should be interpreted as associational and not causal.

The findings emphasize the importance of understanding the role of upstream social and economic factors when addressing the ongoing opioid epidemic in the U.S. State-level differences in drug policies, labor environments, and broader socio-political policy regimes are salient facets of drug-risk environments that shape the health of populations. Critically, the results signal the value of policy interventions and solutions that would reduce the persistent economic precarity experienced by individuals and communities, especially the economic strain placed upon American workers. The value of implementing these upstream social and economic 
policies do not conflict with efforts made by government entities to hold pharmaceutical companies and pill mills accountable for over-prescribing opioid medications to the public, nor does it conflict with the value of health policies aimed at reversing the opioid epidemic. Future research should further investigate the complex relationship between structural unemployment, pain management, prescription drug use, and drug mortality.

This analysis should be interpreted with an understanding of the limitations of the data and analytic method. The data are ecological and do not model how individual-level labor market histories or perceptions of local economic opportunity are associated with mortality. As such, future research should identify datasets which allow for the modeling of individual-level labor market experiences and perceptions in conjunction with macro-level structural economic changes in labor markets. This sort of multi-level approach would further clarify the interrelationship between individual-level risk factors and ecological-level risk environments. Second, although fixed-effects analyses adjust for time-invariant confounders which enter the model specifications linearly and additively, this method does not account for the full set of known and unknown confounders which vary across time. To address this issue, this study adjusted for several important known sources of time-varying unobserved heterogeneity which have been identified by past research to impact mortality rates. Yet, it is still possible that there are omitted variables that might bias the results. Third, the covariates that adjust for state-specific supply-side factors of prescription painkillers (i.e. PDMPs, prescription opioid rates) are imprecise measures of the misuse of prescription opioids and have a number of limitations (Bao et al. 2017; Horwitz et al. 2018); yet, they represent the best available measures for evaluating policy changes that have altered the flow of prescription drugs. Fourth, drug and opioid overdose mortality rates used in this analysis were calculated according to deaths coded as having (or in the case of opioid deaths, 
predicted to have) an underlying or contributing cause related directly to drug or opioid poisonings. Classifying individual-level death records that involve drug and opioid use as an indirect cause is not possible with NCHS vital statistics mortality records, but recent findings from Glei and Preston (2020) suggest that the scale of deaths from the drug epidemic was about two times larger in 2016 than drug-coded deaths when taking into account drug-associated mortality from indirect causes such as circulatory diseases, respiratory diseases, neoplasms, and external causes, to name a few. Finally, the single-year lag structure used in the specifications assesses the immediate relationship between manufacturing decline on overdose deaths. However, it is likely that the full direct and indirect impacts of structural economic change on substance use and ultimately overdose mortality might take a longer time to emerge than a single year (Venkataramani et al. 2020).

\section{Conclusions}

Manufacturing decline over the past two decades represents a continuation of long-term structural economic changes which have fundamentally altered the types of jobs available to U.S. workers, particularly those with only a high school degree. Since the 1980s, job growth has been concentrated in low-skill service industries that provide lower pay, fewer benefits, and decreased job security (Autor et al. 2006; Kalleberg 2018). The findings of this study suggest that these economic changes can predict a substantial proportion of recent increases in U.S. mortality rates over the past two decades, especially for drug overdose deaths. Additionally, state-level differences in manufacturing decline during this time period account for a considerable amount of the geographic variation in drug overdose deaths.

Policymakers and clinicians alike may benefit from understanding the extent to which drug overdose deaths have social and economic determinants which impact the structure of 
opportunities available to U.S. workers. While it is most likely unfeasible to rebuild the country's manufacturing base back to mid- $20^{\text {th }}$ century levels, the findings of the present study would suggest that improvements in wages, benefits, and job stability for workers in low-wage service positions might decrease economic uncertainty and therefore provide a pathway towards reducing opioid and drug overdose mortality. Future research should further investigate and test specific mechanisms through which deteriorating economic conditions and employment prospects impact health and mortality. Moreover, future research should also explore how locallevel, within-state variation in labor market characteristics might also better the explain regional trends in drug and opioid overdose mortality. 


\section{References}

Acemoglu, Daron, and David Autor. 2011. "Skills, Tasks and Technologies: Implications for Employment and Earnings.” Pp. 1043-1171 in Handbook of Labor Economics. Vol. 4b.

Adda, Jerome, and Yarine Fawaz. 2019. The Health Toll of Import Competition.

Ahmad, F. B., Lauren M. Rossen, and Paul D. Sutton. 2020. "Provisional Drug Overdose Death Counts."

Alexander, Monica J., Mathew V Kiang, and Magali Barbieri. 2018. "Trends in Black and White Opioid Mortality in the United States, 1979-2015.” Epidemiology 29(5):707-15. doi: 10.1097/EDE.0000000000000858.

Allison, Paul D. 2009. Fixed Effects Regression Models. Vol. 168. SAGE Publications.

Alpert, Abby E., William N. Evans, Ethan M. J. Lieber, and David Powell. 2019. Origins of the Opioid Crisis and Its Enduring Impacts.

Anderson, RN, and HM Rosenberg. 1998. “Age Standardization of Death Rates: Implementation of the Year 2000 Standard.” National Vital Statistics Reports 47(3).

Atkinson, Robert D., Luke A. Stewart, Scott M. Andes, and Stephen J. Ezell. 2012. Worse than the Great Depression: What Experts Are Missing About American Manufacturing Decline.

Autor, David H., and David Dorn. 2013. "The Growth of Low-Skill Service Jobs and the Polarization of the US Labor Market." American Economic Review 103(5):1553-97. doi: 10.1257/aer.103.5.1553.

Autor, David H., Lawrence F. Katz, and Melissa S. Kearney. 2006. “The Polarization of the U.S. Labor Market." American Economic Review 96(2):189-94. doi: $10.1257 / 000282806777212620$.

Bao, Yuhua, Yijun Pan, Aryn Taylor, Sharmini Radakrishnan, Feijun Luo, Harold Alan Pincus, and Bruce R. Schackman. 2017. "Prescription Drug Monitoring Programs Are Associated With Sustained Reductions in Opioid Prescribing By Physicians." Health Affairs 35(6):1045-51. doi: 10.1377/hlthaff.2015.1673.

Betz, Michael R., and Lauren E. Jones. 2018. "Wage and Employment Growth in America's 
Drug Epidemic: Is All Growth Created Equal.” American Journal of Agricultural Economics 100(5):1357-74. doi: 10.1093/ajae/aay069.

Black, Sandra E., Paul J. Devereux, and Kjell G. Salvanes. 2015. "Losing Heart? The Effect of Job Displacement on Health." Industrial and Labor Relations Review 68(4):833-61. doi: 10.1177/0019793915586381.

Boslett, Andrew J., Alina Denham, and Elaine L. Hill. 2020. "Using Contributing Causes of Death Improves Prediction of Opioid Involvement in Unclassified Drug Overdoses in US Death Records." Addiction 115:1308-17. doi: 10.1111/add.14943.

Bradley, Elizabeth H., Maureen Canavan, Erika Rogan, Kristina Talbert-slagle, Chima Ndumele, Lauren Taylor, and Leslie A. Curry. 2016. "Variation In Health Outcomes: The Role Of Spending On Social Services, Public Health, And Health Care, 2000 - 09." Health Affairs 35(5):760-68.

Brand, Jennie E. 2015. "The Far-Reaching Impact of Job Loss and Unemployment.” Annual Review of Sociology 41:359-75. doi: 10.1146/annurev-soc-071913-043237.

Breiman, Leo. 2001. "Random Forests.” Machine Learning 45:5-32.

Broman, Clifford L., V. Lee Hamilton, and William S. Hoffman. 1990. "Unemployment and Its Effects on Families : Evidence from a Plant Closing Study 1." American Journal of Community Psychology 18(5):643-59.

Browning, Martin, and Eskil Heinesen. 2012. Effect of Job Loss Due to Plant Closure on Mortality and Hospitalization. Vol. 31.

Buchanich, Jeanine M., Lauren C. Balmert, Karl E. Williams, and Donald S. Burke. 2018. "The Effect of Incomplete Death Certificates on Estimates of Unintentional Opioid-Related Overdose Deaths in The." Public Health Reports 133(4):423-31. doi:

10.1177/0033354918774330.

Bureau of Labor Statistics. 2018. "Local Area Unemployment Statistics, State File [Dataset]." 1999-2016.

Burgard, Sarah A., Jennie E. Brand, and James S. House. 2009. "Perceived Job Insecurity and 
Worker Health in the United States." Social Science and Medicine 69(5):777-85. doi: 10.1016/j.socscimed.2009.06.029.

Case, Anne, and Angus Deaton. 2015. "Rising Morbidity and Mortality in Midlife among White Non-Hispanic Americans in the 21st Century." Proceedings of the National Academy of Sciences 112(49):15078-83. doi: 10.1073/pnas.1518393112.

Case, Anne, and Angus Deaton. 2017. "Mortality and Morbidity in the 21st Century." Brookings Papers on Economic Activity 397-476. doi: 10.1073/pnas.1518393112.

Case, Anne, and Angus Deaton. 2018. "Deaths of Despair Redux: A Response to Christopher Ruhm."1-4.

Catalano, R. 1991. "The Health Effects of Economic Insecurity." American Journal of Public Health 81(9):1148-52. doi: 10.2105/AJPH.81.9.1148.

Center for Behavioral Health Statistics and Quality. 2018. 2017 National Survey on Drug Use and Health: Detailed Tables. Rockville, MD.

Centers for Disease Control and Prevention. 2019. "U.S. Opioid Prescribing Rate Maps."

Cerdá, Magdalena, William R. Ponicki, Nathan Smith, Ariadne Rivera-aguirre, Corey S. Davis, Brandon D. L. Marshall, David S. Fink, Stephen G. Henry, Alvaro Castillo-carniglia, Garen J. Wintemute, Andrew Gaidus, Paul J. Gruenewald, and Silvia S. Martins. 2020. "StateLevel Prescription Drug Monitoring Programs and County-Level Fatal Prescription Opioid Overdoses." Epidemiology 31(1). doi: 10.1097/EDE.0000000000001123.

Charles, Kerwin Kofi, and Philip DeCicca. 2008. "Local Labor Market Fluctuations and Health: Is There a Connection and for Whom?" Journal of Health Economics 27(6):1532-50. doi: 10.1016/j.jhealeco.2008.06.004.

Chetty, Raj, Michael Stepner, Sarah Abraham, Shelby Lin, Benjamin Scuderi, Nicholas Turner, Augustin Bergeron, and David Cutler. 2016. "The Association between Income and Life Expectancy in the United States, 2001-2014." JAMA - Journal of the American Medical Association 315(16):1750-66. doi: 10.1001/jama.2016.4226.

Colantone, Italo, Rosario Crinò, and Laura Ogliari. 2019. "Globalization and Mental Distress." 
Journal of International Development 119:181-207. doi: 10.1016/j.jinteco.2019.04.008.

Currie, Janet, Jonas Jin, and Molly Schnell. 2019. “U.S. Employment and Opioids: Is There a Connection?" Pp. 253-80 in Health and Labor Markets (Research in Labor Economics, Volume 47).

Cutcher-Gershenfeld, Joel, Dan Brooks, and Martin Mulloy. 2015. The Decline and Resurgence of the U.S. Auto Industry.

Dasgupta, Nabarun, Leo Beletsky, and Daniel Ciccarone. 2018. "Opioid Crisis : No Easy Fix to Its Social and Economic Determinants." American Journal of Public Health 108(2):182-86. doi: 10.2105/AJPH.2017.304187.

Doleac, Jennifer L., and Anita Mukherjee. 2018. The Moral Hazard of Lifesaving Innovations : Naloxone Access, Opioid Abuse, and Crime.

Eckert, Fabian, Teresa C. Fort, Peter K. Schott, and Natalie J. Yang. 2020. Imputing Missing Values in the US Census Bureau's County Business Patterns.

Elo, Irma T., Arun S. Hendi, Jessica Y. Ho, Yana C. Vierboom, and Samuel H. Preston. 2019. "Trends in Non-Hispanic White Mortality in the United States by Nonmetropolitan Status and Region , 1990 - 2016." Population and Development Review 45(3):549-83. doi: 10.1111/padr.12249.

Ezzati, Majid, Ari B. Friedman, Sandeep C. Kulkarni, and Christopher J. L. Murray. 2008. "The Reversal of Fortunes : Trends in County Mortality and Cross-County Mortality Disparities in the United States." PLoS Medicine 5(4):557-68. doi: 10.1371/journal.pmed.0050066.

Fink, David S., Julia P. Schleimer, Aaron Sarvet, Kiran K. Grover, Chris Delcher, Alvaro Castillo-Carniglia, June H. Kim, Ariadne E. Rivera-Aguirre, Stephen G. Henry, Silvia S. Martins, and Magdalena Cerdá. 2018. "Association Between Prescription Drug Monitoring Programs and Nonfatal and Fatal Drug Overdoses: A Systematic ReviewPrescription Drug Monitoring Programs and Overdose.” Annals of Internal Medicine 168(11):783-90. doi: 10.7326/M17-3074.

Finley, Erin P., Ashley Garcia, Kristen Rosen, Don Mcgeary, Mary Jo Pugh, and Jennifer Sharpe Potter. 2017. "Evaluating the Impact of Prescription Drug Monitoring Program 
Implementation : A Scoping Review." BMC Health Services Research 17:1-8. doi: 10.1186/s12913-017-2354-5.

Flood, Sarah, Miriam King, Renae Rodgers, Steven Ruggles, and J. Robert Warren. 2020. "Integrated Public Use Microdata Series, Current Population Survey: Version 6.0 [Dataset]."

Gallo, William T., Elizabeth H. Bradley, Michele Siegel, and Stanislav V Kasl. 2001. "The Impact of Involuntary Job Loss on Subsequent Alcohol Consumption by Older Workers : Findings From the Health and Retirement Survey." Journal of Gerontology: Social Sciences 56(1):3-9.

Gaydosh, Lauren, Robert A. Hummer, Taylor W. Hargrove, Carolyn T. Halpern, Jon M. Hussey, Eric A. Whitsel, Nancy Dole, and Kathleen Mullan Harris. 2019. "The Depths of Despair Among US Adults Entering Midlife.” American Journal of Public Health 109(5):774-80. doi: 10.2105/AJPH.2019.305002.

Ghertner, Robin, and Lincoln Groves. 2018. The Opioid Crisis and Economic Opportunity: Geographic and Economic Trends.

Glei, Dana A., and Samuel H. Preston. 2020. "Estimating the Impact of Drug Use on US Mortality, 1999-2016.” PLOS ONE 1999-2016.

Grant, Don Sherman I. I., and Michael Wallace. 1994. "The Political Economy of Manufacturing Growth and Decline across the American States, 1970-1985." Social Forces 73(1):33-63.

Grecu, Anca M., Dhaval M. Dave, and Henry Saffer. 2019. "Prescription Drug Monitoring Programs and Prescription Drug Abuse." Journal of Policy Analysis and Management 38(1):181-209. doi: 10.1002/pam.22098.

Guy, Gery P., Kun Zhang, Lyna Z. Schieber, Randall Young, and Deborah Dowell. 2020. "County-Level Opioid Prescribing in the United States , 2015 and 2017." JAMA Internal Medicine 179(4):1033-36. doi: 10.1001/jama.2017.19519.

Hadland, Scott E., Ariadne Rivera-aguirre, Brandon D. L. Marshall, and Magdalena Cerdá. 2019. "Association of Pharmaceutical Industry Marketing of Opioid Products With Mortality From Opioid-Related Overdoses." JAMA Network Open 2(1):1-12. doi: 
10.1001/jamanetworkopen.2018.6007.

Hedegaard, Holly, Arialdi M. Miniño, and Margaret Warner. 2020. "Drug Overdose Deaths in the United States , 1999 - 2018." NCHS Data Brief (356):1-8.

Hedegaard, Holly, Margaret Warner, and Arialdi M. Miniño. 2018. "Drug Overdose Deaths in the United States, 1999-2017." NCHS Data Brief (294):1-8. doi: 10.1016/j.neulet.2010.07.040.

Hederos, Karin, Markus Jantti, Lena Lindahl, and Jenny Torssander. 2017. "Trends in Life Expectancy by Income and the Role of Specific Causes of Death." Economica. doi: 10.1111/ecca.12224.

Hirsch, Barry T., and David A. Macpherson. 2003. "Union Membership and Coverage Database from the Current Population Survey: Note." Industrial and Labor Relations Review 56(2):349-54.

Hollingsworth, Alex, Christopher J. Ruhm, and Kosali Simon. 2017. "Macroeconomic Conditions and Opioid Abuse." Journal of Health Economics 56:222-33. doi: 10.1016/j.jhealeco.2017.07.009.

Horwitz, Jill, Corey S. Davis, Lynn S. McClelland, Rebecca S. Fordon, and Ellen Meara. 2018. "The Problem of Data Quality in Analyses of Opioid Regulation :" NBER Working Paper.

Huijts, Tim, Aaron Reeves, Martin Mckee, and David Stuckler. 2015. "The Impacts of Job Loss and Job Recovery on Self-Rated Health: Testing the Mediating Role of Financial Strain and Income." European Journal of Public Health 25(5):801-6. doi: 10.1093/eurpub/ckv108.

Jacobs, Ken, Zohar Perla, Ian Perry, and Dave Graham-squire. 2016. Producing Poverty: The Public Cost of Low-Wage Production Jobs in Manufacturing.

Janoski, Thomas., David (Research assistant) Luke, and Christopher (Lecturer in Sociology) Oliver. 2014. The Causes of Structural Unemployment : Four Factors That Keep People from the Jobs They Deserve. Polity Press.

Jolly, Nicholas A., and Brian J. Phelan. 2017. "The Long-Run Effects of Job Displacement on Sources of Health Insurance Coverage." Journal of Labor Research 38(2):187-205. doi: 
$10.1007 / \mathrm{s} 12122-017-9246-7$.

Kalleberg, Arne L. 2009. "Precarious Work, Insecure Workers: Employment Relations in Transition.” American Sociological Review 74(1):1-22.

Kalleberg, Arne L. 2018. Precarious Lives: Job Insecurity and Well-Being in Rich Democracies. Wiley.

Kalleberg, Arne L., and Till M. von Wachter. 2017. "The U.S. Labor Market During and After the Great Recession: Continuities and Transformations." RSF: The Russell Sage Foundation Journal of the Social Sciences 3(3):1-19. doi: 10.7758/rsf.2017.3.3.01.

Kim, Ae-sook, and Edward T. Jr Jennings. 2009. "Effects of U.S. States' Social Welfare Systems on Population Health.” The Policy Studies Journal 37(4).

Kirsch, Julie A., and Carol D. Ryff. 2016. "Hardships of the Great Recession and Health: Understanding Varieties of Vulnerability." Health Psychology Open 3(1). doi: $10.1177 / 2055102916652390$.

Kolodny, Andrew, David Courtwright, Catherine S. Hwang, Peter Kreiner, John L. Eadie, Thomas Clark, and G. Alexander. 2015. "The Prescription Opioid and Heroin Crisis: A Public Health Approach to an Epidemic of Addiction.” Annual Review OfPublic Health Is 36:559-74. doi: 10.1146/annurev-publhealth-031914-122957.

Krueger, Alan B. 2017. Where Have All the Workers Gone? An Inquiry into the Decline of the U.S. Labor Force Participation Rate. Vol. 2.

Lang, Matthew, T. Clay McManus, and Georg Schaur. 2019. "The Effects of Import Competition on Health in the Local Economy." Health Economics (December 2017):44-56. doi: 10.1002/hec.3826.

Lim, Sojung. 2017. “'Bad Jobs' for Marriage: Precarious Work and the Transition to First Marriage." Pp. 399-427 in Precarious Work (Research in the Sociology of Work, Volume 31), edited by A. L. Kalleberg and S. P. Vallas. Emerald Publishing Limited.

Lindo, Jason M. 2015. "Aggregation and the Estimated Effects of Economic Conditions on Health." Journal of Health Economics 40:83-96. doi: 10.1016/j.jhealeco.2014.11.009. 
Massoglia, Michael, and Brianna Remster. 2019. "Linkages Between Incarceration and Health." Public Health Reports (Washington, D.C. : 1974) 134(1):8S--14S. doi: $10.1177 / 0033354919826563$.

McCall, Leslie, Derek Burk, Marie Laperrière, and Jennifer A. Richeson. 2017. "Exposure to Rising Inequality Shapes Americans' Opportunity Beliefs and Policy Support.” Proceedings of the National Academy of Sciences 114(36):9593-98. doi: 10.1073/pnas.1706253114.

Mclean, Katherine. 2018. “““There’s Nothing Here””: Deindustrialization as Risk Environment for Overdose.” International Journal of Drug Policy 29(2016):19-26. doi: 10.1016/j.drugpo.2016.01.009.

McLean, Katherine. 2016. ""There's Nothing Here": Deindustrialization as Risk Environment for Overdose." International Journal of Drug Policy 29:19-26.

Merline, Alicia C., Patrick M. O. Malley, John E. Schulenberg, Jerald G. Bachman, and Lloyd D. Johnston. 2004. "Substance Use Among Adults 35 Years of Age: Prevalence, Adulthood Predictors, and Impact of Adolescent Substance Use." American Journal of Public Health 94(1).

Miller, Sarah, Sean Altekruse, Norman Johnson, and Laura R. Wherry. 2019. Medicaid and Mortality: New Evidence from Linked Survey and Administrative Data.

Monnat, Shannon M. 2018. "Factors Associated With County-Level Differences in U.S. DrugRelated Mortality Rates." American Journal of Preventive Medicine 1-10. doi: 10.1016/j.amepre.2018.01.040.

Monnat, Shannon M. 2019. "The Contributions of Socioeconomic and Opioid Supply Factors to U.S. Drug Mortality Rates: Urban-Rural and within-Rural Differences.” Journal of Rural Studies 68(December 2018):319-35. doi: 10.1016/j.jrurstud.2018.12.004.

Montez, Jennifer Karas, Jason Beckfield, Julene Kemp Cooney, Jacob M. Grumbach, Mark D. Hayward, Huseyin Zeyd Koytak, Steven H. Woolf, and Anna Zajacova. 2020. "US State Policies, Politics, and Life Expectancy." The Milbank Quarterly 1-32. doi: 10.1111/14680009.12469.

Montez, Jennifer Karas, Mark D. Hayward, and Anna Zajacova. 2019. "Educational Disparities The Economic Underpinnings of the Drug Epidemic 44 
in Adult Health : U.S . States as Institutional Actors on the Association.” Socius. doi: $10.1177 / 2378023119835345$.

Murphy, Sherry L., Jiaquan Xu, Kenneth D. Kochanek, and Elizabeth Arias. 2018. Mortality in the United States, 2017.

Nagelhout, Gera E., Karin Hummel, Moniek C. M. de Goeij, Hein de Vries, Eileen Kaner, and Paul Lemmens. 2017. "How Economic Recessions and Unemployment Affect Illegal Drug Use: A Systematic Realist Literature Review.” International Journal of Drug Policy 44:6983. doi: 10.1016/j.drugpo.2017.03.013.

Nosrati, Elias, Michael Ash, Michael Marmot, Martin McKee, and Lawrence P. King. 2017. "The Association between Income and Life Expectancy Revisited: Deindustrialization, Incarceration and the Widening Health Gap.” International Journal of Epidemiology (February 2018):1-11. doi: 10.1093/ije/dyx243.

Okie, Susan. 2010. “A Flood of Opioids, a Rising Tide of Deaths.” New England Journal of Medicine 363(21):1981-85.

Oster, Emily. 2019. "Unobservable Selection and Coefficient Stability: Theory and Evidence Unobservable Selection and Coefficient Stability : Theory and Evidence.” Journal of Business \& Economic Statistics 37(2):187-204. doi: 10.1080/07350015.2016.1227711.

Pew Research Center. 2015. The American Middle Class Is Losing Ground: No Longer the Majority and Falling behind Financially. Washington, D.C.

Rhodes, Tim. 2009. "Risk Environments and Drug Harms: A Social Science for Harm Reduction Approach.” International Journal of Drug Policy 20(3):193-201. doi:

10.1016/j.drugpo.2008.10.003.

Riumallo-Herl, Carlos, Sanjay Basu, David Stuckler, Emilie Courtin, and Mauricio Avendano. 2014. "Job Loss, Wealth and Depression during the Great Recession in the USA and Europe." International Journal of Epidemiology 43(5):1508-17. doi: 10.1093/ije/dyu048.

Rolfs, Robert T., Michael D. Friedrichs, Todd C. Grey, Kristina Russell, and Jonathan Anderson. 2012. “Risk Factors for Prescription Opioid-Related Death, Utah, 2008 - 2009.” Pain Medicine 1580-89. 
Ruhm, Christopher J. 2017. "Geographic Variation in Opioid and Heroin Involved Drug Poisoning Mortality Rates.” American Journal of Preventive Medicine 53(6):745-53. doi: 10.1016/j.amepre.2017.06.009.

Ruhm, Christopher J. 2019. "Drivers of the Fatal Drug Epidemic." Journal of Health Economics 64:25-42. doi: 10.1016/j.jhealeco.2019.01.001.

Ruhm, Christopher J. 2020. "Commentary on Boslett et Al. (2020): Towards Better Measurement of Drug Involvement in Fatal Overdoses." Addiction 115:1318-19. doi: 10.1111/add.14988.

Schaller, Jessamyn, and Ann Huff Stevens. 2015. "Short-Run Effects of Job Loss on Health Conditions, Health Insurance, and Health Care Utilization." Journal of Health Economics 43:190-203. doi: 10.1016/j.jhealeco.2015.07.003.

Schoenfeld, Elinor R., George S. Leibowitz, Yu Wang, Xin Chen, Wei Hou, Sina Rashidian, Mary M. Saltz, Joel H. Saltz, and Fusheng Wang. 2019. "Geographic, Temporal, and Sociodemographic Differences in Opioid Poisoning." American Journal of Preventive Medicine 57(2):153-64. doi: 10.1016/j.amepre.2019.03.020.

Strully, Kate W. 2009. "Job Loss and Health in the u.s. Labor Market.” Demography 46(2):22146.

Sullivan, D., and T. von Wachter. 2009. "Job Displacement and Mortality: An Analysis Using Administrative Data." The Quarterly Journal of Economics 124(3):1265-1307. doi: 10.1162/qjec.2009.124.3.1265.

Thiede, Brian C., and Shannon M. Monnat. 2016. "The Great Recession and America's Geography of Unemployment.” Demographic Research 35(1):891-928. doi: 10.4054/DemRes.2016.35.30.

Tolbert, Charles M., and Molly Sizer. 1996. U.S. Commuting Zones and Labor Market Areas: A 1990 Update.

van Tulder, Maurits, Antti Malmivaara, and Bart Koes. 2007. "Repetitive Strain Injury.” The Lancet 369:1815-22. doi: 10.1016/j.nuclphysa.2012.12.077. 
U.S. Census Bureau. 2018. “County Business Patterns, State File [Dataset].” 1999-2016.

United States Department of Agriculture, E. R. S. 2019. "2013 Rural-Urban Continuum Codes.”

Venkataramani, Atheendar S., Elizabeth F. Bair, Rourke L. O’Brien, and Alexander C. Tsai. 2020. "Association Between Automotive Assembly Plant Closures and Opioid Overdose Mortality in the United States A Difference-in-Differences Analysis." JAMA Internal Medicine 19104:1-9. doi: 10.1001/jamainternmed.2019.5686.

Warner, Margaret, Leonard J. Paulozzi, Kurt B. Nolte, Gregory G. Davis, and Lewis S. Nelson. 2013. "State Variation in Certifying Manner of Death and Drugs Involved in Drug Intoxication Deaths." Academic Forensic Pathology 3(2):231-37. doi: 10.23907/2013.029.

Weiss, Audrey J., Anne Elixhauser, Marguerite L. Barrett, Claudia A. Steiner, Molly K. Bailey, and Lauren O. Malley. 2017. Opioid-Related Inpatient Stays and Emergency Department Visits by State, 2009-2014.

Wolfers, Justin. 2006. "Did Unilateral Divorce Laws Raise Divorce Rates? A Reconciliation and New Results." The American Economic Review 96(5):1802-20.

Woolf, Steven H., Derek A. Chapman, Jeanine M. Buchanich, Kendra J. Bobby, Emily B. Zimmerman, and Sarah M. Blackburn. 2018. "Changes in Midlife Death Rates across Racial and Ethnic Groups in the United States : Systematic Analysis of Vital Statistics." BMJ 362(k3096):1-16. doi: 10.1136/bmj.k3096.

Woolf, Steven H., and Heidi Schoomaker. 2020. "Life Expectancy and Mortality Rates in the United States, 1959-2017." JAMA - Journal of the American Medical Association 322(20):1996-2016. doi: 10.1001/jama.2019.16932.

Zivin, K., M. Paczkowski, and S. Galea. 2011. "Economic Downturns and Population Mental Health: Research Findings, Gaps, Challenges and Priorities." Psychological Medicine 41(7):1343-48. doi: 10.1017/s003329171000173x.

Zoorob, Michael J., and Jason L. Salemi. 2020. "Bowling Alone, Dying Together : The Role of Social Capital in Mitigating the Drug Overdose Epidemic in the United States." Drug and Alcohol Dependence 173(2017):1-9. doi: 10.1016/j.drugalcdep.2016.12.011. 


\section{Figures}

Figure 1a. Total Number of Workers Employed in the Manufacturing Sector, 1980-2019

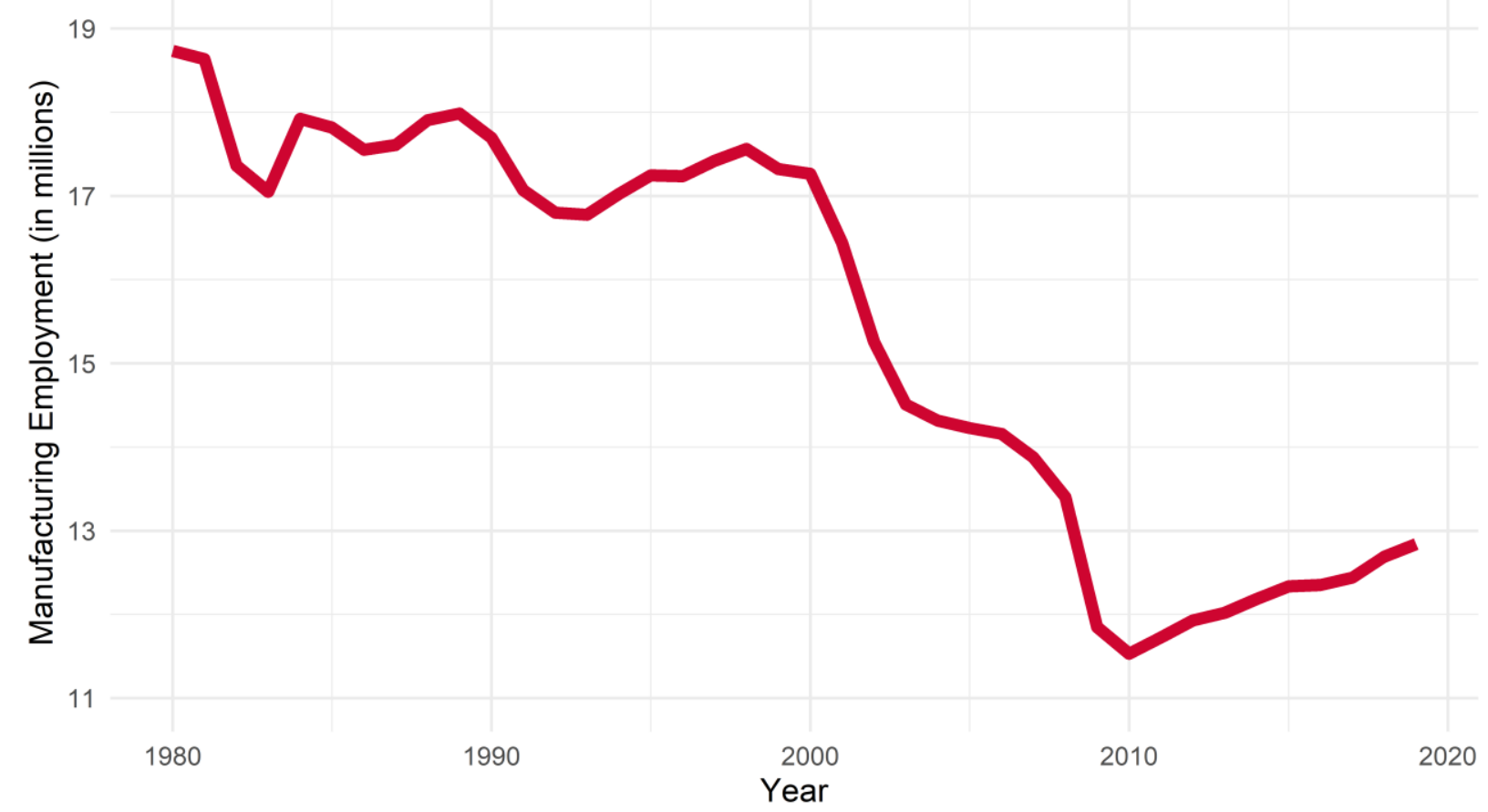

Figure 1b. Annual Percent Change in Manufacturing Employment, 1980-2019

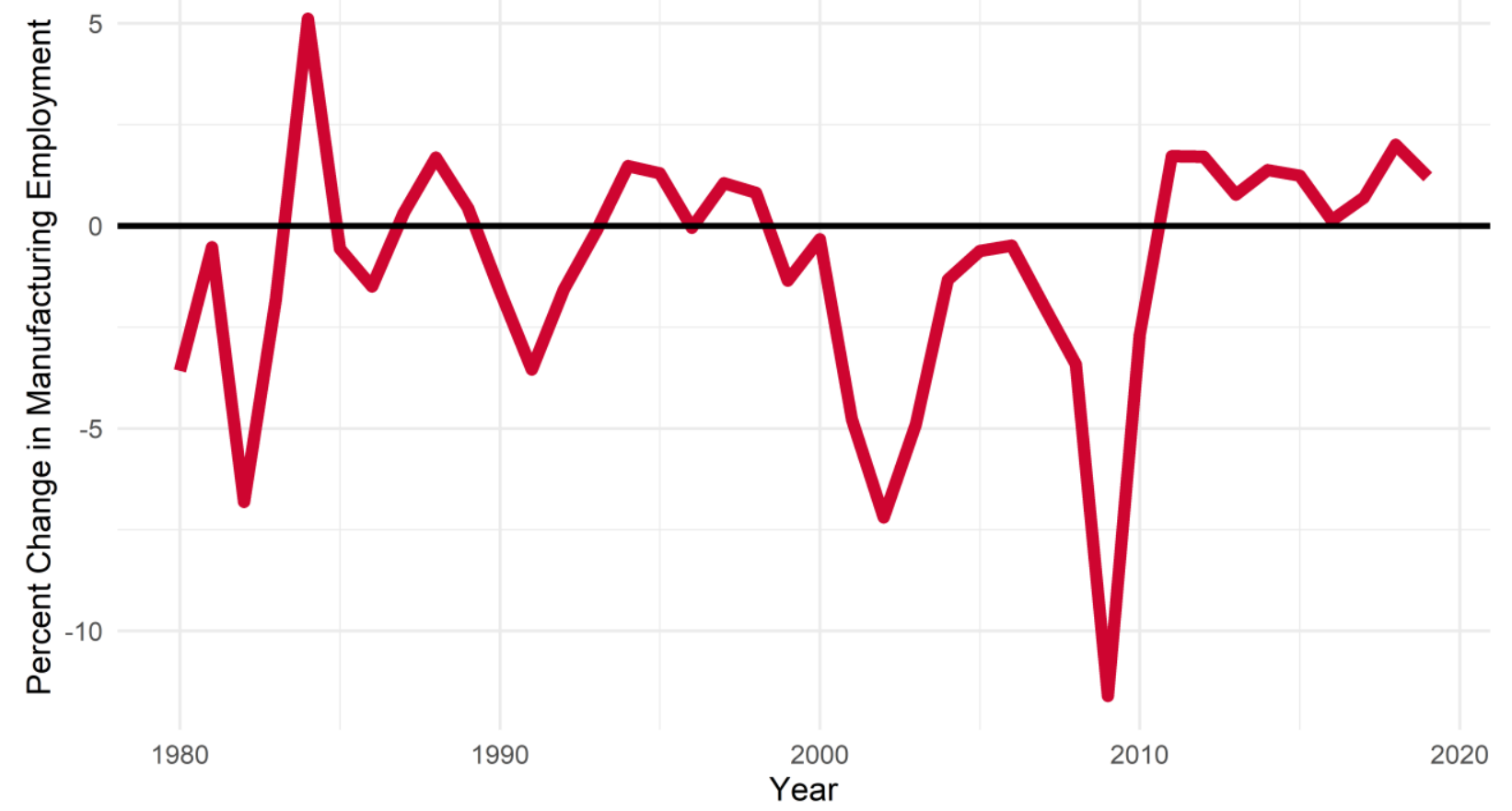

Data Source: U.S. Bureau of Labor Statistics, All Employees, Manufacturing [MANEMP], retrieved from FRED, Federal Reserve Bank of St. Louis; https://fred.stlouisfed.org/series/MANEMP, January 28, 2020. 
Figure 2a. Change in the Share of Employees in Manufacturing Sector by State, 1998-2016

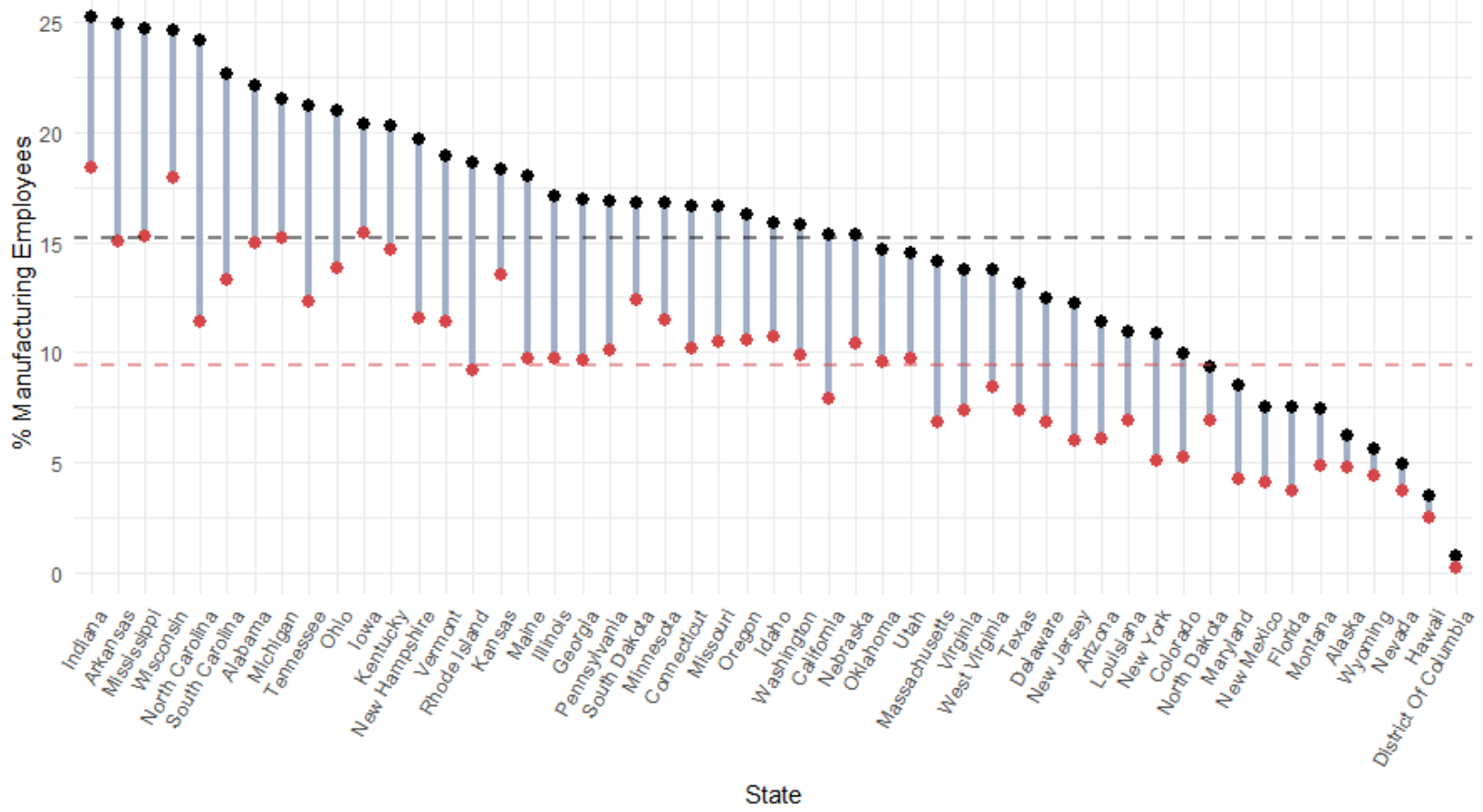

Notes: Black dots represent percentage of workers employed in manufacturing in 1998; Red dots represent percentage of workers employed in manufacturing in 2016; Vertical lines represent percentage point decline between 1998-2016. Horizontal grey dotted line represents state average in 1998; Horizontal pink dotted line represents state average in 2016. Data: U.S. Census Bureau, County Business Patterns Program 
Figure 2b. Change in the Share of Annual Payroll in Manufacturing Sector by State, 1998-2016

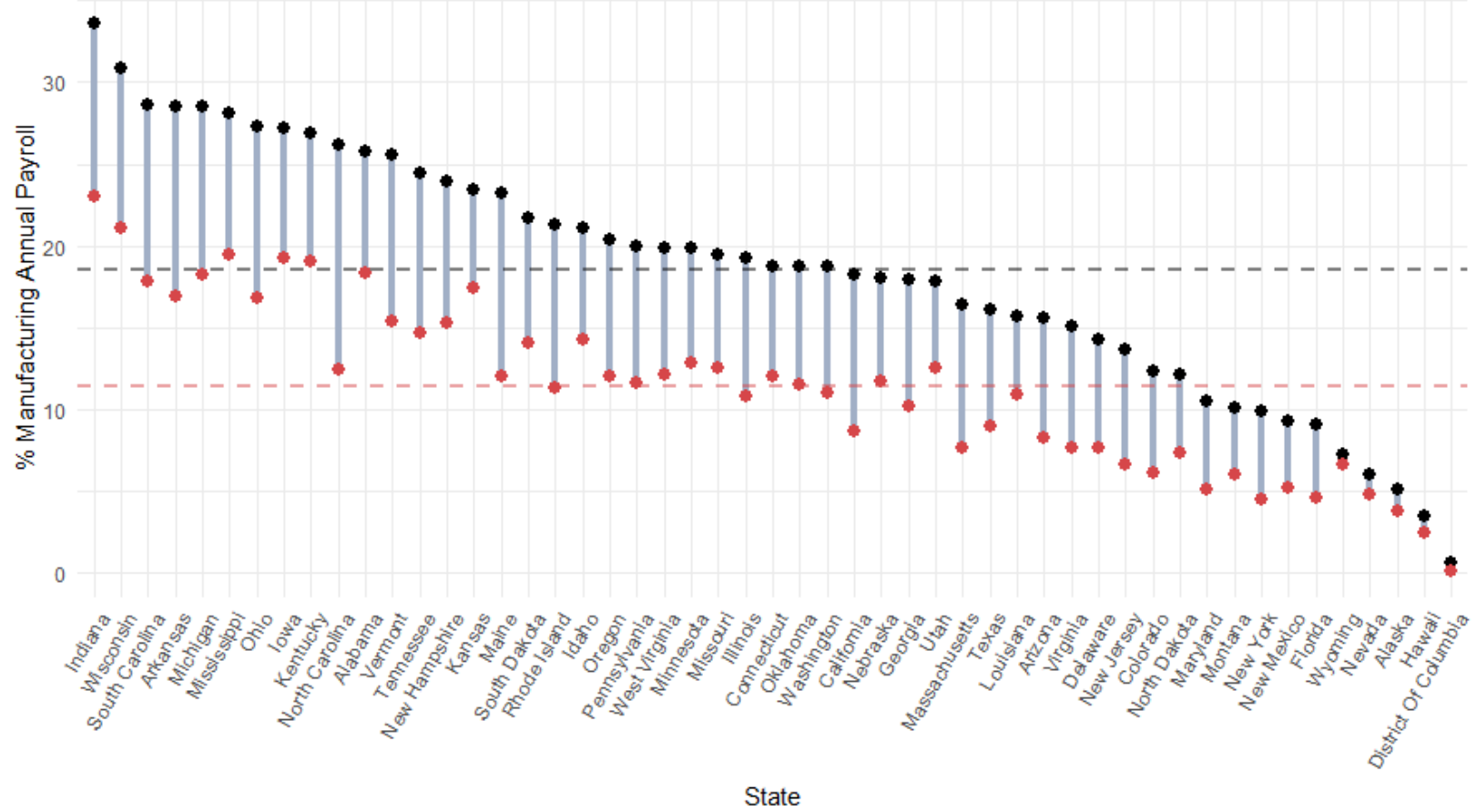

Notes: Black dots represent percentage of manufacturing annual payroll in 1998; Red dots represent percentage of manufacturing annual payroll in 2016; Vertical lines represent percentage point decline between 1998-2016.

Horizontal grey dotted line represents state average in 1998; Horizontal pink dotted line represents state average in 2016. Data: U.S. Census Bureau, County Business Patterns Program. 
Figure 3. State-Level Overdose Rates for Females, Males, and White, Non-Hispanic Males Ages 45-54

Female
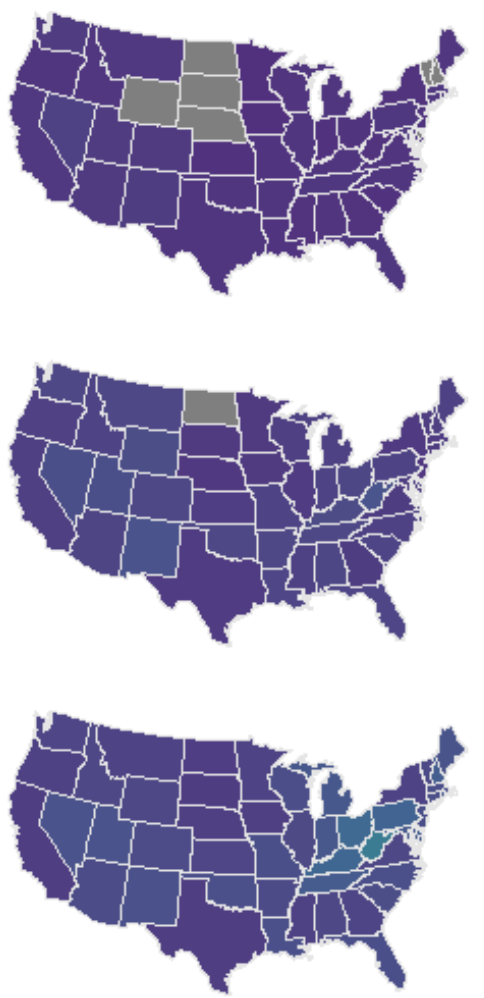

Male
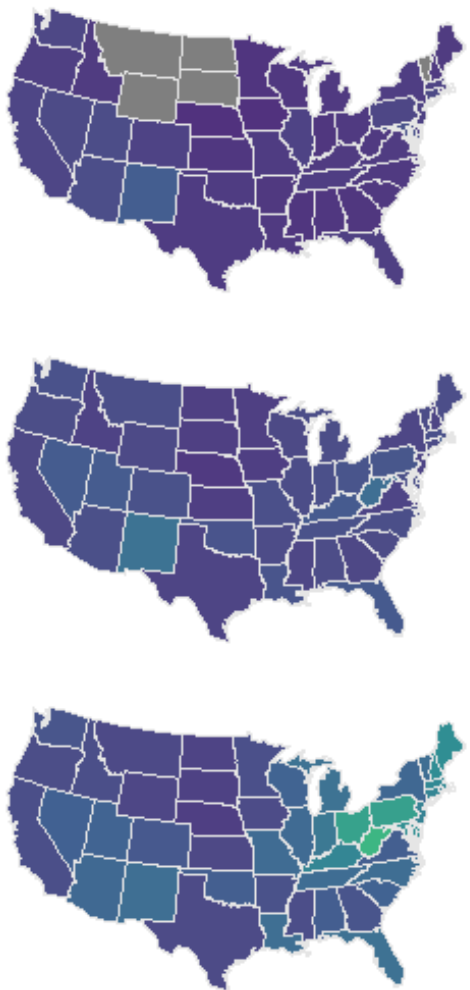

White, Non-Hispanic Males Ages 45-54

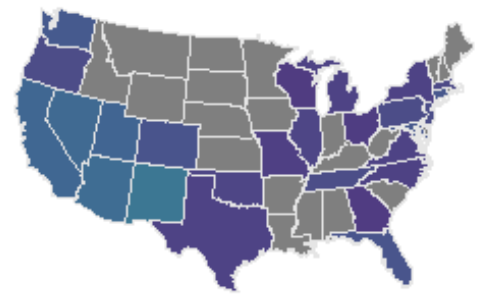

1999

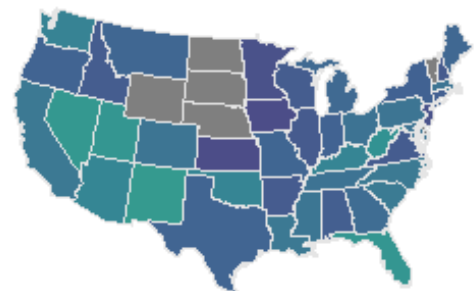

2008

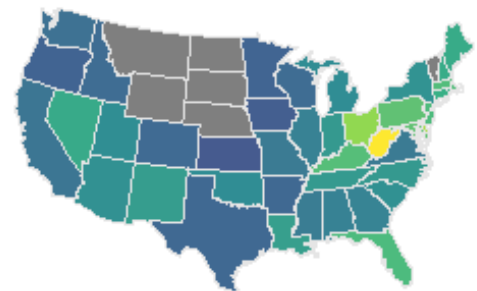

Notes: Death rates are age-adjusted for females and males. Grey shading represents states with less than 10 deaths per year; rates are not displayed in accordance with requirements of the data use agreement with the NCHS. 
Figure 4. Percentage of Drug Deaths between 1999-2017 Predicted by Manufacturing Decline A. Women
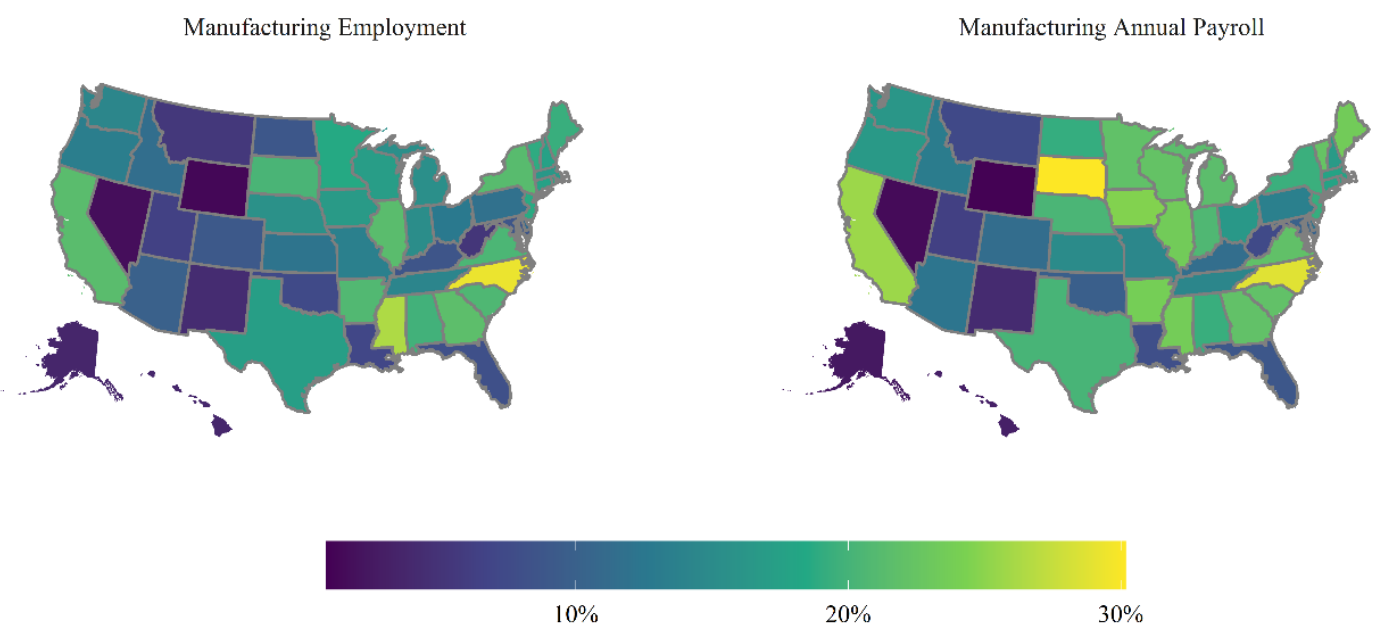

B. Men
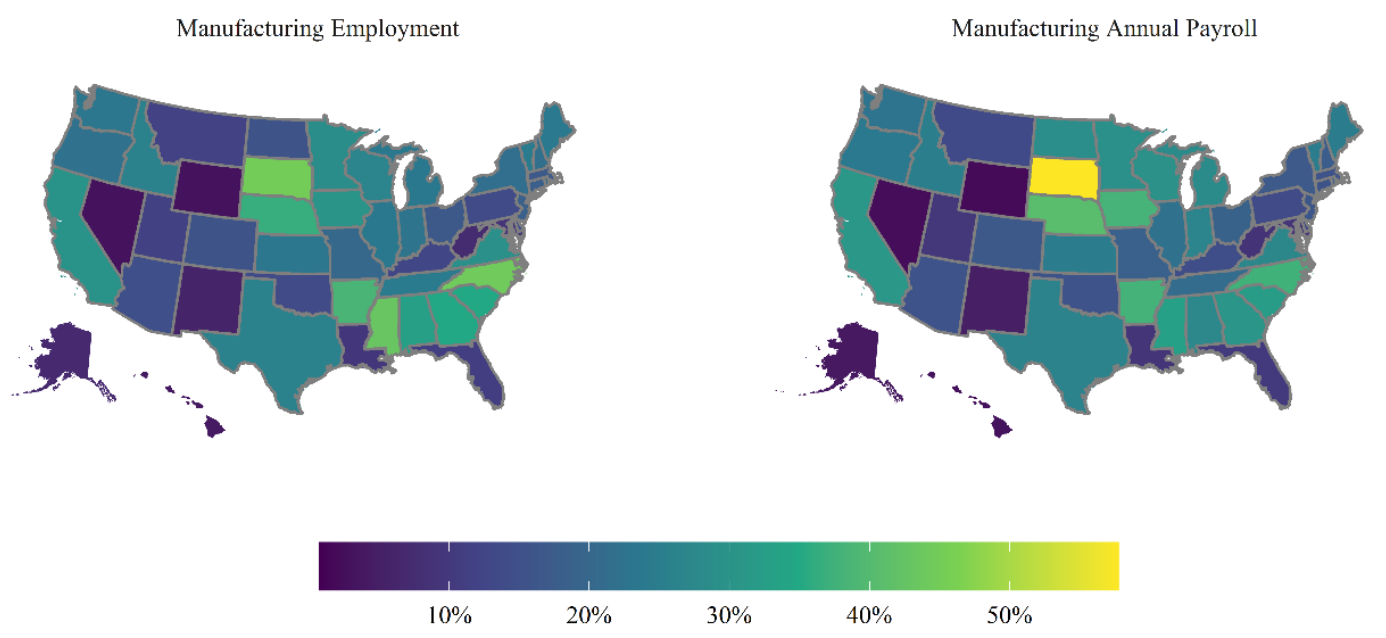


\section{Tables}

Table 1. Descriptive Statistics

\begin{tabular}{|c|c|c|c|}
\hline \multirow[b]{2}{*}{ Variables } & \multicolumn{3}{|c|}{$1999-2017$} \\
\hline & Mean & S.D. & $\begin{array}{r}\text { State-Year } \\
\text { Observations }\end{array}$ \\
\hline \multicolumn{4}{|c|}{ Drug Overdose Age-Adjusted Death Rate (per 100,000 population) } \\
\hline Female & 9.5 & 5 & 969 \\
\hline Male & 15.9 & 9.4 & 969 \\
\hline \multicolumn{4}{|c|}{ Opioid Overdose Age-Adjusted Death Rate (per 100,000 population) } \\
\hline Female & 5.3 & 4.1 & 969 \\
\hline Male & 9.9 & 8.3 & 969 \\
\hline \multirow{2}{*}{\multicolumn{4}{|c|}{$\begin{array}{l}\text { Corrected Opioid Overdose Age-Adjusted Death Rate (per 100,000 } \\
\text { population) }\end{array}$}} \\
\hline & & & \\
\hline Female & 7 & 4.7 & 969 \\
\hline Male & 12.3 & 8.7 & 969 \\
\hline \multicolumn{4}{|l|}{ Logged Drug Overdose Age-Adjusted Death Rate (per 100,000 } \\
\hline \multicolumn{4}{|l|}{ population) } \\
\hline Female & 2.1 & 0.6 & 969 \\
\hline Male & 2.6 & 0.6 & 969 \\
\hline \multicolumn{4}{|c|}{ Logged Opioid Overdose Age-Adjusted Death Rate (per 100,000 } \\
\hline Female & 1.4 & 0.8 & 967 \\
\hline Male & 2 & 0.8 & 968 \\
\hline \multicolumn{4}{|c|}{ Corrected Logged Opioid Overdose Age-Adjusted Death Rate (per } \\
\hline \multicolumn{4}{|c|}{100,000 population) } \\
\hline Female & 1.7 & 0.8 & 967 \\
\hline Male & 2.3 & 0.7 & 968 \\
\hline \multicolumn{4}{|c|}{ Logged Emergency Department Visits (per 100,000 population) } \\
\hline Female & 4.8 & 0.6 & 381 \\
\hline Male & 4.9 & 0.7 & 381 \\
\hline \multicolumn{4}{|l|}{ Logged Inpatient Hospital Stays (per 100,000 population) } \\
\hline Female & 5.3 & 0.5 & 553 \\
\hline Male & 5.2 & 0.6 & 553 \\
\hline \multicolumn{4}{|l|}{ Manufacturing Measures } \\
\hline Manufacturing Employment (\%) & 11.5 & 5.0 & 969 \\
\hline Manufacturing Annual Payroll (\%) & 13.9 & 6.3 & 969 \\
\hline \multicolumn{4}{|l|}{ State-Level Covariates } \\
\hline Labor Force Participation Rate & 65 & 4.3 & 969 \\
\hline College Graduates (\%) & 19.6 & 5 & 969 \\
\hline Ever-Married (\%) & 56.5 & 3.5 & 969 \\
\hline Hispanic $(\%)$ & 9.3 & 9.7 & 969 \\
\hline Black $(\%)$ & 11.3 & 11.5 & 969 \\
\hline$\%$ Population Ages 15-64 & 66.7 & 1.6 & 969 \\
\hline$\%$ Population Ages 65 or Above & 13.3 & 2 & 969 \\
\hline Population Living in Metropolitan Area Counties (\%) & 75.6 & 18.5 & 969 \\
\hline Self-Reported Health Score (1-Excellent to 5-Poor) & 2.2 & 0.12 & 969 \\
\hline \multicolumn{4}{|l|}{ State-Level Labor and Drug Policy Covariates } \\
\hline Union Coverage $(\%)$ & 12.8 & 5.5 & 969 \\
\hline Prescription Drug Monitoring Program & & & \\
\hline
\end{tabular}


\# of states in 1999

\# of states in 2017

Naloxone Access Laws

\# of states in 1999

\# of states in 2017

Good Samaritan Laws

\# of states in 1999

\# of states in 2017

Opioid Prescriptions Filled (per 100 population)
16

50

0

48

0

37

81
950

950

969

969

969

969

561

Note: All covariates are lagged one year. 
Table 2. Regression Analyses Predicting Logged Drug, Opioid, and Corrected Opioid Overdose Mortality Rates

\begin{tabular}{|c|c|c|}
\hline \multicolumn{3}{|l|}{ A. Logged Drug Overdose Mortality } \\
\hline Manufacturing Measure & Model 1 & Model 2 \\
\hline \multicolumn{3}{|l|}{ Female } \\
\hline$\%$ Employees in Manufacturing & $\begin{array}{l}-0.033 * * \\
(0.011)\end{array}$ & $\begin{array}{l}-0.034 * * \\
(0.011)\end{array}$ \\
\hline \% Annual Payroll in Manufacturing & $\begin{array}{l}-0.030 * * \\
(0.010)\end{array}$ & $\begin{array}{l}-0.031 * * \\
(0.009)\end{array}$ \\
\hline \multicolumn{3}{|l|}{ Male } \\
\hline$\%$ Employees in Manufacturing & $\begin{array}{l}-0.049 * * * \\
(0.013)\end{array}$ & $\begin{array}{l}-0.050 * * * \\
(0.013)\end{array}$ \\
\hline \% Annual Payroll in Manufacturing & $\begin{array}{l}-0.039 * * * \\
(0.011)\end{array}$ & $\begin{array}{l}-0.039 * * * \\
(0.011)\end{array}$ \\
\hline \multicolumn{3}{|l|}{ B. Logged Opioid Overdose Mortality } \\
\hline Manufacturing Measure & Model 1 & Model 2 \\
\hline \multicolumn{3}{|l|}{ Female } \\
\hline$\%$ Employees in Manufacturing & $\begin{array}{l}-0.051^{*} \\
(0.025)\end{array}$ & $\begin{array}{l}-0.055^{*} \\
(0.023)\end{array}$ \\
\hline$\%$ Annual Payroll in Manufacturing & $\begin{array}{l}-0.046^{*} \\
(0.020)\end{array}$ & $\begin{array}{l}-0.049 * * \\
(0.018)\end{array}$ \\
\hline \multicolumn{3}{|l|}{ Male } \\
\hline \% Employees in Manufacturing & $\begin{array}{c}-0.067 * \\
(0.030)\end{array}$ & $\begin{array}{l}-0.071 * \\
(0.028)\end{array}$ \\
\hline$\%$ Annual Payroll in Manufacturing & $\begin{array}{l}-0.051^{*} \\
(0.023) \\
\end{array}$ & $\begin{array}{l}-0.053^{*} \\
(0.021) \\
\end{array}$ \\
\hline \multicolumn{3}{|c|}{ C. Logged Corrected Opioid Overdose Mortality } \\
\hline Manufacturing Measure & Model 1 & Model 2 \\
\hline \multicolumn{3}{|l|}{ Female } \\
\hline$\%$ Employees in Manufacturing & $\begin{array}{l}-0.057 * \\
(0.021)\end{array}$ & $\begin{array}{l}-0.061 * * \\
(0.021)\end{array}$ \\
\hline$\%$ Annual Payroll in Manufacturing & $\begin{array}{l}-0.047 * * \\
(0.017)\end{array}$ & $\begin{array}{l}-0.049 * * \\
(0.016)\end{array}$ \\
\hline \multicolumn{3}{|l|}{ Male } \\
\hline \% Employees in Manufacturing & $\begin{array}{l}-0.074 * * * \\
(0.019)\end{array}$ & $\begin{array}{l}-0.077 \text { *** } \\
(0.019)\end{array}$ \\
\hline$\%$ Annual Payroll in Manufacturing & $\begin{array}{l}-0.056^{* * * *} \\
(0.016)\end{array}$ & $\begin{array}{l}-0.057 * * * \\
(0.015)\end{array}$ \\
\hline State and Year Fixed Effects & Yes & Yes \\
\hline Compositional and Economic Covariates & Yes & Yes \\
\hline Labor and Drug Policy Covariates & No & Yes \\
\hline
\end{tabular}

$* \mathrm{p}<.05, * * \mathrm{p}<.01, * * * \mathrm{p}<.001$ (two tailed tests)

Notes: (a) All covariates are lagged one year. (b) State-clustered standard errors are in parentheses. (c) Drug overdose models have 969 observations, representing 50 states and the District of Columbia over 19 years. Uncorrected and corrected opioid overdose models have 967 
observations for women and 968 observations for men. (d) Compositional and economic covariates include state-level measures of the labor force participation rate, the percentage with a college degree, the percentage who have ever been married, the percentage who are Hispanic, the percentage who are Black, the percentage who are ages 18-64, the percentage who are ages 65 or above, the percentage living in metropolitan counties, and the average self-reported health score. (e) Labor and drug policy covariates include state-level measures of the percent of workers covered or represented by labor unions, and binary indicators of whether states have implemented three types of drug policies: PDMPs, naloxone access laws, and Good Samaritan laws for reporting drug overdoses. 
Table 3A. Negative Binomial Regression Analyses Predicting Age-Specific Drug Overdose Deaths for White, non-Hispanic Females and Males for 10-year age groups

\begin{tabular}{|c|c|c|c|c|}
\hline \multirow[t]{2}{*}{ Age-Specific Drug Deaths } & \multicolumn{2}{|c|}{$\begin{array}{c}\text { White Females, non- } \\
\text { Hispanic }\end{array}$} & \multicolumn{2}{|c|}{$\begin{array}{l}\text { White Males, non- } \\
\text { Hispanic }\end{array}$} \\
\hline & Model 1 & Model 2 & Model 1 & Model 2 \\
\hline \multicolumn{5}{|l|}{ Ages 25-34 } \\
\hline$\%$ Employees in Manufacturing & $\begin{array}{l}-0.051 * * * \\
(0.013)\end{array}$ & $\begin{array}{l}-0.042 * * * \\
(0.013)\end{array}$ & $\begin{array}{l}-0.053 * * * \\
(0.011)\end{array}$ & $\begin{array}{l}-0.048 * * * \\
(0.011)\end{array}$ \\
\hline$\%$ Annual Payroll in Manufacturing & $\begin{array}{l}-0.047 * * * \\
(0.010)\end{array}$ & $\begin{array}{l}-0.038^{* * *} \\
(0.010)\end{array}$ & $\begin{array}{l}-0.043^{* * *} \\
(0.008)\end{array}$ & $\begin{array}{l}-0.039 * * * \\
(0.008)\end{array}$ \\
\hline $\mathrm{N}$ & 969 & 969 & 969 & 969 \\
\hline \multicolumn{5}{|l|}{ Ages $35-44$} \\
\hline$\%$ Employees in Manufacturing & $\begin{array}{l}-0.050 * * * \\
(0.011)\end{array}$ & $\begin{array}{l}-0.046^{* * * *} \\
(0.011)\end{array}$ & $\begin{array}{l}-0.068 * * * \\
(0.011)\end{array}$ & $\begin{array}{l}-0.062 * * * \\
(0.010)\end{array}$ \\
\hline$\%$ Annual Payroll in Manufacturing & $\begin{array}{l}-0.045^{* * *} \\
(0.008)\end{array}$ & $\begin{array}{l}-0.041 * * * \\
(0.008)\end{array}$ & $\begin{array}{l}-0.056^{* * *} \\
(0.008)\end{array}$ & $\begin{array}{l}-0.051 * * * \\
(0.008)\end{array}$ \\
\hline $\mathrm{N}$ & 969 & 969 & 969 & 969 \\
\hline \multicolumn{5}{|l|}{ Ages 45-54 } \\
\hline$\%$ Employees in Manufacturing & $\begin{array}{l}-0.064 * * * \\
(0.011)\end{array}$ & $\begin{array}{l}-0.062 * * * \\
(0.011)\end{array}$ & $\begin{array}{l}-0.093 * * * \\
(0.011)\end{array}$ & $\begin{array}{l}-0.092 * * * \\
(0.011)\end{array}$ \\
\hline$\%$ Annual Payroll in Manufacturing & $\begin{array}{l}-0.051 * * * \\
(0.008)\end{array}$ & $\begin{array}{l}-0.048 * * * \\
(0.008)\end{array}$ & $\begin{array}{l}-0.070^{* * * *} \\
(0.008)\end{array}$ & $\begin{array}{l}-0.068 * * * \\
(0.008)\end{array}$ \\
\hline $\mathrm{N}$ & 969 & 969 & 969 & 969 \\
\hline \multicolumn{5}{|l|}{ Ages 55-64 } \\
\hline$\%$ Employees in Manufacturing & $\begin{array}{l}-0.026 \\
(0.013)\end{array}$ & $\begin{array}{l}-0.024 \\
(0.013)\end{array}$ & $\begin{array}{l}-0.058 * * * \\
(0.015)\end{array}$ & $\begin{array}{l}-0.058 * * * \\
(0.014)\end{array}$ \\
\hline$\%$ Annual Payroll in Manufacturing & $\begin{array}{l}-0.017 \\
(0.010)\end{array}$ & $\begin{array}{l}-0.012 \\
(0.010)\end{array}$ & $\begin{array}{l}-0.041 * * * \\
(0.011)\end{array}$ & $\begin{array}{l}-0.038 * * * \\
(0.011)\end{array}$ \\
\hline $\mathrm{N}$ & 969 & 969 & 969 & 969 \\
\hline
\end{tabular}

Notes: (a) All covariates are lagged one year. (b) Exposure variable set to annual state-level sexspecific population size. (c) All models include state and year fixed effects. (d) Compositional and economic covariates (Model 1 and Model 2) include state-level measures of the labor force participation rate, the percentage with a college degree, the percentage who have ever been married, the percentage who are Hispanic, the percentage who are Black, the percentage who are ages 18-64, the percentage who are ages 65 or above, the percentage living in metropolitan counties, and the average self-reported health score. (e) Labor and drug policy covariates (Model 2) include state-level measures of the percent of workers covered or represented by labor unions, and binary indicators of whether states have implemented three types of drug policies: PDMPs, naloxone access laws, and Good Samaritan laws for reporting drug overdoses. 
Table 3B. Negative Binomial Regression Analyses Predicting Age-Specific Drug Overdose Deaths for Black, non-Hispanic Females and Males for 10-year age groups

\begin{tabular}{|c|c|c|c|c|}
\hline \multirow[t]{2}{*}{ Age-Specific Drug Deaths } & \multicolumn{2}{|c|}{$\begin{array}{c}\text { Black Females, non- } \\
\text { Hispanic }\end{array}$} & \multicolumn{2}{|c|}{$\begin{array}{c}\text { Black Males, non- } \\
\text { Hispanic }\end{array}$} \\
\hline & Model 1 & Model 2 & Model 1 & Model 2 \\
\hline \multicolumn{5}{|l|}{ Ages 25-34 } \\
\hline$\%$ Employees in Manufacturing & $\begin{array}{l}-0.023 \\
(0.030)\end{array}$ & $\begin{array}{l}-0.022 \\
(0.030)\end{array}$ & $\begin{array}{l}-0.006 \\
(0.021)\end{array}$ & $\begin{array}{l}-0.005 \\
(0.021)\end{array}$ \\
\hline$\%$ Annual Payroll in Manufacturing & $\begin{array}{l}-0.038 \\
(0.023)\end{array}$ & $\begin{array}{l}-0.031 \\
(0.023)\end{array}$ & $\begin{array}{l}-0.031 \\
(0.017)\end{array}$ & $\begin{array}{l}-0.028 \\
(0.017)\end{array}$ \\
\hline $\mathrm{N}$ & 893 & 893 & 931 & 931 \\
\hline \multicolumn{5}{|l|}{ Ages 35-44 } \\
\hline$\%$ Employees in Manufacturing & $\begin{array}{l}0.004 \\
(0.022)\end{array}$ & $\begin{array}{l}0.003 \\
(0.022)\end{array}$ & $\begin{array}{l}-0.016 \\
(0.020)\end{array}$ & $\begin{array}{l}-0.016 \\
(0.019)\end{array}$ \\
\hline$\%$ Annual Payroll in Manufacturing & $\begin{array}{l}-0.010 \\
(0.017)\end{array}$ & $\begin{array}{l}-0.008 \\
(0.017)\end{array}$ & $\begin{array}{l}-0.052 * * * \\
(0.014)\end{array}$ & $\begin{array}{l}-0.049 * * * \\
(0.015)\end{array}$ \\
\hline $\mathrm{N}$ & 893 & 893 & 969 & 969 \\
\hline \multicolumn{5}{|l|}{ Ages $45-54$} \\
\hline$\%$ Employees in Manufacturing & $\begin{array}{l}-0.053^{*} \\
(0.022)\end{array}$ & $\begin{array}{l}-0.054^{*} \\
(0.022)\end{array}$ & $\begin{array}{l}-0.014 \\
(0.017)\end{array}$ & $\begin{array}{l}-0.015 \\
(0.017)\end{array}$ \\
\hline$\%$ Annual Payroll in Manufacturing & $\begin{array}{l}-0.036^{*} \\
(0.017)\end{array}$ & $\begin{array}{l}-0.035^{*} \\
(0.017)\end{array}$ & $\begin{array}{l}-0.023 \\
(0.014)\end{array}$ & $\begin{array}{l}-0.021 \\
(0.014)\end{array}$ \\
\hline $\mathrm{N}$ & 950 & 950 & 950 & 950 \\
\hline \multicolumn{5}{|l|}{ Ages 55-64 } \\
\hline$\%$ Employees in Manufacturing & $\begin{array}{l}-0.015 \\
(0.038)\end{array}$ & $\begin{array}{l}-0.038 \\
(0.039)\end{array}$ & $\begin{array}{l}-0.037 \\
(0.025)\end{array}$ & $\begin{array}{l}-0.040 \\
(0.024)\end{array}$ \\
\hline$\%$ Annual Payroll in Manufacturing & $\begin{array}{l}-0.002 \\
(0.030)\end{array}$ & $\begin{array}{l}-0.006 \\
(0.030)\end{array}$ & $\begin{array}{l}-0.058 * * \\
(0.019)\end{array}$ & $\begin{array}{l}-0.052 * * \\
(0.019)\end{array}$ \\
\hline $\mathrm{N}$ & 874 & 874 & 912 & 912 \\
\hline
\end{tabular}

Notes: (a) All covariates are lagged one year. (b) Exposure variable set to annual state-level sexspecific population size. (c) Missing state-year observations are the result of states with no drug deaths over the 19-year period between 1999-2017. (d) All models include state and year fixed effects. (e) Compositional and economic covariates (Model 1 and Model 2) include state-level measures of the labor force participation rate, the percentage with a college degree, the percentage who have ever been married, the percentage who are Hispanic, the percentage who are Black, the percentage who are ages 18-64, the percentage who are ages 65 or above, the percentage living in metropolitan counties, and the average self-reported health score. (f) Labor and drug policy covariates (Model 2) include state-level measures of the percent of workers covered or represented by labor unions, and binary indicators of whether states have implemented three types of drug policies: PDMPs, naloxone access laws, and Good Samaritan laws for reporting drug overdoses. 
Table 4. Regression Models Testing for Differences in Manufacturing Decline across Triplicate and Non-Triplicate States

\begin{tabular}{|c|c|c|}
\hline \multicolumn{3}{|l|}{ A. Logged Drug Overdose Mortality } \\
\hline Manufacturing Measure & $\begin{array}{l}\text { Main } \\
\text { Effect }\end{array}$ & $\begin{array}{c}\text { Interaction } \\
\text { Effect }\end{array}$ \\
\hline \multicolumn{3}{|l|}{ Female } \\
\hline \% Employees in Manufacturing & $\begin{array}{l}-0.0337 * * \\
(0.0114)\end{array}$ & $\begin{array}{l}0.0251 \\
(0.0493)\end{array}$ \\
\hline$\%$ Annual Payroll in Manufacturing & $\begin{array}{l}-0.0292 * * \\
(0.0093)\end{array}$ & $\begin{array}{l}0.0253 \\
(0.0336) \\
\end{array}$ \\
\hline \multicolumn{3}{|l|}{ Male } \\
\hline$\%$ Employees in Manufacturing & $\begin{array}{l}-0.0488 * * * \\
(0.0136)\end{array}$ & $\begin{array}{l}-0.0004 \\
(0.0347)\end{array}$ \\
\hline$\%$ Annual Payroll in Manufacturing & $\begin{array}{l}-0.0381 * * \\
(0.0109)\end{array}$ & $\begin{array}{l}0.0154 \\
(0.0334) \\
\end{array}$ \\
\hline \multicolumn{3}{|l|}{ B. Logged Opioid Overdose Mortality } \\
\hline \multicolumn{3}{|l|}{ Manufacturing Measure } \\
\hline \multicolumn{3}{|l|}{ Female } \\
\hline \% Employees in Manufacturing & $\begin{array}{l}-0.0500 * \\
(0.0237)\end{array}$ & $\begin{array}{l}-0.0257 \\
(0.0661)\end{array}$ \\
\hline$\%$ Annual Payroll in Manufacturing & $\begin{array}{l}-0.0406^{*} \\
(0.0183)\end{array}$ & $\begin{array}{l}-0.0074 \\
(0.0578) \\
\end{array}$ \\
\hline \multicolumn{3}{|l|}{ Male } \\
\hline$\%$ Employees in Manufacturing & $\begin{array}{l}-0.0669 * \\
(0.0285)\end{array}$ & $\begin{array}{l}-0.0390 \\
(0.0530)\end{array}$ \\
\hline$\%$ Annual Payroll in Manufacturing & $\begin{array}{l}-0.0476^{*} \\
(0.0218) \\
\end{array}$ & $\begin{array}{l}-0.0157 \\
(0.0461) \\
\end{array}$ \\
\hline \multicolumn{3}{|c|}{ C. Logged Corrected Opioid Overdose Mortality } \\
\hline Manufacturing Measure & Model 1 & Model 2 \\
\hline \multicolumn{3}{|l|}{ Female } \\
\hline$\%$ Employees in Manufacturing & $\begin{array}{l}-0.0576^{* * *} \\
(0.0211)\end{array}$ & $\begin{array}{l}0.0122 \\
(0.0508)\end{array}$ \\
\hline$\%$ Annual Payroll in Manufacturing & $\begin{array}{l}-0.0443^{* *} \\
(0.0162)\end{array}$ & $\begin{array}{l}0.0149 \\
(0.0364)\end{array}$ \\
\hline \multicolumn{3}{|l|}{ Male } \\
\hline \% Employees in Manufacturing & $\begin{array}{l}-0.0759 * * * \\
(0.0190)\end{array}$ & $\begin{array}{l}0.0187 \\
(0.0367)\end{array}$ \\
\hline$\%$ Annual Payroll in Manufacturing & $\begin{array}{l}-0.0568 * * * \\
(0.0150)\end{array}$ & $\begin{array}{l}0.0277 \\
(0.0327)\end{array}$ \\
\hline
\end{tabular}

$* \mathrm{p}<.05, * * \mathrm{p}<.01, * * * \mathrm{p}<.001$ (two tailed tests)

Notes: (a) All covariates are lagged one year. (b) State-clustered standard errors are in parentheses. (c) Drug overdose models have 969 observations, representing 50 states and the District of Columbia over 19 years. Uncorrected and corrected opioid overdose models have 967 observations for women and 968 observations for men. (d) Main effect represents the coefficient 
for non-triplicate states; Interaction effect represents the difference in coefficient size and significance between non-triplicate and triplicate states (i.e. the coefficient for triplicate states is equivalent to the Main Effect + the Interaction Effect). (e) Compositional and economic covariates include state-level measures of the labor force participation rate, the percentage with a college degree, the percentage who have ever been married, the percentage who are Hispanic, the percentage who are Black, the percentage who are ages 18-64, the percentage who are ages 65 or above, the percentage living in metropolitan counties, and the average self-reported health score. (f) Labor and drug policy covariates include state-level measures of the percent of workers covered or represented by labor unions, and binary indicators of whether states have implemented three types of drug policies: PDMPs, naloxone access laws, and Good Samaritan laws for reporting drug overdoses. 
Table 5. Regression Analyses Predicting County-Level Drug and Opioid Mortality Rates

\begin{tabular}{|c|c|c|c|c|c|}
\hline \multirow{3}{*}{$\begin{array}{l}\text { A. Logged Drug Overdose Mortality } \\
\text { Manufacturing Measure }\end{array}$} & \multicolumn{5}{|c|}{ Level of Manufacturing Measure Aggregation } \\
\hline & \multicolumn{2}{|c|}{ County } & \multicolumn{2}{|c|}{ Commuting Zone } & \multirow{2}{*}{$\begin{array}{l}\text { State } \\
\text { CBP }\end{array}$} \\
\hline & CBP & CBP Imputed & CBP & CBP Imputed & \\
\hline \multicolumn{6}{|l|}{ Female } \\
\hline \% Employees in Manufacturing & $\begin{array}{c}-0.0045^{* *} \\
(0.0014)\end{array}$ & $\begin{array}{c}-0.0092 * * * \\
(0.0021)\end{array}$ & $\begin{array}{c}-0.0116^{*} \\
(0.0049)\end{array}$ & $\begin{array}{l}-0.0158^{*} \\
(0.0067)\end{array}$ & $\begin{array}{l}-0.0324^{*} \\
(0.0122)\end{array}$ \\
\hline \% Annual Payroll in Manufacturing & $\begin{array}{c}-0.0043 * * \\
(0.0013)\end{array}$ & & $\begin{array}{c}-0.0110^{*} \\
(0.0044)\end{array}$ & & $\begin{array}{c}-0.0283 * * \\
(0.0105)\end{array}$ \\
\hline \multicolumn{6}{|l|}{ Male } \\
\hline$\%$ Employees in Manufacturing & $\begin{array}{c}-0.0053 * * * \\
(0.0015)\end{array}$ & $\begin{array}{c}-0.0101 * * * \\
(0.0028)\end{array}$ & $\begin{array}{c}-0.0138 * * \\
(0.0051)\end{array}$ & $\begin{array}{c}-0.0204 * * \\
(0.0073)\end{array}$ & $\begin{array}{c}-0.0479 * * * * \\
(0.0119)\end{array}$ \\
\hline$\%$ Annual Payroll in Manufacturing & $\begin{array}{c}-0.0051^{* *} * \\
(0.0015) \\
\end{array}$ & & $\begin{array}{c}-0.0125^{*} \\
(0.0048)\end{array}$ & & $\begin{array}{c}-0.0365^{* *} \\
(0.0117)\end{array}$ \\
\hline Counties & 2,932 & 3,120 & 3,132 & 3,132 & 3,132 \\
\hline County-Year Observations & 55,517 & 57,620 & 59,458 & 59,455 & 59,375 \\
\hline B. Logged Corrected Opioid Overdose Mortality & \multicolumn{5}{|c|}{ Level of Manufacturing Measure Aggregation } \\
\hline & \multicolumn{2}{|c|}{ County } & \multicolumn{2}{|c|}{ Commuting Zone } & State \\
\hline Manufacturing Measure & $\mathrm{CBP}$ & CBP Imputed & CBP & CBP Imputed & $\mathrm{CBP}$ \\
\hline Female & & & & & \\
\hline$\%$ Employees in Manufacturing & $\begin{array}{c}-0.0034 * \\
(0.0015)\end{array}$ & $\begin{array}{c}-0.0089 * * * \\
(0.0022)\end{array}$ & $\begin{array}{l}-0.0102 \\
(0.0057)\end{array}$ & $\begin{array}{c}-0.0166^{*} \\
(0.0076)\end{array}$ & $\begin{array}{c}-0.0466 * \\
(0.0203)\end{array}$ \\
\hline$\%$ Annual Payroll in Manufacturing & $\begin{array}{c}-0.0039 * \\
(0.0014) \\
\end{array}$ & & $\begin{array}{c}-0.0096 \\
(0.0049) \\
\end{array}$ & & $\begin{array}{c}-0.0346 * \\
(0.0165) \\
\end{array}$ \\
\hline Male & & & & & \\
\hline$\%$ Employees in Manufacturing & $\begin{array}{c}-0.0053 * * \\
(0.0019)\end{array}$ & $\begin{array}{c}-0.0132 * * * \\
(0.0034)\end{array}$ & $\begin{array}{l}-0.0110 \\
(0.0064)\end{array}$ & $\begin{array}{c}-0.0225^{*} \\
(0.0085)\end{array}$ & $\begin{array}{c}-0.0674 * * \\
(0.0227)\end{array}$ \\
\hline \% Annual Payroll in Manufacturing & $\begin{array}{c}-0.0054 * * \\
(0.0017) \\
\end{array}$ & & $\begin{array}{c}-0.0101 \\
(0.0057) \\
\end{array}$ & & $\begin{array}{l}-0.0462^{*} \\
(0.0203)\end{array}$ \\
\hline Counties & 2,932 & 3,120 & 3,132 & 3,132 & 3,132 \\
\hline County-Year Observations & 55,517 & 57,620 & 59,458 & 59,455 & 59,375 \\
\hline County and Year Fixed Effects & Yes & Yes & Yes & Yes & Yes \\
\hline County, CZ, and State Covariates & Yes & Yes & Yes & Yes & Yes \\
\hline State Labor and Drug Policy Covariates & Yes & Yes & Yes & Yes & Yes \\
\hline
\end{tabular}

Notes: (a) County and commuting zone manufacturing measures were constructed using the county-level County Business Patterns dataset while the state manufacturing measures were constructed using the state-level County Business Patterns dataset. The CBP Imputed data was accessed from Eckert et al. (2020). (b) The county-level CBP model (Column 1) excludes counties that have no information on manufacturing employment over the entire 19992017 period. (c) The CBP Imputed dataset does not have imputed annual payroll numbers. (d) All models are weighted by county population in 1999. (e) Standard errors are clustered at the state-level. 


\section{Online Supplement}

Note S1. Methodology for Opioid Undercount Correcting Procedure

Note S1 Figure 1. Predictive Accuracy Rate of Annual Logistic Regression and Random Forest Models Predicting Opioid Involvement in Drug Overdose Deaths

Note S1 Figure 2. Annual Number of Total Drug Overdoses, Specified Opioid Overdoses, and Corrected Opioid Overdoses

Note S2. Formal Bounds Analysis based on Oster (2019)

Figure S1. Distributions of Age-Adjusted Mortality Rates, 1999-2017

Table S1. ICD10 Codes for Drug Overdose Deaths

Table S2A. Full Models: Regression Analyses Predicting Logged Drug Overdose Mortality Rates

Table S2B. Full Models: Regression Analyses Predicting Logged Opioid Overdose Mortality Rates

Table S2B. Full Models: Regression Analyses Predicting Logged Corrected Opioid Overdose Mortality Rates

Table S3. Number of Drug Overdose Deaths Attributable to Manufacturing Decline Between 1999-2017, by State and Measure of Manufacturing

Table S4. Sensitivity Analyses, including Negative Binomial Regression Models, Population Weights, and Removed Labor Force Participation Rates

Table S5. Sensitivity Analyses, including Detailed Age Structure Controls, Percentage of the Population Born Outside of the U.S., and State-by-Year Linear Time Trends

Table S6. Regression Analyses Predicting Rates of Emergency Department Visits and Inpatient Stays for Women and Men 
Note S1. Methodology for Opioid Undercount Correcting Procedure

Previous research (e.g. Boslett et al. 2020; Ruhm 2017, 2020) has documented that a considerable amount of drug overdose deaths in the NCHS multiple cause of death datasets are coded as solely involving an unspecified drug, medicament, or biological substance (ICD10 code T50.9). In the 1999-2017 NCHS multiple cause of death file, approximately $21 \%$ of overdose deaths involved unclassified drugs; this roughly matches Boslett et al. (2020) who found that $21.8 \%$ of overdose deaths were unclassified between 1999-2016 and Buchanich et al. (2018) who found that that $22 \%$ of overdose deaths were unclassified between 1999-2015.

I implemented a correction procedure proposed by Boslett et al. (2020) to predict opioid involvement in unclassified drug overdose deaths which used logistic regression and a parsimonious set of decedent characteristics as predictors. Decedent characteristics included age at death, sex, race, Hispanic ethnicity, marital status, day of week and month of death, place of death, and state of residence. I first estimated year-specific models by randomly splitting deaths with specified opioid or non-opioid contributing causes into annual training datasets (80\% of annual observations) and annual testing datasets (20\% of annual observations). Next, I estimated the logistic regression models on the training datasets and benchmarked their predictive accuracy on the testing datasets by calculating the total predictive accuracy rate:

Predictive Accuracy $=\frac{\text { True Positives }+ \text { True Negatives }}{\text { True Positives }+ \text { True Negatives }+ \text { False Positives }+ \text { False Negatives }}$ If the predicted probability of opioid involvement was greater or equal to 0.5 , I classified it as an opioid overdose; otherwise, if the predicted probability was lower than 0.5 , I classified it as a non-opioid overdose.

Note S1 Figure 1 presents the predictive accuracy rate for each annual logit model (red line and points) when applied to the annual testing datasets. The results of these models are comparable to the highest performing predictive models estimated by Boslett et al. (2020; Figure 2). I additionally estimated a set of random forests models (Breiman 2001) (grey line and points) using the same set of predictors, but these machine learning models were consistently outperformed by the logistic regression models. These results align with the findings of Boslett et al. (2020). 
Upon assessing the accuracy of the predictive logistic regression models on the testing datasets, I applied the predictive models to the $21 \%$ of death records in the 1999-2017 NCHS multiple cause of death dataset that were unclassified, and assigned opioid or nonopioid classifications based on predicted probabilities. I combined these predicted opioid/non-opioid classifications with the specified opioid or non-opioid drug overdose deaths to calculate annual state-year counts of total opioid deaths.

Note S1 Figure 2 presents the total annual number of deaths from (a) all drug overdoses, (b) specified opioid overdoses only, and (c) the corrected estimates of opioid overdoses which includes specified opioid overdoses and predicted opioid overdoses for death records that had an unspecified contributing cause. The points in this graph represent the total number of deaths while the lines represent loess smoothed trends. The corrected estimates are comparable to those estimated by Boslett et al. (2020) in Figure 3 of their study. 
Note S1 Figure 1. Predictive Accuracy Rate of Annual Logistic Regression and Random Forest Models Predicting Opioid Involvement in Drug Overdose Deaths

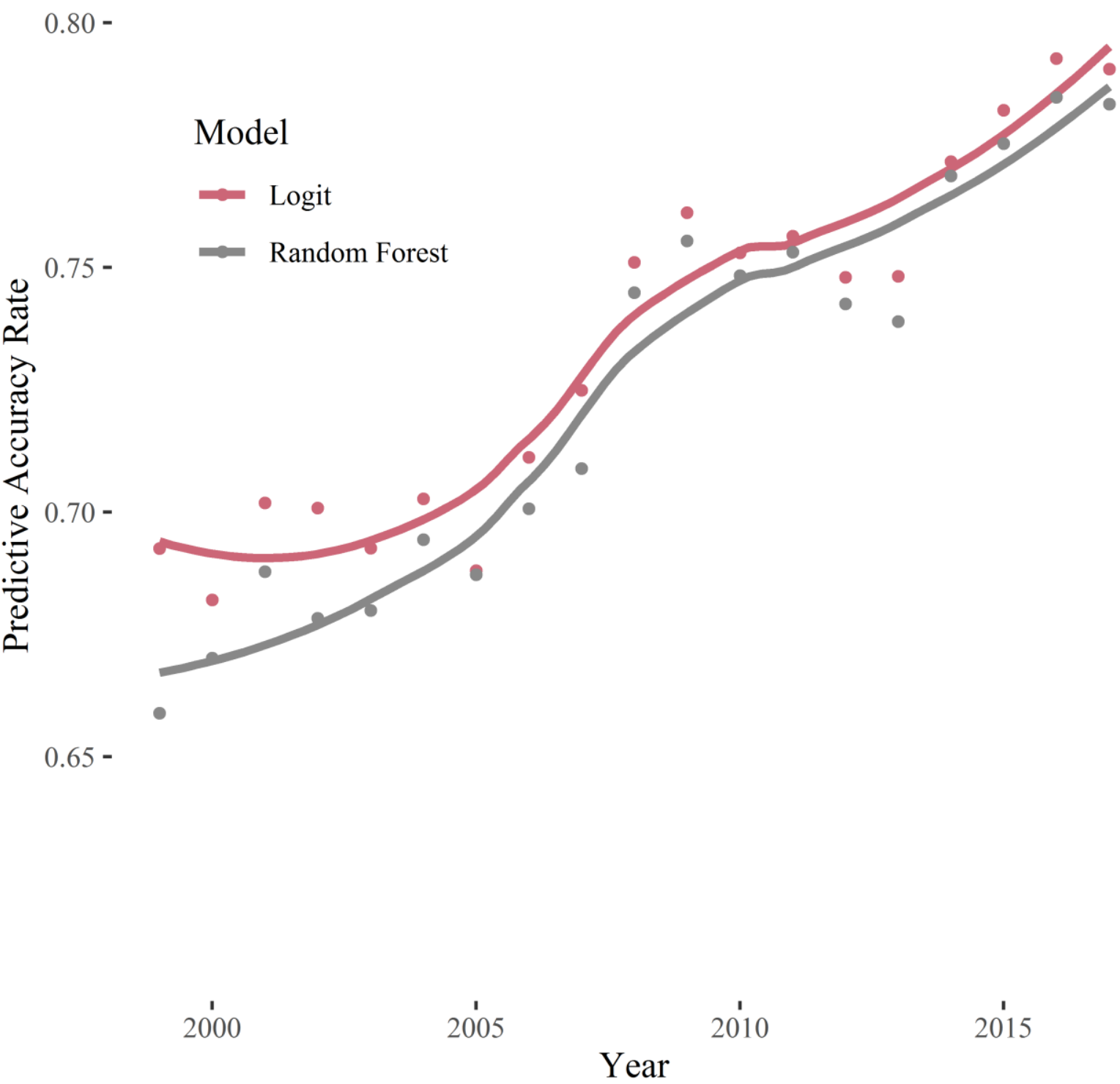

Notes: Points represent the predictive accuracy rate of each annual model when applied to the annual testing datasets. The lines represent loess smoothed trends, indicating improved accuracy over time for both models. The accuracy of the logit models are comparable to the highest performing predictive models estimated by Boslett et al. (2020; Figure 2). 
Note S1 Figure 2. Annual Number of Total Drug Overdoses, Specified Opioid Overdoses, and Corrected Opioid Overdoses

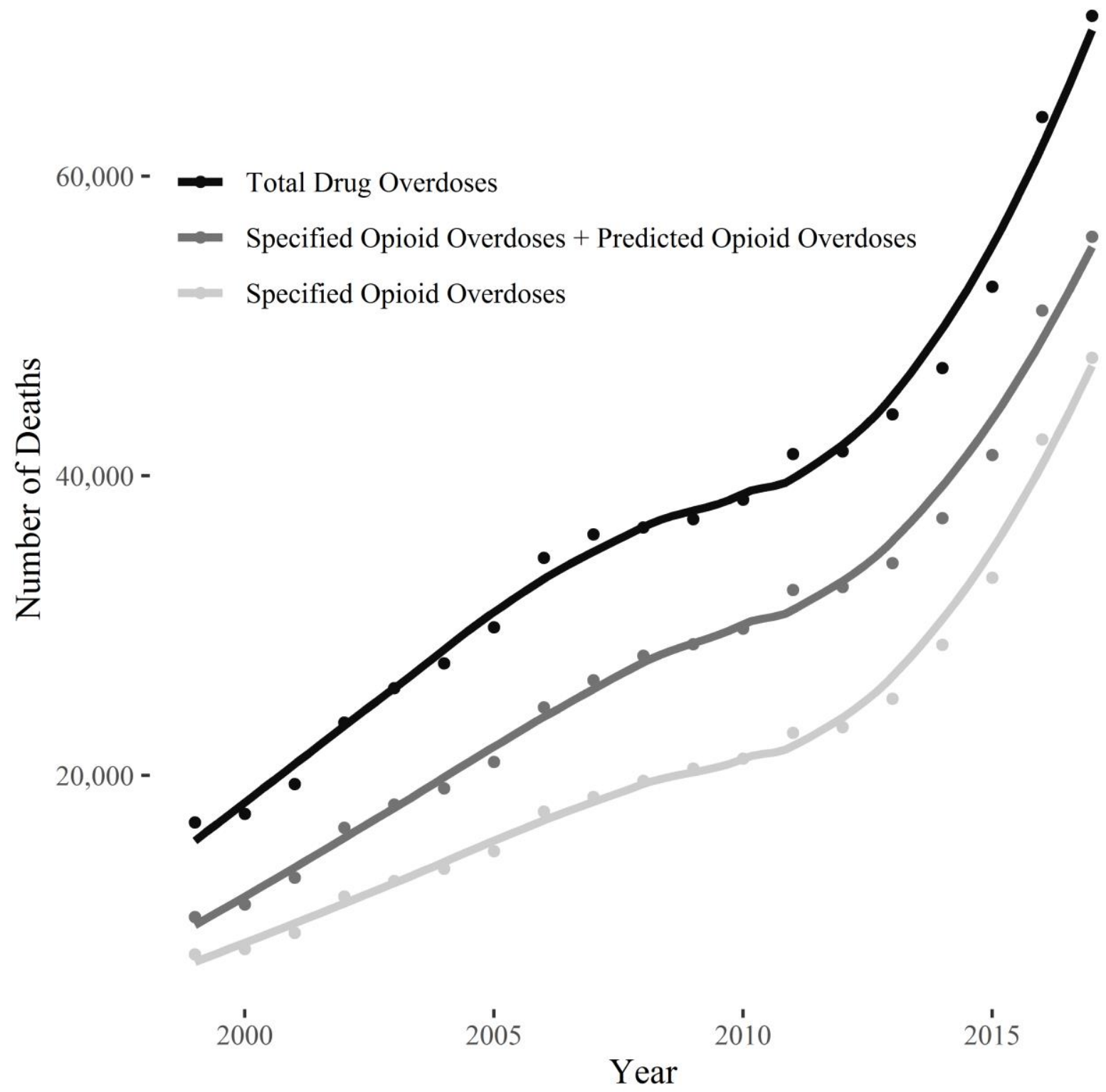

Notes: Points represent the total annual number of deaths from (a) all drug overdoses, (b) specified opioid overdoses only, and (c) the corrected estimates of opioid overdoses which includes specified opioid overdoses and predicted opioid overdoses for death records that had an unspecified contributing cause. Lines represent loess smoothed trends. The corrected estimates (Specified Opioid Overdoses + Predicted Opioid Overdoses) are approximately comparable to those estimated by Boslett et al. (2020) in Figure 3 of their study. 
Note S2. Formal Bounds Analysis based on Oster (2019)

I further investigated how unobservable omitted variables might influence the parameter estimates of the main specifications by conducting a formal bounding analysis based on Oster (2019). I calculated $\delta$ test statistics using a restricted model that only included time-invariant state and year fixed effects, and an unrestricted model that added the time-varying covariates used in the "Model 2" specifications throughout this study. A $\delta$ value that is larger than 1 in absolute value terms indicates that selection on unobservables would have to be larger in magnitude than selection on observables in order to generate an estimate of the manufacturing decline coefficient that is zero (Oster 2019). The results (Note S2, Table 1) show that the values of $\delta$ are above 1 when using the employment measure of manufacturing, but not for the annual payroll measure of manufacturing. This suggests that the models that use the employment measure of manufacturing are highly robust to omitted variable bias (i.e. selection on unobservables would have to be 10 times larger in magnitude than selection on observables for the models predicting drug overdose mortality for men to produce a zero effect size), but also that the employment models are considerably more robust to the threat of selection on observables than the annual payroll models. This might be because the employment measure is a more accurate measure of structural economic change in the manufacturing sector than the annual payroll measure. Overall, for the primary set of findings, selection on omitted variables would have to be extreme to reduce the coefficients to zero.

Note S2 Table 1. Delta Values of Bounds Analysis

\begin{tabular}{lcc}
\hline & $\begin{array}{c}\text { Drug } \\
\text { Mortality }\end{array}$ & $\begin{array}{c}\text { Corrected } \\
\text { Opioid } \\
\text { Mortality }\end{array}$ \\
\hline Men & & \\
Manufacturing Employment & 10.09 & -5.07 \\
$\quad$ Manufacturing Annual Payroll & 0.69 & 0.60 \\
\hline Women & & \\
Manufacturing Employment & -1.71 & -8.37 \\
Manufacturing Annual Payroll & 0.68 & 0.54 \\
\hline
\end{tabular}


Figure S1. Distributions of Age-Adjusted Mortality Rates, 1999-2017

A1. Drug Mortality Rate

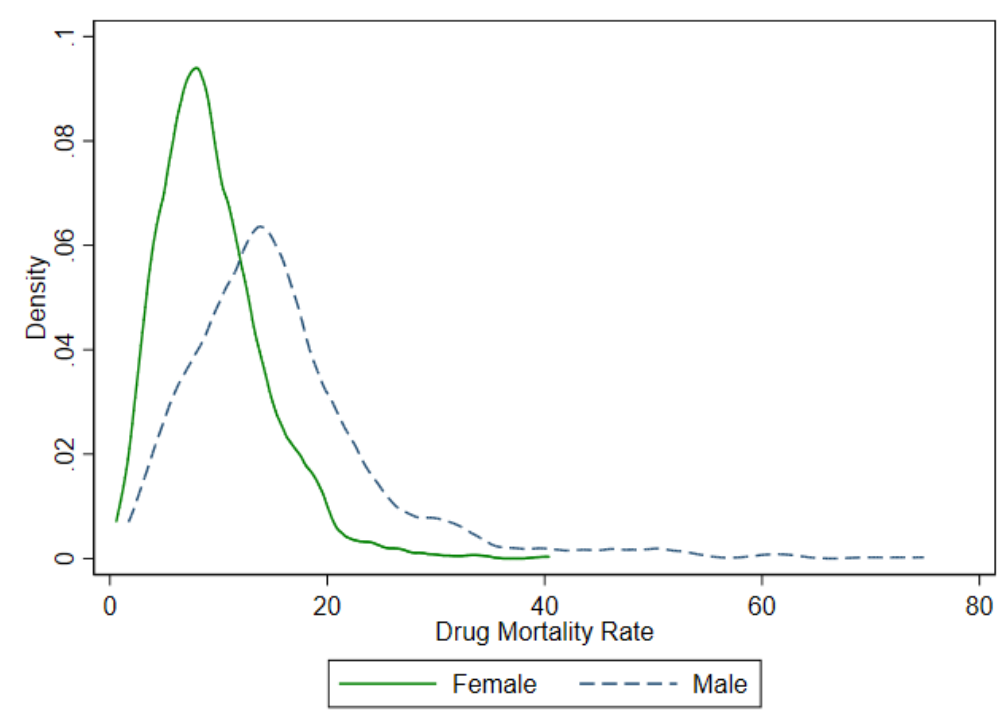

A2. Logged Drug Mortality Rate

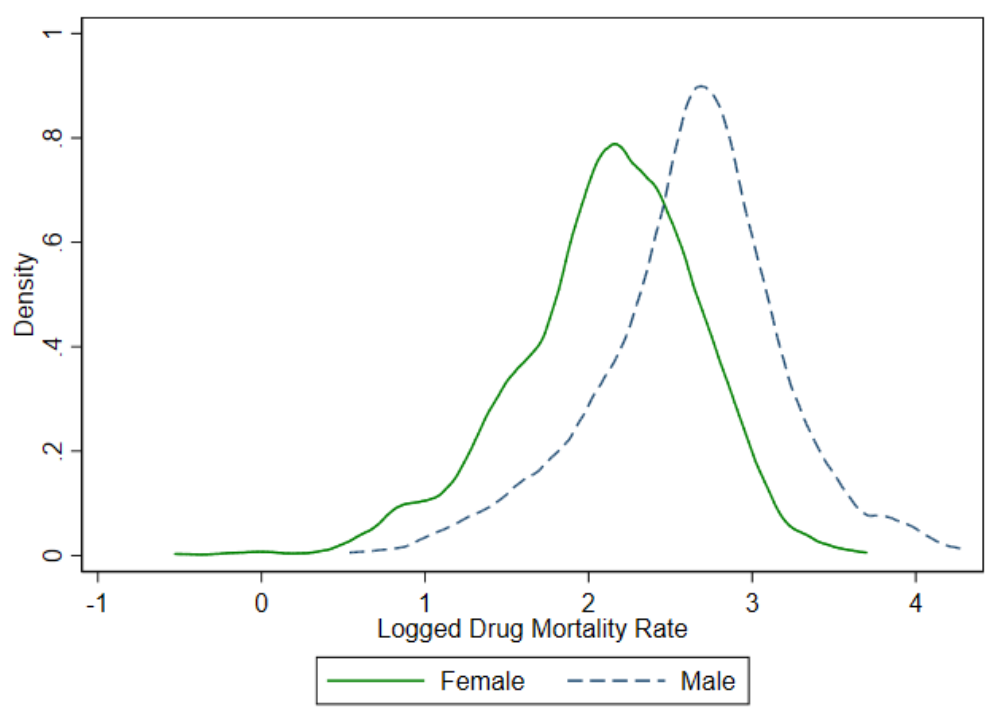


B1. Opioid Mortality Rate

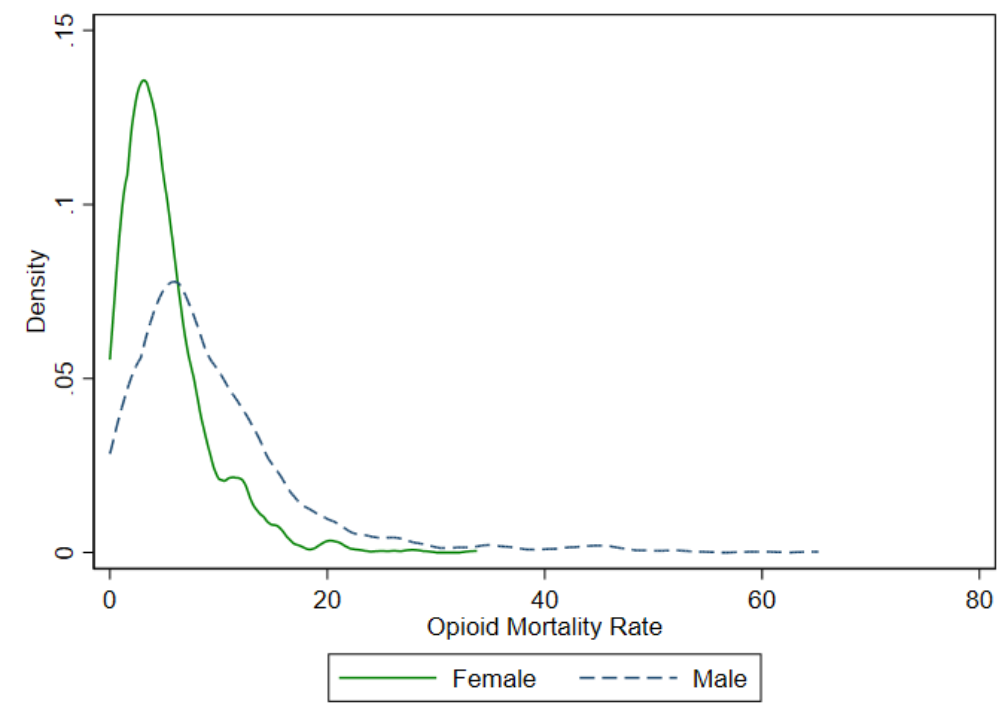

\section{B2. Logged Opioid Mortality Rate}

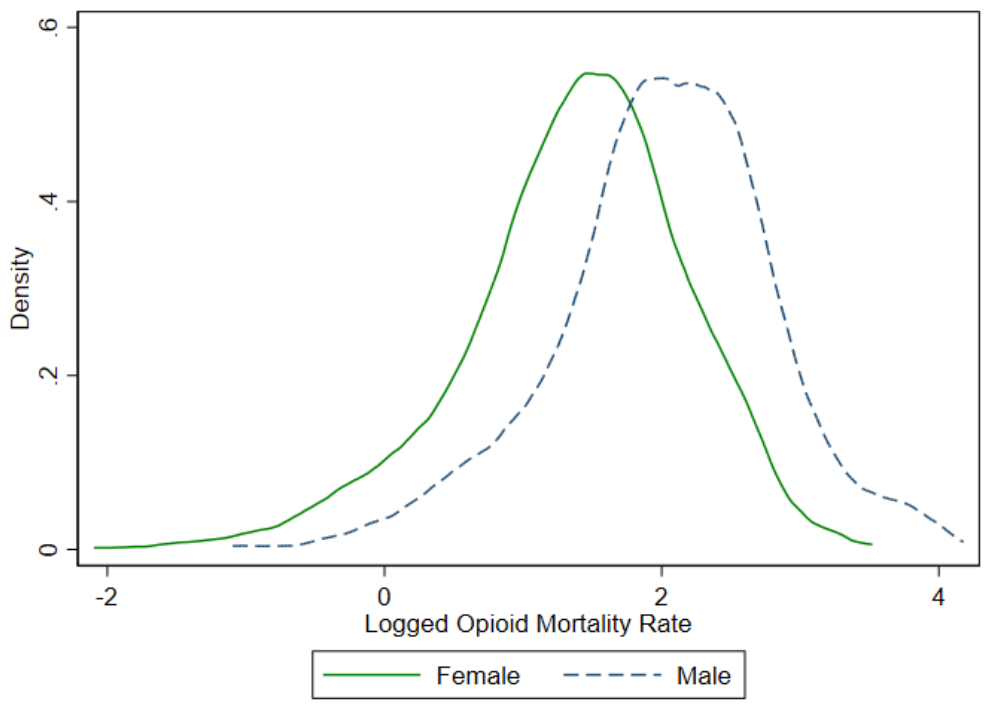




\section{C1. Corrected Opioid Mortality Rate}

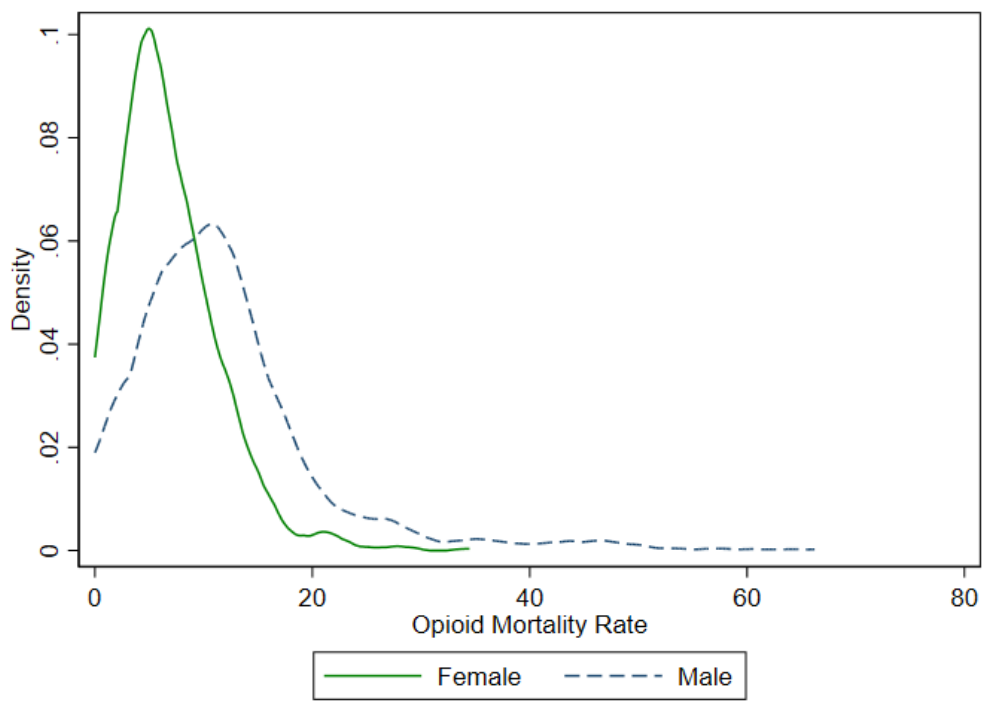

\section{C2. Logged Corrected Opioid Mortality Rate}

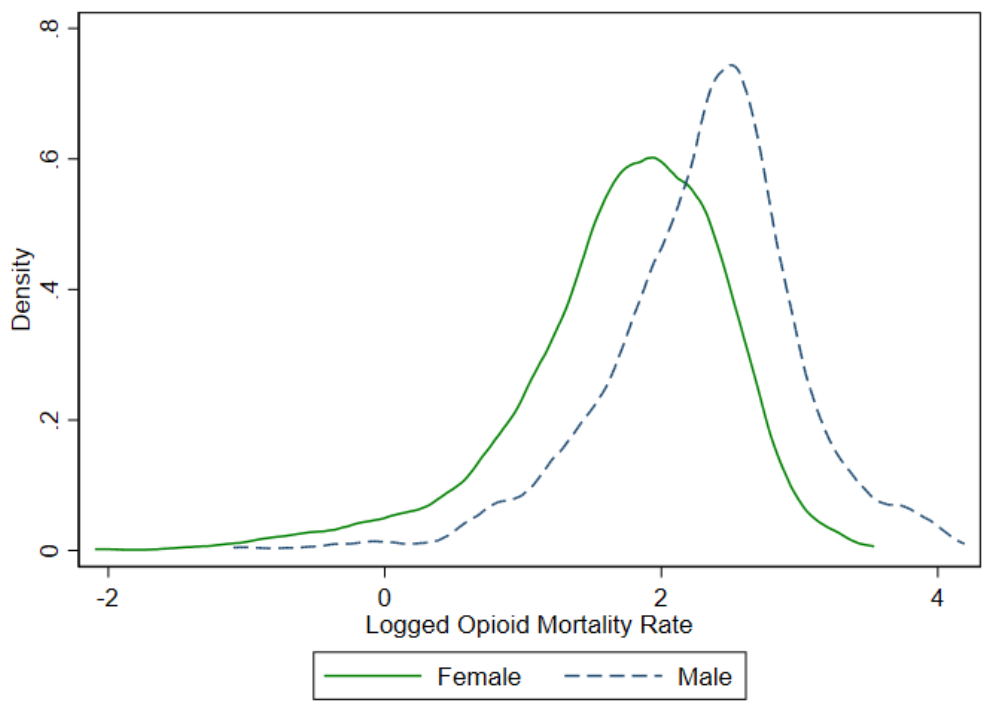


Table S1. ICD10 Codes for Drug Overdose Deaths

\begin{tabular}{|c|c|}
\hline ICD10 Code & Description \\
\hline \multicolumn{2}{|c|}{ Underlying Causes } \\
\hline $\mathrm{X} 40$ & $\begin{array}{l}\text { Accidental poisoning by and exposure to nonopioid analgesics, } \\
\text { antipyretics and antirheumatics }\end{array}$ \\
\hline $\mathrm{X} 41$ & $\begin{array}{l}\text { Accidental poisoning by and exposure to antiepileptic, sedative- } \\
\text { hypnotic, antiparkinsonism and psychotropic drugs, not elsewhere } \\
\text { classified }\end{array}$ \\
\hline $\mathrm{X} 42$ & $\begin{array}{l}\text { Accidental poisoning by and exposure to narcotics and psychodysleptics } \\
\text { [hallucinogens], not elsewhere classified }\end{array}$ \\
\hline $\mathrm{X} 43$ & $\begin{array}{l}\text { Accidental poisoning by and exposure to other drugs acting on the } \\
\text { autonomic nervous system }\end{array}$ \\
\hline $\mathrm{X} 44$ & $\begin{array}{l}\text { Accidental poisoning by and exposure to other and unspecified drugs, } \\
\text { medicaments and biological substances }\end{array}$ \\
\hline X60 & $\begin{array}{l}\text { Intentional self-poisoning by and exposure to nonopioid analgesics, } \\
\text { antipyretics and antirheumatics }\end{array}$ \\
\hline X61 & $\begin{array}{l}\text { Intentional self-poisoning by and exposure to antiepileptic, sedative- } \\
\text { hypnotic, antiparkinsonism and psychotropic drugs, not elsewhere } \\
\text { classified }\end{array}$ \\
\hline $\mathrm{X} 62$ & $\begin{array}{l}\text { Intentional self-poisoning by and exposure to narcotics and } \\
\text { psychodysleptics [hallucinogens], not elsewhere classified }\end{array}$ \\
\hline X63 & $\begin{array}{l}\text { Intentional self-poisoning by and exposure to other drugs acting on the } \\
\text { autonomic nervous system }\end{array}$ \\
\hline X64 & $\begin{array}{l}\text { Intentional self-poisoning by and exposure to other and unspecified } \\
\text { drugs, medicaments and biological substances }\end{array}$ \\
\hline $\mathrm{X} 85$ & Assault by drugs, medicaments and biological substances \\
\hline Y10 & $\begin{array}{l}\text { Poisoning by and exposure to nonopioid analgesics, antipyretics and } \\
\text { antirheumatics, undetermined intent }\end{array}$ \\
\hline Y11 & $\begin{array}{l}\text { Poisoning by and exposure to antiepileptic, sedative-hypnotic, } \\
\text { antiparkinsonism and psychotropic drugs, not elsewhere classified, } \\
\text { undetermined intent }\end{array}$ \\
\hline Y12 & $\begin{array}{l}\text { Poisoning by and exposure to narcotics and psychodysleptics } \\
\text { [hallucinogens], not elsewhere classified, undetermined intent }\end{array}$ \\
\hline Y13 & $\begin{array}{l}\text { Poisoning by and exposure to other drugs acting on the autonomic } \\
\text { nervous system, undetermined intent }\end{array}$ \\
\hline Y14 & $\begin{array}{l}\text { Poisoning by and exposure to other and unspecified drugs, medicaments } \\
\text { and biological substances, undetermined intent }\end{array}$ \\
\hline \multicolumn{2}{|c|}{ Contributing Causes } \\
\hline T40.0 & Opium \\
\hline T40.1 & Heroin \\
\hline T40.2 & Other Opioids \\
\hline $\mathrm{T} 40.3$ & Methadone \\
\hline T40.4 & Other Synthetic Narcotics \\
\hline T40.6 & Other Unspecified Narcotics \\
\hline
\end{tabular}


Table S2A. Full Models: Regression Analyses Predicting Logged Drug Overdose Mortality Rates

\begin{tabular}{|c|c|c|c|c|c|c|c|c|}
\hline \multirow{3}{*}{$\begin{array}{l}\text { Outcome: Logged Drug } \\
\text { Overdose Mortality Rates }\end{array}$} & \multicolumn{4}{|c|}{ Men } & \multicolumn{4}{|c|}{ Women } \\
\hline & \multicolumn{2}{|c|}{$\begin{array}{l}\text { Manufacturing } \\
\text { Employment }\end{array}$} & \multicolumn{2}{|c|}{$\begin{array}{c}\text { Manufacturing Annual } \\
\text { Payroll }\end{array}$} & \multicolumn{2}{|c|}{$\begin{array}{l}\text { Manufacturing } \\
\text { Employment }\end{array}$} & \multicolumn{2}{|c|}{$\begin{array}{c}\text { Manufacturing Annual } \\
\text { Payroll }\end{array}$} \\
\hline & Model 1 & Model 2 & Model 1 & Model 2 & Model 1 & Model 2 & Model 1 & Model 2 \\
\hline \multirow[t]{2}{*}{1999} & 0.000 & 0.000 & 0.000 & 0.000 & 0.000 & 0.000 & 0.000 & 0.000 \\
\hline & (.) & (.) & (.) & (.) & (.) & (.) & (.) & (.) \\
\hline \multirow[t]{2}{*}{2000} & $0.105^{* *}$ & $0.106^{* *}$ & $0.107 * *$ & $0.108 * *$ & 0.116 & 0.116 & 0.115 & 0.116 \\
\hline & $(0.038)$ & $(0.039)$ & $(0.037)$ & $(0.038)$ & $(0.064)$ & $(0.064)$ & $(0.063)$ & $(0.063)$ \\
\hline \multirow[t]{2}{*}{2001} & $0.221 * * *$ & $0.212 * * *$ & $0.223^{* * *}$ & $0.215^{* * *}$ & $0.326 * * *$ & $0.317 * * *$ & $0.323 * * *$ & $0.315^{* * *}$ \\
\hline & $(0.051)$ & $(0.055)$ & $(0.050)$ & $(0.053)$ & $(0.070)$ & $(0.075)$ & $(0.070)$ & $(0.074)$ \\
\hline \multirow[t]{2}{*}{2002} & $0.401 * * *$ & $0.389 * * *$ & $0.380 * * *$ & $0.371 * * *$ & $0.513 * * *$ & $0.502 * * *$ & $0.491 * * *$ & $0.481 * * *$ \\
\hline & $(0.064)$ & $(0.068)$ & $(0.063)$ & $(0.067)$ & $(0.071)$ & $(0.078)$ & $(0.072)$ & $(0.078)$ \\
\hline \multirow[t]{2}{*}{2003} & $0.469 * * *$ & $0.453 * * *$ & $0.463 * * *$ & $0.450 * * *$ & $0.642 * * *$ & $0.627 * * *$ & $0.626 * * *$ & $0.613 * * *$ \\
\hline & $(0.079)$ & $(0.085)$ & $(0.076)$ & $(0.081)$ & $(0.095)$ & $(0.102)$ & (0.094) & $(0.101)$ \\
\hline \multirow[t]{2}{*}{2004} & $0.541 * * *$ & $0.518 * * *$ & $0.529 * * *$ & $0.511 * * *$ & $0.758 * * *$ & $0.736 * * *$ & $0.735 * * *$ & $0.717 * * *$ \\
\hline & $(0.098)$ & $(0.105)$ & $(0.096)$ & $(0.101)$ & $(0.110)$ & $(0.120)$ & $(0.109)$ & $(0.117)$ \\
\hline \multirow[t]{2}{*}{2005} & $0.604 * * *$ & $0.574 * * *$ & $0.599 * * *$ & $0.575^{* * *}$ & $0.823^{* * *}$ & $0.795^{* * *}$ & $0.804 * * *$ & $0.781 * * *$ \\
\hline & (0.099) & $(0.107)$ & $(0.095)$ & $(0.101)$ & $(0.110)$ & $(0.121)$ & $(0.108)$ & $(0.117)$ \\
\hline \multirow[t]{2}{*}{2006} & $0.767 * * *$ & $0.735^{* * *}$ & $0.753 * * *$ & $0.727 * * *$ & $0.961 * * *$ & $0.932 * * *$ & $0.935^{* * *}$ & $0.910 * * *$ \\
\hline & $(0.121)$ & $(0.129)$ & $(0.118)$ & $(0.124)$ & $(0.135)$ & $(0.146)$ & $(0.135)$ & $(0.143)$ \\
\hline \multirow[t]{2}{*}{2007} & $0.788 * * *$ & $0.750 * * *$ & $0.773 * * *$ & $0.742 * * *$ & $1.063 * * *$ & $1.029 * * *$ & $1.035^{* * * *}$ & $1.006^{* * *}$ \\
\hline & $(0.128)$ & $(0.137)$ & $(0.124)$ & $(0.130)$ & $(0.136)$ & $(0.148)$ & $(0.137)$ & $(0.146)$ \\
\hline \multirow[t]{2}{*}{2008} & $0.824 * * *$ & $0.785 * * *$ & $0.807 * * *$ & $0.775^{* * *}$ & $1.126^{* * *}$ & $1.090 * * *$ & $1.095 * * *$ & $1.064 * * *$ \\
\hline & $(0.143)$ & $(0.153)$ & $(0.141)$ & $(0.148)$ & $(0.140)$ & $(0.152)$ & $(0.140)$ & $(0.149)$ \\
\hline \multirow[t]{2}{*}{2009} & $0.797 * * *$ & $0.762 * * *$ & $0.776 * * *$ & $0.748 * * *$ & $1.097 * * *$ & $1.065 * * *$ & $1.062 * * *$ & $1.035 * * *$ \\
\hline & $(0.141)$ & $(0.148)$ & $(0.139)$ & $(0.143)$ & $(0.135)$ & $(0.145)$ & $(0.136)$ & $(0.143)$ \\
\hline \multirow[t]{2}{*}{2010} & $0.809 * * *$ & $0.770 * * *$ & $0.784 * * *$ & $0.753 * * *$ & $1.217 * * *$ & $1.181^{* * *}$ & $1.176 * * *$ & $1.145^{* * *}$ \\
\hline & $(0.164)$ & $(0.173)$ & $(0.161)$ & $(0.166)$ & $(0.166)$ & $(0.179)$ & $(0.167)$ & $(0.176)$ \\
\hline \multirow[t]{2}{*}{2011} & $0.908 * * *$ & $0.858 * * *$ & $0.896 * * *$ & $0.856^{* * *}$ & $1.310 * * *$ & $1.264 * * *$ & $1.278 * * *$ & $1.239 * * *$ \\
\hline & $(0.174)$ & $(0.184)$ & $(0.170)$ & $(0.175)$ & $(0.179)$ & $(0.196)$ & $(0.178)$ & $(0.191)$ \\
\hline \multirow[t]{2}{*}{2012} & $0.946 * * *$ & $0.891 * * *$ & $0.933 * * *$ & $0.888 * * *$ & $1.353 * * *$ & $1.302 * * *$ & $1.320 * * *$ & $1.276 * * *$ \\
\hline & $(0.182)$ & $(0.191)$ & $(0.177)$ & $(0.182)$ & $(0.186)$ & $(0.202)$ & $(0.184)$ & $(0.197)$ \\
\hline \multirow[t]{2}{*}{2013} & $1.053 * * *$ & $0.984 * * *$ & $1.038 * * *$ & $0.980 * * *$ & $1.429 * * *$ & $1.364 * * *$ & $1.395 * * *$ & $1.337 * * *$ \\
\hline & $(0.197)$ & $(0.204)$ & $(0.193)$ & $(0.198)$ & $(0.193)$ & $(0.210)$ & $(0.192)$ & $(0.207)$ \\
\hline \multirow[t]{2}{*}{2014} & $1.166^{* * *}$ & $1.084 * * *$ & $1.147 * * *$ & $1.076^{* * *}$ & $1.546^{* * * *}$ & $1.470 * * *$ & $1.509 * * *$ & $1.441 * * *$ \\
\hline & $(0.207)$ & $(0.209)$ & $(0.203)$ & $(0.204)$ & $(0.198)$ & $(0.214)$ & $(0.197)$ & $(0.211)$ \\
\hline \multirow[t]{2}{*}{2015} & $1.319 * * *$ & $1.225 * * *$ & $1.300 * * *$ & $1.218^{* * *}$ & $1.626 * * *$ & $1.539 * * *$ & $1.589 * * *$ & $1.511 * * *$ \\
\hline & $(0.216)$ & $(0.216)$ & $(0.213)$ & $(0.211)$ & $(0.212)$ & $(0.228)$ & $(0.210)$ & $(0.225)$ \\
\hline \multirow[t]{2}{*}{2016} & $1.514 * * *$ & $1.407 * * *$ & $1.488 * * *$ & $1.392 * * *$ & $1.747 * * *$ & $1.648 * * *$ & $1.704 * * *$ & $1.613 * * *$ \\
\hline & $(0.233)$ & $(0.226)$ & $(0.229)$ & $(0.222)$ & $(0.226)$ & $(0.241)$ & $(0.225)$ & $(0.240)$ \\
\hline 2017 & $1.602 * * *$ & $1.484 * * *$ & $1.577 * * *$ & $1.471 * * *$ & $1.839 * * *$ & $1.730 * * *$ & $1.796 * * *$ & $1.696 * * *$ \\
\hline
\end{tabular}




\begin{tabular}{|c|c|c|c|c|c|c|c|c|}
\hline & $(0.247)$ & $(0.238)$ & $(0.242)$ & $(0.234)$ & $(0.244)$ & $(0.260)$ & $(0.241)$ & $(0.259)$ \\
\hline \multirow{2}{*}{$\begin{array}{l}\text { Labor Force Participation } \\
\text { Rate }\end{array}$} & $0.018^{*}$ & $0.019^{*}$ & $0.016^{*}$ & $0.017 *$ & $0.016^{*}$ & $0.018^{*}$ & $0.016^{*}$ & $0.017 *$ \\
\hline & $(0.008)$ & $(0.007)$ & $(0.008)$ & $(0.007)$ & $(0.008)$ & $(0.007)$ & $(0.008)$ & $(0.007)$ \\
\hline \multirow[t]{2}{*}{$\%$ with College Degree } & -0.011 & -0.011 & -0.012 & -0.011 & -0.010 & -0.010 & -0.010 & -0.010 \\
\hline & $(0.012)$ & $(0.011)$ & $(0.011)$ & $(0.011)$ & $(0.010)$ & $(0.010)$ & $(0.010)$ & $(0.009)$ \\
\hline \multirow[t]{2}{*}{$\%$ Ever-Married } & -0.010 & -0.008 & -0.010 & -0.008 & -0.005 & -0.003 & -0.004 & -0.003 \\
\hline & $(0.010)$ & $(0.011)$ & $(0.010)$ & $(0.010)$ & $(0.011)$ & $(0.011)$ & $(0.011)$ & $(0.011)$ \\
\hline \multirow[t]{2}{*}{$\%$ Hispanic } & $-0.037 * * *$ & $-0.038 * * *$ & $-0.035^{* * *}$ & $-0.036^{* * *}$ & $-0.033^{* * *}$ & $-0.033^{* * *}$ & $-0.031 * * *$ & $-0.031 * * *$ \\
\hline & $(0.009)$ & $(0.009)$ & $(0.009)$ & $(0.009)$ & $(0.009)$ & $(0.008)$ & $(0.008)$ & $(0.008)$ \\
\hline \multirow[t]{2}{*}{$\%$ Black } & 0.013 & 0.015 & 0.012 & 0.014 & 0.009 & 0.010 & 0.008 & 0.009 \\
\hline & $(0.008)$ & $(0.009)$ & $(0.009)$ & $(0.009)$ & $(0.009)$ & $(0.009)$ & $(0.009)$ & $(0.009)$ \\
\hline \multirow[t]{2}{*}{$\%$ Population 15-64 } & -0.039 & -0.043 & -0.031 & -0.036 & -0.085 & -0.090 & -0.080 & -0.084 \\
\hline & $(0.054)$ & $(0.057)$ & $(0.055)$ & $(0.058)$ & $(0.048)$ & $(0.049)$ & $(0.048)$ & $(0.050)$ \\
\hline \multirow[t]{2}{*}{$\%$ Population $65+$} & -0.046 & -0.041 & -0.038 & -0.035 & $-0.095^{*}$ & -0.092 & -0.090 & -0.087 \\
\hline & $(0.055)$ & $(0.058)$ & $(0.055)$ & $(0.059)$ & $(0.045)$ & $(0.048)$ & $(0.045)$ & $(0.048)$ \\
\hline \multirow[t]{2}{*}{$\%$ Metropolitan } & -0.040 & -0.034 & -0.041 & -0.036 & -0.031 & -0.026 & -0.032 & -0.027 \\
\hline & $(0.022)$ & $(0.024)$ & $(0.022)$ & $(0.023)$ & $(0.020)$ & $(0.021)$ & $(0.019)$ & $(0.021)$ \\
\hline \multirow[t]{2}{*}{ Self-Reported Health } & 0.389 & 0.382 & 0.331 & 0.323 & -0.057 & -0.066 & -0.092 & -0.102 \\
\hline & $(0.239)$ & $(0.234)$ & $(0.238)$ & $(0.234)$ & $(0.261)$ & $(0.264)$ & $(0.259)$ & $(0.263)$ \\
\hline \multirow{2}{*}{\multicolumn{2}{|c|}{$\%$ Labor Union Coverage }} & -0.017 & & -0.015 & & -0.016 & & -0.014 \\
\hline & & $(0.009)$ & & $(0.009)$ & & $(0.009)$ & & $(0.009)$ \\
\hline \multirow{2}{*}{$\begin{array}{l}\text { Good Samaritan Law } \\
\text { Implementation }\end{array}$} & & 0.018 & & 0.022 & & 0.032 & & 0.037 \\
\hline & & $(0.062)$ & & $(0.063)$ & & $(0.051)$ & & $(0.051)$ \\
\hline \multirow{2}{*}{$\begin{array}{l}\text { Naloxone Access Law } \\
\text { Implementation }\end{array}$} & & 0.024 & & 0.023 & & 0.011 & & 0.007 \\
\hline & & $(0.066)$ & & $(0.067)$ & & $(0.058)$ & & (0.059) \\
\hline \multirow{2}{*}{$\begin{array}{l}\text { Prescription Drug } \\
\text { Monitoring Program } \\
\text { Implementation }\end{array}$} & & 0.009 & & 0.010 & & 0.008 & & 0.009 \\
\hline & & $(0.051)$ & & $(0.051)$ & & $(0.044)$ & & $(0.043)$ \\
\hline \multirow{2}{*}{$\begin{array}{l}\% \text { Manufacturing } \\
\text { Employment }\end{array}$} & $-0.049 * * *$ & $-0.050 * * *$ & & & $-0.033^{* *} *$ & $-0.034 * *$ & & \\
\hline & $(0.013)$ & $(0.013)$ & & & $(0.011)$ & $(0.011)$ & & \\
\hline \multirow{2}{*}{$\begin{array}{l}\% \text { Manufacturing Annual } \\
\text { Payroll }\end{array}$} & & & $-0.039 * * *$ & $-0.039 * * *$ & & & $-0.030 * *$ & $-0.031 * *$ \\
\hline & & & $(0.011)$ & $(0.011)$ & & & $(0.010)$ & (0.009) \\
\hline \multirow[t]{2}{*}{ Intercept } & 7.607 & 7.491 & 7.280 & 7.230 & $10.456^{*}$ & $10.404 *$ & $10.308^{*}$ & $10.290 *$ \\
\hline & $(5.001)$ & (5.297) & (5.078) & (5.388) & $(4.366)$ & $(4.669)$ & $(4.383)$ & (4.697) \\
\hline $\mathrm{N}$ & 969 & 969 & 969 & 969 & 969 & 969 & 969 & 969 \\
\hline R-Squared & 0.749 & 0.751 & 0.749 & 0.751 & 0.764 & 0.765 & 0.765 & 0.766 \\
\hline BIC & -80 & -61 & -80 & -59 & 7 & 28 & 3 & 24 \\
\hline
\end{tabular}

$* \mathrm{p}<.05, * * \mathrm{p}<.01, * * * \mathrm{p}<.001$ (two tailed tests) 
Table S2B. Full Models: Regression Analyses Predicting Logged Opioid Overdose Mortality Rates

\begin{tabular}{|c|c|c|c|c|c|c|c|c|}
\hline \multirow{3}{*}{$\begin{array}{l}\text { Outcome: Logged Opioid } \\
\text { Overdose Mortality Rates }\end{array}$} & \multicolumn{4}{|c|}{ Men } & \multicolumn{4}{|c|}{ Women } \\
\hline & \multicolumn{2}{|c|}{$\begin{array}{l}\text { Manufacturing } \\
\text { Employment }\end{array}$} & \multicolumn{2}{|c|}{$\begin{array}{l}\text { Manufacturing Annual } \\
\text { Payroll }\end{array}$} & \multicolumn{2}{|c|}{$\begin{array}{l}\text { Manufacturing } \\
\text { Employment }\end{array}$} & \multicolumn{2}{|c|}{$\begin{array}{c}\text { Manufacturing Annual } \\
\text { Payroll }\end{array}$} \\
\hline & Model 1 & Model 2 & Model 1 & Model 2 & Model 1 & Model 2 & Model 1 & Model 2 \\
\hline \multirow[t]{2}{*}{1999} & 0.000 & 0.000 & 0.000 & 0.000 & 0.000 & 0.000 & 0.000 & 0.000 \\
\hline & (.) & (.) & (.) & (.) & (.) & (.) & (.) & (.) \\
\hline \multirow[t]{2}{*}{2000} & 0.111 & 0.112 & 0.115 & 0.117 & 0.164 & 0.165 & 0.162 & 0.164 \\
\hline & $(0.064)$ & $(0.064)$ & $(0.063)$ & $(0.063)$ & $(0.091)$ & $(0.090)$ & $(0.091)$ & $(0.090)$ \\
\hline \multirow[t]{2}{*}{2001} & $0.301 * * *$ & $0.278 * *$ & $0.306^{* * *}$ & $0.286^{* *}$ & $0.449 * * *$ & $0.431 * * *$ & $0.444 * * *$ & $0.427 * * *$ \\
\hline & $(0.086)$ & $(0.089)$ & $(0.085)$ & $(0.087)$ & $(0.105)$ & $(0.108)$ & $(0.104)$ & $(0.108)$ \\
\hline \multirow[t]{2}{*}{2002} & $0.521 * * *$ & $0.491 * * *$ & $0.498 * * *$ & $0.472 * * *$ & $0.735 * * *$ & $0.713 * * *$ & $0.702 * * *$ & $0.681 * * *$ \\
\hline & $(0.116)$ & $(0.120)$ & $(0.120)$ & $(0.123)$ & $(0.132)$ & $(0.137)$ & $(0.139)$ & $(0.144)$ \\
\hline \multirow[t]{2}{*}{2003} & $0.533 * * *$ & $0.492 * * *$ & $0.531 * * *$ & $0.496 * * *$ & $0.783 * * *$ & $0.753 * * *$ & $0.757 * * *$ & $0.731 * * *$ \\
\hline & $(0.124)$ & $(0.129)$ & $(0.124)$ & $(0.127)$ & $(0.142)$ & $(0.148)$ & $(0.146)$ & $(0.152)$ \\
\hline \multirow[t]{2}{*}{2004} & $0.678 * * *$ & $0.623 * * *$ & $0.669 * * *$ & $0.622 * * *$ & $0.952 * * *$ & $0.913 * * *$ & $0.917 * * *$ & $0.882 * * *$ \\
\hline & $(0.171)$ & $(0.176)$ & $(0.173)$ & $(0.176)$ & $(0.168)$ & $(0.174)$ & $(0.173)$ & $(0.179)$ \\
\hline \multirow[t]{2}{*}{2005} & $0.735 * * *$ & $0.663 * *$ & $0.736 * * *$ & $0.675 * * *$ & $1.054 * * *$ & $1.003 * * *$ & $1.025^{* * *}$ & $0.981 * * *$ \\
\hline & $(0.190)$ & $(0.195)$ & $(0.190)$ & $(0.193)$ & $(0.176)$ & $(0.182)$ & $(0.179)$ & $(0.185)$ \\
\hline \multirow[t]{2}{*}{2006} & $0.889 * * *$ & $0.813 * * *$ & $0.879 * * *$ & $0.813 * * *$ & $1.162 * * *$ & $1.111 * * *$ & $1.122 * * *$ & $1.077 * * *$ \\
\hline & $(0.215)$ & $(0.220)$ & $(0.220)$ & $(0.221)$ & (0.199) & $(0.204)$ & $(0.205)$ & $(0.209)$ \\
\hline \multirow[t]{2}{*}{2007} & $0.924 * * *$ & $0.838 * * *$ & $0.914 * * *$ & $0.839 * * *$ & $1.279 * * *$ & $1.223 * * *$ & $1.235^{* * *} *$ & $1.186 * * *$ \\
\hline & $(0.233)$ & $(0.237)$ & $(0.238)$ & $(0.238)$ & $(0.214)$ & $(0.222)$ & $(0.223)$ & $(0.229)$ \\
\hline \multirow[t]{2}{*}{2008} & $1.036 * * *$ & $0.947 * * *$ & $1.023 * * *$ & $0.945^{* * *}$ & $1.379 * * *$ & $1.320 * * *$ & $1.331 * * *$ & $1.278 * * *$ \\
\hline & $(0.259)$ & $(0.262)$ & $(0.264)$ & $(0.262)$ & $(0.221)$ & $(0.226)$ & $(0.228)$ & $(0.232)$ \\
\hline \multirow[t]{2}{*}{2009} & $1.046^{* * *}$ & $0.964 * * *$ & $1.028 * * *$ & $0.958 * * *$ & $1.355^{* * *}$ & $1.302 * * *$ & $1.302 * * *$ & $1.255^{* * *}$ \\
\hline & $(0.269)$ & $(0.268)$ & $(0.275)$ & $(0.270)$ & $(0.227)$ & $(0.230)$ & $(0.232)$ & $(0.235)$ \\
\hline \multirow[t]{2}{*}{2010} & $1.037 * * *$ & $0.945 * *$ & $1.016^{* *}$ & $0.935^{* *}$ & $1.467 * * *$ & $1.404 * * *$ & $1.404 * * *$ & $1.348 * * *$ \\
\hline & $(0.292)$ & $(0.295)$ & $(0.299)$ & $(0.297)$ & $(0.251)$ & $(0.257)$ & $(0.261)$ & $(0.266)$ \\
\hline \multirow[t]{2}{*}{2011} & $1.105^{* * *}$ & $0.993 * *$ & $1.102 * *$ & $1.004 * *$ & $1.541 * * *$ & $1.464 * * *$ & $1.492 * * *$ & $1.423 * * *$ \\
\hline & $(0.315)$ & $(0.318)$ & $(0.317)$ & $(0.315)$ & $(0.266)$ & $(0.277)$ & $(0.272)$ & $(0.282)$ \\
\hline \multirow[t]{2}{*}{2012} & $1.166 * * *$ & $1.040 * *$ & $1.161 * * *$ & $1.050 * *$ & $1.596 * * *$ & $1.508 * * *$ & $1.546 * * *$ & $1.466 * * *$ \\
\hline & $(0.323)$ & $(0.327)$ & $(0.326)$ & $(0.325)$ & $(0.285)$ & $(0.295)$ & $(0.290)$ & $(0.299)$ \\
\hline \multirow[t]{2}{*}{2013} & $1.287 * * *$ & $1.129 * *$ & $1.281 * * *$ & $1.138 * *$ & $1.711 * * *$ & $1.590 * * *$ & $1.658 * * *$ & $1.547 * * *$ \\
\hline & $(0.340)$ & $(0.344)$ & $(0.345)$ & $(0.344)$ & $(0.284)$ & $(0.301)$ & $(0.292)$ & $(0.310)$ \\
\hline \multirow[t]{2}{*}{2014} & $1.471 * * *$ & $1.295^{* * *}$ & $1.459 * * *$ & $1.299 * * *$ & $1.880 * * *$ & $1.740^{* * *}$ & $1.822 * * *$ & $1.693 * * *$ \\
\hline & $(0.358)$ & $(0.356)$ & $(0.363)$ & $(0.358)$ & $(0.291)$ & $(0.307)$ & $(0.299)$ & $(0.317)$ \\
\hline \multirow[t]{2}{*}{2015} & $1.634 * * *$ & $1.439 * * *$ & $1.623 * * *$ & $1.444 * * *$ & $1.969 * * *$ & $1.810^{* * *}$ & $1.912 * * *$ & $1.763 * * *$ \\
\hline & $(0.370)$ & $(0.368)$ & $(0.376)$ & $(0.372)$ & $(0.310)$ & $(0.333)$ & $(0.318)$ & $(0.343)$ \\
\hline \multirow[t]{2}{*}{2016} & $1.862 * * *$ & $1.648 * * *$ & $1.840 * * *$ & $1.642 * * *$ & $2.119 * * *$ & $1.935 * * *$ & $2.052 * * *$ & $1.879 * * *$ \\
\hline & $(0.389)$ & $(0.385)$ & $(0.396)$ & $(0.391)$ & $(0.330)$ & $(0.360)$ & $(0.338)$ & $(0.373)$ \\
\hline 2017 & $1.944 * * *$ & $1.713 * * *$ & $1.924 * * *$ & $1.709 * * *$ & $2.222 * * *$ & $2.022 * * *$ & $2.155^{* * * *}$ & $1.968 * * *$ \\
\hline
\end{tabular}




\begin{tabular}{|c|c|c|c|c|c|c|c|c|}
\hline & $(0.414)$ & $(0.408)$ & $(0.421)$ & $(0.415)$ & $(0.352)$ & $(0.383)$ & $(0.359)$ & $(0.396)$ \\
\hline \multirow{2}{*}{$\begin{array}{l}\text { Labor Force Participation } \\
\text { Rate }\end{array}$} & 0.019 & $0.022 *$ & 0.017 & 0.020 & 0.018 & $0.021 *$ & 0.017 & $0.020 *$ \\
\hline & $(0.011)$ & $(0.011)$ & $(0.012)$ & $(0.011)$ & $(0.010)$ & $(0.009)$ & $(0.010)$ & $(0.010)$ \\
\hline \multirow[t]{2}{*}{$\%$ with College Degree } & -0.027 & $-0.027 *$ & -0.028 & $-0.028 *$ & -0.026 & $-0.026^{*}$ & -0.026 & $-0.027 *$ \\
\hline & $(0.014)$ & $(0.013)$ & $(0.014)$ & $(0.013)$ & $(0.013)$ & $(0.013)$ & $(0.013)$ & $(0.013)$ \\
\hline \multirow[t]{2}{*}{$\%$ Ever-Married } & -0.016 & -0.012 & -0.016 & -0.012 & -0.020 & -0.017 & -0.020 & -0.017 \\
\hline & $(0.014)$ & $(0.014)$ & $(0.014)$ & $(0.014)$ & $(0.014)$ & $(0.014)$ & $(0.014)$ & $(0.014)$ \\
\hline \multirow[t]{2}{*}{$\%$ Hispanic } & $-0.067 * * *$ & $-0.067 * * *$ & $-0.065^{* * *}$ & $-0.065^{* * *}$ & $-0.056^{* * *}$ & $-0.056^{* * *}$ & $-0.053^{* * *}$ & $-0.053 * * *$ \\
\hline & $(0.014)$ & $(0.014)$ & $(0.014)$ & $(0.014)$ & $(0.015)$ & $(0.014)$ & $(0.014)$ & $(0.014)$ \\
\hline \multirow[t]{2}{*}{$\%$ Black } & 0.000 & 0.003 & -0.001 & 0.002 & -0.001 & 0.001 & -0.003 & -0.001 \\
\hline & $(0.012)$ & $(0.012)$ & $(0.012)$ & $(0.013)$ & $(0.014)$ & $(0.014)$ & $(0.014)$ & $(0.014)$ \\
\hline \multirow[t]{2}{*}{$\%$ Population 15-64 } & -0.005 & -0.013 & 0.006 & -0.002 & 0.011 & -0.003 & 0.019 & 0.005 \\
\hline & $(0.093)$ & $(0.093)$ & $(0.095)$ & $(0.094)$ & $(0.080)$ & $(0.080)$ & $(0.082)$ & $(0.081)$ \\
\hline \multirow[t]{2}{*}{$\%$ Population $65+$} & -0.011 & -0.002 & 0.000 & 0.008 & -0.015 & -0.011 & -0.007 & -0.004 \\
\hline & $(0.090)$ & $(0.091)$ & $(0.089)$ & $(0.090)$ & $(0.063)$ & $(0.067)$ & $(0.063)$ & $(0.066)$ \\
\hline \multirow[t]{2}{*}{$\%$ Metropolitan } & 0.006 & 0.019 & 0.005 & 0.017 & 0.039 & 0.053 & 0.037 & 0.050 \\
\hline & $(0.052)$ & $(0.055)$ & $(0.052)$ & $(0.055)$ & $(0.043)$ & $(0.048)$ & $(0.043)$ & $(0.047)$ \\
\hline \multirow[t]{2}{*}{ Self-Reported Health } & 0.481 & 0.451 & 0.401 & 0.368 & -0.136 & -0.151 & -0.189 & -0.210 \\
\hline & $(0.334)$ & $(0.322)$ & $(0.346)$ & $(0.338)$ & $(0.375)$ & $(0.379)$ & $(0.364)$ & $(0.372)$ \\
\hline \multirow{2}{*}{\multicolumn{2}{|c|}{$\%$ Labor Union Coverage }} & $-0.036^{*}$ & & $-0.033^{*}$ & & -0.029 & & -0.027 \\
\hline & & $(0.014)$ & & $(0.014)$ & & $(0.016)$ & & $(0.015)$ \\
\hline \multirow{2}{*}{$\begin{array}{l}\text { Good Samaritan Law } \\
\text { Implementation }\end{array}$} & & 0.099 & & 0.103 & & 0.142 & & 0.149 \\
\hline & & $(0.115)$ & & $(0.114)$ & & $(0.109)$ & & $(0.109)$ \\
\hline \multirow{2}{*}{$\begin{array}{l}\text { Naloxone Access Law } \\
\text { Implementation }\end{array}$} & & -0.028 & & -0.028 & & -0.040 & & -0.046 \\
\hline & & $(0.096)$ & & $(0.097)$ & & $(0.083)$ & & $(0.083)$ \\
\hline \multirow{2}{*}{$\begin{array}{l}\text { Prescription Drug } \\
\text { Monitoring Program } \\
\text { Implementation }\end{array}$} & & 0.014 & & 0.015 & & -0.008 & & -0.007 \\
\hline & & $(0.083)$ & & $(0.083)$ & & $(0.079)$ & & $(0.077)$ \\
\hline \multirow{2}{*}{$\begin{array}{l}\% \text { Manufacturing } \\
\text { Employment }\end{array}$} & $-0.067 *$ & $-0.071^{*}$ & & & $-0.051 *$ & $-0.055^{*}$ & & \\
\hline & $(0.030)$ & $(0.028)$ & & & $(0.025)$ & $(0.023)$ & & \\
\hline \multirow{2}{*}{$\begin{array}{l}\% \text { Manufacturing Annual } \\
\text { Payroll }\end{array}$} & & & $-0.051^{*}$ & $-0.053^{*}$ & & & $-0.046^{*}$ & $-0.049 * *$ \\
\hline & & & $(0.023)$ & $(0.021)$ & & & $(0.020)$ & $(0.018)$ \\
\hline \multirow[t]{2}{*}{ Intercept } & 1.578 & 1.248 & 1.039 & 0.775 & -1.476 & -1.459 & -1.686 & -1.629 \\
\hline & (9.724) & (9.788) & (9.728) & (9.819) & $(7.571)$ & (7.619) & $(7.645)$ & (7.691) \\
\hline $\mathrm{N}$ & 968 & 968 & 968 & 968 & 967 & 967 & 967 & 967 \\
\hline R-Squared & 0.685 & 0.690 & 0.684 & 0.689 & 0.729 & 0.733 & 0.730 & 0.734 \\
\hline BIC & 752 & 762 & 754 & 765 & 876 & 888 & 872 & 885 \\
\hline
\end{tabular}

$* \mathrm{p}<.05, * * \mathrm{p}<.01, * * * \mathrm{p}<.001$ (two tailed tests) 
Table S2C. Full Models: Regression Analyses Predicting Corrected Logged Opioid Overdose Mortality Rates

\begin{tabular}{|c|c|c|c|c|c|c|c|c|}
\hline \multirow{3}{*}{$\begin{array}{l}\text { Outcome: Corrected } \\
\text { Logged Opioid Overdose } \\
\text { Mortality Rates }\end{array}$} & \multicolumn{4}{|c|}{ Men } & \multicolumn{4}{|c|}{ Women } \\
\hline & \multicolumn{2}{|c|}{$\begin{array}{l}\text { Manufacturing } \\
\text { Employment }\end{array}$} & \multicolumn{2}{|c|}{$\begin{array}{l}\text { Manufacturing Annual } \\
\text { Payroll } \\
\end{array}$} & \multicolumn{2}{|c|}{$\begin{array}{c}\text { Manufacturing } \\
\text { Employment }\end{array}$} & \multicolumn{2}{|c|}{$\begin{array}{c}\text { Manufacturing Annual } \\
\text { Payroll }\end{array}$} \\
\hline & Model 1 & Model 2 & Model 1 & Model 2 & Model 1 & Model 2 & Model 1 & Model 2 \\
\hline \multirow[t]{2}{*}{1999} & 0.000 & 0.000 & 0.000 & 0.000 & 0.000 & 0.000 & 0.000 & 0.000 \\
\hline & (.) & (.) & (.) & (.) & (.) & (.) & (.) & (.) \\
\hline \multirow[t]{2}{*}{2000} & 0.069 & 0.070 & 0.075 & 0.076 & $0.239^{*}$ & $0.239^{*}$ & $0.240^{*}$ & $0.241^{*}$ \\
\hline & $(0.074)$ & $(0.074)$ & $(0.073)$ & $(0.073)$ & $(0.100)$ & $(0.099)$ & $(0.099)$ & $(0.098)$ \\
\hline \multirow[t]{2}{*}{2001} & $0.314 * * *$ & $0.292 * * *$ & $0.321 * * *$ & $0.303 * * *$ & $0.657 * * *$ & $0.634 * * *$ & $0.657 * * *$ & $0.637 * * *$ \\
\hline & $(0.074)$ & $(0.077)$ & $(0.071)$ & $(0.073)$ & $(0.104)$ & $(0.106)$ & $(0.102)$ & $(0.104)$ \\
\hline \multirow[t]{2}{*}{2002} & $0.518 * * *$ & $0.491 * * *$ & $0.496 * * *$ & $0.473 * * *$ & $0.921 * * *$ & $0.893 * * *$ & $0.894 * * *$ & $0.869 * * *$ \\
\hline & $(0.100)$ & $(0.104)$ & $(0.102)$ & (0.104) & $(0.124)$ & $(0.128)$ & $(0.129)$ & $(0.132)$ \\
\hline \multirow[t]{2}{*}{2003} & $0.469 * * *$ & $0.432 * * *$ & $0.471 * * *$ & $0.440 * * *$ & $0.956 * * *$ & $0.917 * * *$ & $0.944 * * *$ & $0.910 * * *$ \\
\hline & $(0.108)$ & $(0.111)$ & $(0.106)$ & $(0.108)$ & $(0.146)$ & $(0.150)$ & $(0.147)$ & $(0.151)$ \\
\hline \multirow[t]{2}{*}{2004} & $0.617 * * *$ & $0.565 * * *$ & $0.612 * * *$ & $0.568 * * *$ & $1.100 * * *$ & $1.047 * * *$ & $1.081 * * *$ & $1.034 * * *$ \\
\hline & $(0.153)$ & $(0.157)$ & $(0.152)$ & $(0.153)$ & $(0.173)$ & $(0.173)$ & $(0.172)$ & $(0.172)$ \\
\hline \multirow[t]{2}{*}{2005} & $0.676^{* * *}$ & $0.609 * * *$ & $0.683 * * *$ & $0.626 * * *$ & $1.216^{* * *}$ & $1.147 * * *$ & $1.205^{* * *}$ & $1.144 * * *$ \\
\hline & $(0.159)$ & $(0.163)$ & $(0.156)$ & $(0.157)$ & $(0.181)$ & $(0.182)$ & $(0.180)$ & $(0.180)$ \\
\hline \multirow[t]{2}{*}{2006} & $0.825 * * *$ & $0.752 * * *$ & $0.820 * * *$ & $0.757 * * *$ & $1.322 * * *$ & $1.248 * * *$ & $1.300 * * *$ & $1.234 * * *$ \\
\hline & $(0.181)$ & $(0.185)$ & $(0.181)$ & $(0.181)$ & $(0.198)$ & $(0.198)$ & $(0.201)$ & $(0.200)$ \\
\hline \multirow[t]{2}{*}{2007} & $0.870 * * *$ & $0.786 * * *$ & $0.864 * * *$ & $0.792 * * *$ & $1.462 * * *$ & $1.376^{* * *}$ & $1.438 * * *$ & $1.361 * * *$ \\
\hline & $(0.198)$ & $(0.200)$ & $(0.198)$ & $(0.196)$ & $(0.209)$ & $(0.209)$ & $(0.213)$ & $(0.211)$ \\
\hline \multirow[t]{2}{*}{2008} & $0.957 * * *$ & $0.869 * * *$ & $0.949 * * *$ & $0.873 * * *$ & $1.545 * * *$ & $1.455^{* * *}$ & $1.518 * * *$ & $1.437 * * *$ \\
\hline & $(0.223)$ & $(0.225)$ & $(0.224)$ & $(0.222)$ & $(0.222)$ & $(0.220)$ & $(0.226)$ & $(0.223)$ \\
\hline \multirow[t]{2}{*}{2009} & $0.941 * * *$ & $0.861 * * *$ & $0.928 * * *$ & $0.859 * * *$ & $1.532 * * *$ & $1.447 * * *$ & $1.501 * * *$ & $1.425 * * *$ \\
\hline & $(0.227)$ & $(0.225)$ & $(0.229)$ & $(0.223)$ & $(0.231)$ & $(0.229)$ & $(0.234)$ & $(0.230)$ \\
\hline \multirow[t]{2}{*}{2010} & $0.922 * * *$ & $0.830 * *$ & $0.905^{* * *}$ & $0.827 * *$ & $1.613 * * *$ & $1.518 * * *$ & $1.575^{* * * *}$ & $1.490 * * *$ \\
\hline & $(0.250)$ & $(0.252)$ & $(0.251)$ & $(0.248)$ & $(0.251)$ & $(0.250)$ & $(0.257)$ & $(0.253)$ \\
\hline \multirow[t]{2}{*}{2011} & $1.004 * * *$ & $0.893 * *$ & $1.009 * * *$ & $0.913 * * *$ & $1.685^{* * *}$ & $1.571 * * *$ & $1.664 * * *$ & $1.561 * * *$ \\
\hline & $(0.267)$ & $(0.269)$ & $(0.264)$ & $(0.261)$ & $(0.268)$ & $(0.270)$ & $(0.269)$ & $(0.269)$ \\
\hline \multirow[t]{2}{*}{2012} & $1.049 * * *$ & $0.925 * *$ & $1.052 * * *$ & $0.942 * *$ & $1.731 * * *$ & $1.601 * * *$ & $1.708 * * *$ & $1.590 * * *$ \\
\hline & $(0.277)$ & $(0.279)$ & $(0.276)$ & $(0.272)$ & $(0.282)$ & $(0.283)$ & $(0.284)$ & $(0.283)$ \\
\hline \multirow[t]{2}{*}{2013} & $1.146^{* * *}$ & $0.991 * *$ & $1.146^{* * *}$ & $1.008 * *$ & $1.807 * * *$ & $1.645^{* * *}$ & $1.782 * * *$ & $1.633 * * *$ \\
\hline & $(0.294)$ & $(0.295)$ & $(0.293)$ & $(0.289)$ & $(0.290)$ & $(0.294)$ & $(0.292)$ & $(0.294)$ \\
\hline \multirow[t]{2}{*}{2014} & $1.274 * * *$ & $1.100 * * *$ & $1.268 * * *$ & $1.111 * * *$ & $1.914 * * *$ & $1.734 * * *$ & $1.884 * * *$ & $1.717 * * *$ \\
\hline & $(0.308)$ & $(0.305)$ & $(0.307)$ & $(0.300)$ & $(0.298)$ & $(0.299)$ & $(0.299)$ & $(0.300)$ \\
\hline \multirow[t]{2}{*}{2015} & $1.406^{* * *}$ & $1.213 * * *$ & $1.401 * * *$ & $1.226 * * *$ & $1.951 * * *$ & $1.752 * * *$ & $1.921 * * *$ & $1.736 * * *$ \\
\hline & $(0.322)$ & $(0.317)$ & $(0.321)$ & $(0.313)$ & $(0.317)$ & $(0.319)$ & $(0.317)$ & $(0.322)$ \\
\hline \multirow[t]{2}{*}{2016} & $1.608 * * *$ & $1.394 * * *$ & $1.592 * * *$ & $1.395 * * *$ & $2.068 * * *$ & $1.849 * * *$ & $2.029 * * *$ & $1.823 * * *$ \\
\hline & $(0.340)$ & $(0.331)$ & $(0.339)$ & $(0.330)$ & $(0.333)$ & $(0.339)$ & $(0.335)$ & $(0.343)$ \\
\hline
\end{tabular}




\begin{tabular}{|c|c|c|c|c|c|c|c|c|}
\hline 2017 & $\begin{array}{l}1.654 * * * \\
(0.359)\end{array}$ & $\begin{array}{l}1.423 * * * \\
(0.349)\end{array}$ & $\begin{array}{l}1.640 * * * \\
(0.358)\end{array}$ & $\begin{array}{l}1.427 * * * \\
(0.348)\end{array}$ & $\begin{array}{l}2.117 * * * \\
(0.353)\end{array}$ & $\begin{array}{l}1.881 * * * \\
(0.359)\end{array}$ & $\begin{array}{l}2.079 * * * \\
(0.353)\end{array}$ & $\begin{array}{l}1.858 * * * \\
(0.363)\end{array}$ \\
\hline Labor Force Participation & $0.021^{*}$ & $0.024 *$ & 0.019 & $0.022 *$ & 0.014 & 0.018 & 0.013 & 0.016 \\
\hline Rate & $(0.011)$ & $(0.010)$ & $(0.011)$ & $(0.010)$ & $(0.011)$ & $(0.010)$ & $(0.011)$ & $(0.010)$ \\
\hline$\%$ with College Degree & $\begin{array}{l}-0.009 \\
(0.013)\end{array}$ & $\begin{array}{l}-0.009 \\
(0.012)\end{array}$ & $\begin{array}{l}-0.010 \\
(0.013)\end{array}$ & $\begin{array}{l}-0.010 \\
(0.012)\end{array}$ & $\begin{array}{l}-0.006 \\
(0.014)\end{array}$ & $\begin{array}{l}-0.006 \\
(0.013)\end{array}$ & $\begin{array}{l}-0.006 \\
(0.013)\end{array}$ & $\begin{array}{l}-0.006 \\
(0.012)\end{array}$ \\
\hline$\%$ Ever-Married & $\begin{array}{l}-0.013 \\
(0.013)\end{array}$ & $\begin{array}{l}-0.010 \\
(0.013)\end{array}$ & $\begin{array}{l}-0.013 \\
(0.013)\end{array}$ & $\begin{array}{l}-0.010 \\
(0.013)\end{array}$ & $\begin{array}{l}-0.021 \\
(0.014)\end{array}$ & $\begin{array}{l}-0.017 \\
(0.014)\end{array}$ & $\begin{array}{l}-0.021 \\
(0.014)\end{array}$ & $\begin{array}{l}-0.017 \\
(0.014)\end{array}$ \\
\hline$\%$ Hispanic & $\begin{array}{l}-0.048 * * * \\
(0.012)\end{array}$ & $\begin{array}{l}-0.048 * * * \\
(0.012)\end{array}$ & $\begin{array}{l}-0.046 * * * \\
(0.012)\end{array}$ & $\begin{array}{l}-0.046^{* * *} \\
(0.012)\end{array}$ & $\begin{array}{l}-0.044 * * \\
(0.013)\end{array}$ & $\begin{array}{l}-0.044 * * \\
(0.013)\end{array}$ & $\begin{array}{l}-0.042 * * \\
(0.013)\end{array}$ & $\begin{array}{l}-0.041 * * \\
(0.013)\end{array}$ \\
\hline$\%$ Black & $\begin{array}{l}0.006 \\
(0.010)\end{array}$ & $\begin{array}{l}0.010 \\
(0.011)\end{array}$ & $\begin{array}{l}0.005 \\
(0.010)\end{array}$ & $\begin{array}{l}0.009 \\
(0.011)\end{array}$ & $\begin{array}{l}0.003 \\
(0.016)\end{array}$ & $\begin{array}{l}0.006 \\
(0.016)\end{array}$ & $\begin{array}{l}0.002 \\
(0.016)\end{array}$ & $\begin{array}{l}0.005 \\
(0.016)\end{array}$ \\
\hline$\%$ Population 15-64 & $\begin{array}{l}-0.039 \\
(0.080)\end{array}$ & $\begin{array}{l}-0.047 \\
(0.082)\end{array}$ & $\begin{array}{l}-0.027 \\
(0.082)\end{array}$ & $\begin{array}{l}-0.035 \\
(0.084)\end{array}$ & $\begin{array}{l}-0.058 \\
(0.074)\end{array}$ & $\begin{array}{l}-0.070 \\
(0.074)\end{array}$ & $\begin{array}{l}-0.049 \\
(0.075)\end{array}$ & $\begin{array}{l}-0.060 \\
(0.075)\end{array}$ \\
\hline$\%$ Population $65+$ & $\begin{array}{l}-0.060 \\
(0.077)\end{array}$ & $\begin{array}{l}-0.054 \\
(0.080)\end{array}$ & $\begin{array}{l}-0.048 \\
(0.078)\end{array}$ & $\begin{array}{l}-0.043 \\
(0.081)\end{array}$ & $\begin{array}{l}-0.089 \\
(0.065)\end{array}$ & $\begin{array}{l}-0.085 \\
(0.068)\end{array}$ & $\begin{array}{l}-0.080 \\
(0.065)\end{array}$ & $\begin{array}{l}-0.077 \\
(0.069)\end{array}$ \\
\hline$\%$ Metropolitan & $\begin{array}{l}0.005 \\
(0.038)\end{array}$ & $\begin{array}{l}0.015 \\
(0.041)\end{array}$ & $\begin{array}{l}0.004 \\
(0.038)\end{array}$ & $\begin{array}{l}0.014 \\
(0.041)\end{array}$ & $\begin{array}{l}0.048 \\
(0.034)\end{array}$ & $\begin{array}{l}0.058 \\
(0.037)\end{array}$ & $\begin{array}{l}0.046 \\
(0.035)\end{array}$ & $\begin{array}{l}0.056 \\
(0.038)\end{array}$ \\
\hline Self-Reported Health & $\begin{array}{l}0.543 \\
(0.322)\end{array}$ & $\begin{array}{l}0.510 \\
(0.305)\end{array}$ & $\begin{array}{l}0.453 \\
(0.343)\end{array}$ & $\begin{array}{l}0.418 \\
(0.331)\end{array}$ & $\begin{array}{l}0.036 \\
(0.319)\end{array}$ & $\begin{array}{l}-0.005 \\
(0.312)\end{array}$ & $\begin{array}{l}-0.029 \\
(0.326)\end{array}$ & $\begin{array}{l}-0.076 \\
(0.323)\end{array}$ \\
\hline \% Labor Union Coverage & & $\begin{array}{l}-0.035^{* *} \\
(0.012)\end{array}$ & & $\begin{array}{l}-0.032 * * \\
(0.012)\end{array}$ & & $\begin{array}{l}-0.035^{*} \\
(0.015)\end{array}$ & & $\begin{array}{l}-0.033^{*} \\
(0.014)\end{array}$ \\
\hline $\begin{array}{l}\text { Good Samaritan Law } \\
\text { Implementation }\end{array}$ & & $\begin{array}{l}0.081 \\
(0.083)\end{array}$ & & $\begin{array}{l}0.085 \\
(0.083)\end{array}$ & & $\begin{array}{l}0.115 \\
(0.078)\end{array}$ & & $\begin{array}{l}0.120 \\
(0.078)\end{array}$ \\
\hline $\begin{array}{l}\text { Naloxone Access Law } \\
\text { Implementation }\end{array}$ & & $\begin{array}{l}-0.005 \\
(0.087)\end{array}$ & & $\begin{array}{l}-0.004 \\
(0.088)\end{array}$ & & $\begin{array}{l}-0.030 \\
(0.079)\end{array}$ & & $\begin{array}{l}-0.032 \\
(0.081)\end{array}$ \\
\hline $\begin{array}{l}\text { Prescription Drug } \\
\text { Monitoring Program } \\
\text { Implementation }\end{array}$ & & $(0.074)$ & & $(0.073)$ & & $(0.068)$ & & $(0.067)$ \\
\hline $\begin{array}{l}\text { \% Manufacturing } \\
\text { Employment }\end{array}$ & $\begin{array}{l}-0.074 * * * \\
(0.019)\end{array}$ & $\begin{array}{l}-0.077 * * * \\
(0.019)\end{array}$ & & & $\begin{array}{l}-0.057 * \\
(0.021)\end{array}$ & $\begin{array}{l}-0.061 * * \\
(0.021)\end{array}$ & & \\
\hline $\begin{array}{l}\% \text { Manufacturing Annual } \\
\text { Payroll }\end{array}$ & & & $\begin{array}{l}-0.056^{* * *} \\
(0.016)\end{array}$ & $\begin{array}{l}-0.057 * * * \\
(0.015)\end{array}$ & & & $\begin{array}{l}-0.047^{* *} \\
(0.017)\end{array}$ & $\begin{array}{l}-0.049 * * \\
(0.016)\end{array}$ \\
\hline Intercept & $\begin{array}{l}4.055 \\
(7.870)\end{array}$ & $\begin{array}{l}3.906 \\
(8.248)\end{array}$ & $\begin{array}{l}3.431 \\
(7.980)\end{array}$ & $\begin{array}{l}3.368 \\
(8.361)\end{array}$ & $\begin{array}{l}3.131 \\
(6.892)\end{array}$ & $\begin{array}{l}3.211 \\
(7.158)\end{array}$ & $\begin{array}{l}2.777 \\
(6.998)\end{array}$ & $\begin{array}{l}2.908 \\
(7.262)\end{array}$ \\
\hline $\mathrm{N}$ & 968 & 968 & 968 & 968 & 968 & 968 & 968 & 968 \\
\hline R-Squared & 0.677 & 0.683 & 0.675 & 0.681 & 0.746 & 0.751 & 0.746 & 0.751 \\
\hline $\mathrm{BIC}$ & 607 & 616 & 612 & 622 & 781 & 789 & 780 & 789 \\
\hline
\end{tabular}

$* \mathrm{p}<.05, * * \mathrm{p}<.01, * * * \mathrm{p}<.001$ (two tailed tests) 
Table S3. Number of Drug Overdose Deaths Attributable to Manufacturing Decline Between 1999-2017, by State and Measure of Manufacturing

\begin{tabular}{|c|c|c|c|c|}
\hline \multirow[b]{2}{*}{ State } & \multicolumn{2}{|c|}{ Men } & \multicolumn{2}{|c|}{ Women } \\
\hline & Employment & Annual Payroll & Employment & Annual Payroll \\
\hline Alabama & 1705 & 1430 & 755 & 737 \\
\hline Alaska & 72 & 42 & 27 & 18 \\
\hline Arizona & 1625 & 1717 & 683 & 839 \\
\hline Arkansas & 1188 & 1169 & 507 & 580 \\
\hline California & 13056 & 13437 & 5471 & 6556 \\
\hline Colorado & 1182 & 1271 & 478 & 598 \\
\hline Connecticut & 1126 & 985 & 497 & 506 \\
\hline Delaware & 225 & 212 & 100 & 110 \\
\hline District of Columbia & 16 & 11 & 7 & 5 \\
\hline Florida & 3284 & 3100 & 1437 & 1579 \\
\hline Georgia & 3517 & 3080 & 1520 & 1549 \\
\hline Hawaii & 68 & 48 & 28 & 23 \\
\hline Idaho & 389 & 379 & 160 & 181 \\
\hline Illinois & 4255 & 4016 & 1795 & 1972 \\
\hline Indiana & 2162 & 2538 & 911 & 1245 \\
\hline Iowa & 649 & 817 & 267 & 391 \\
\hline Kansas & 608 & 646 & 250 & 309 \\
\hline Kentucky & 1200 & 1368 & 507 & 673 \\
\hline Louisiana & 707 & 688 & 304 & 344 \\
\hline Maine & 506 & 529 & 230 & 279 \\
\hline Maryland & 1066 & 1059 & 471 & 545 \\
\hline Massachusetts & 2214 & 2047 & 968 & 1042 \\
\hline Michigan & 3500 & 4189 & 1494 & 2081 \\
\hline Minnesota & 1283 & 1306 & 524 & 621 \\
\hline Mississippi & 1291 & 994 & 571 & 512 \\
\hline Missouri & 1834 & 1685 & 779 & 834 \\
\hline Montana & 125 & 144 & 51 & 69 \\
\hline Nebraska & 340 & 379 & 139 & 181 \\
\hline Nevada & 156 & 117 & 63 & 55 \\
\hline New Hampshire & 532 & 434 & 230 & 218 \\
\hline New Jersey & 2465 & 2181 & 1070 & 1102 \\
\hline New Mexico & 289 & 242 & 123 & 120 \\
\hline New York & 5003 & 3930 & 2194 & 2007 \\
\hline North Carolina & 5721 & 4827 & 2488 & 2444 \\
\hline North Dakota & 52 & 97 & 20 & 42 \\
\hline Ohio & 3807 & 4282 & 1632 & 2137 \\
\hline Oklahoma & 844 & 952 & 350 & 459 \\
\hline Oregon & 1051 & 1130 & 442 & 553 \\
\hline Pennsylvania & 3754 & 3713 & 1598 & 1840 \\
\hline
\end{tabular}




\begin{tabular}{|c|c|c|c|c|}
\hline Rhode Island & 463 & 402 & 207 & 209 \\
\hline South Carolina & 2011 & 1843 & 889 & 949 \\
\hline south Dakota & 198 & 254 & 79 & 118 \\
\hline Tennessee & 2561 & 2218 & 1117 & 1126 \\
\hline Texas & 6453 & 6487 & 2663 & 3116 \\
\hline Utah & 585 & 491 & 227 & 221 \\
\hline Vermont & 207 & 211 & 92 & 109 \\
\hline Virginia & 2563 & 2367 & 1080 & 1161 \\
\hline Washington & 2314 & 2261 & 963 & 1095 \\
\hline west Virginia & 382 & 463 & 158 & 224 \\
\hline Wisconsin & 1886 & 2109 & 783 & 1019 \\
\hline Wyoming & 18 & 12 & 7 & 5 \\
\hline
\end{tabular}

Note: Estimates based off Table 2, Panel A, Model 2. 
Table S4. Sensitivity Analyses, including Negative Binomial Regression Models, Population Weights, and Removed Labor Force Participation Rates

\begin{tabular}{|c|c|c|c|c|}
\hline & $\begin{array}{l}\text { Negative } \\
\text { Binomial }\end{array}$ & $\begin{array}{c}\text { Adjusting } \\
\text { For Opioid } \\
\text { Prescriptions } \\
\text { per } 100 \\
\text { Population } \\
\end{array}$ & $\begin{array}{c}\text { Population } \\
\text { Weights }\end{array}$ & $\begin{array}{c}\text { Removed } \\
\text { Labor Force } \\
\text { Participation } \\
\text { Rate }\end{array}$ \\
\hline \multicolumn{5}{|l|}{ A. Drug Overdose Deaths } \\
\hline \multicolumn{5}{|l|}{ Manufacturing Measure } \\
\hline \multicolumn{5}{|l|}{ Female } \\
\hline \% Employees in Manufacturing & $\begin{array}{l}-0.034 * * * \\
(0.008)\end{array}$ & $\begin{array}{l}-0.032 \\
(0.025)\end{array}$ & $\begin{array}{l}-0.039 * \\
(0.017)\end{array}$ & $\begin{array}{l}-0.030 * \\
(0.012)\end{array}$ \\
\hline$\%$ Annual Payroll in Manufacturing & $\begin{array}{l}-0.033 * * * \\
(0.006)\end{array}$ & $\begin{array}{l}-0.014 \\
(0.020)\end{array}$ & $\begin{array}{l}-0.036^{*} \\
(0.014)\end{array}$ & $\begin{array}{l}-0.028 * * \\
(0.010)\end{array}$ \\
\hline \multicolumn{5}{|l|}{ Male } \\
\hline \% Employees in Manufacturing & $\begin{array}{l}-0.045^{* * *} \\
(0.008)\end{array}$ & $\begin{array}{l}-0.062 * \\
(0.025)\end{array}$ & $\begin{array}{l}-0.058 * * * \\
(0.016)\end{array}$ & $\begin{array}{l}-0.045^{* *} \\
(0.014)\end{array}$ \\
\hline$\%$ Annual Payroll in Manufacturing & $\begin{array}{l}-0.039 * * * \\
(0.006)\end{array}$ & $\begin{array}{l}-0.039 \\
(0.021) \\
\end{array}$ & $\begin{array}{l}-0.048 * * \\
(0.015) \\
\end{array}$ & $\begin{array}{l}-0.037 * * \\
(0.011) \\
\end{array}$ \\
\hline \multicolumn{5}{|l|}{ B. Opioid Overdose Deaths } \\
\hline \multicolumn{5}{|l|}{ Manufacturing Measure } \\
\hline \multicolumn{5}{|l|}{ Female } \\
\hline \% Employees in Manufacturing & $\begin{array}{l}-0.090 * * * \\
(0.011)\end{array}$ & $\begin{array}{l}-0.030 \\
(0.023)\end{array}$ & $\begin{array}{l}-0.063 \\
(0.032)\end{array}$ & $\begin{array}{l}-0.050 * \\
(0.024)\end{array}$ \\
\hline$\%$ Annual Payroll in Manufacturing & $\begin{array}{l}-0.064 * * * \\
(0.008)\end{array}$ & $\begin{array}{l}-0.009 \\
(0.016)\end{array}$ & $\begin{array}{l}-0.056^{*} \\
(0.026)\end{array}$ & $\begin{array}{l}-0.046^{*} \\
(0.019)\end{array}$ \\
\hline \multicolumn{5}{|l|}{ Male } \\
\hline \% Employees in Manufacturing & $\begin{array}{l}-0.081 * * * \\
(0.010)\end{array}$ & $\begin{array}{l}-0.030 \\
(0.021)\end{array}$ & $\begin{array}{l}-0.071 * \\
(0.028)\end{array}$ & $\begin{array}{l}-0.066^{*} \\
(0.028)\end{array}$ \\
\hline \% Annual Payroll in Manufacturing & $\begin{array}{l}-0.059 * * * \\
(0.007)\end{array}$ & $\begin{array}{l}-0.013 \\
(0.015) \\
\end{array}$ & $\begin{array}{l}-0.053 * \\
(0.021) \\
\end{array}$ & $\begin{array}{l}-0.051 * \\
(0.022) \\
\end{array}$ \\
\hline \multicolumn{5}{|l|}{ C. Corrected Opioid Overdose Deaths } \\
\hline \multicolumn{5}{|l|}{ Manufacturing Measure } \\
\hline \multicolumn{5}{|l|}{ Female } \\
\hline$\%$ Employees in Manufacturing & $\begin{array}{l}-0.060 * * * \\
(0.010)\end{array}$ & $\begin{array}{l}0.004 \\
(0.020)\end{array}$ & $\begin{array}{l}-0.055 \\
(0.032)\end{array}$ & $\begin{array}{l}-0.057 * \\
(0.021)\end{array}$ \\
\hline$\%$ Annual Payroll in Manufacturing & $\begin{array}{l}-0.041 * * * \\
(0.008)\end{array}$ & $\begin{array}{l}0.012 \\
(0.014)\end{array}$ & $\begin{array}{l}-0.044 \\
(0.025)\end{array}$ & $\begin{array}{l}-0.047 * * \\
(0.017)\end{array}$ \\
\hline \multicolumn{5}{|l|}{ Male } \\
\hline$\%$ Employees in Manufacturing & $\begin{array}{l}-0.063 * * * \\
(0.009)\end{array}$ & $\begin{array}{l}0.003 \\
(0.020)\end{array}$ & $\begin{array}{l}-0.075^{* *} \\
(0.023)\end{array}$ & $\begin{array}{l}-0.071 * * * \\
(0.019)\end{array}$ \\
\hline$\%$ Annual Payroll in Manufacturing & $\begin{array}{l}-0.044 * * * \\
(0.007)\end{array}$ & $\begin{array}{l}0.004 \\
(0.014)\end{array}$ & $\begin{array}{l}-0.055^{*} \\
(0.022)\end{array}$ & $\begin{array}{l}-0.054 * * * \\
(0.015)\end{array}$ \\
\hline State and Year Fixed Effects & Yes & Yes & Yes & Yes \\
\hline Compositional and Economic Covariates & Yes & Yes & Yes & Yes \\
\hline Labor and Drug Policy Covariates & Yes & Yes & Yes & Yes \\
\hline
\end{tabular}

$* \mathrm{p}<.05, * * \mathrm{p}<.01, * * * \mathrm{p}<.001$ (two tailed tests)

Notes: (a) All models are equivalent to Model 2 specifications for covariates (unless otherwise indicated in Section 4.6 Additional Sensitivity Analyses), which include state and year fixed effects, compositional and economic covariates, and labor and drug policy covariates. (b) All 
covariates are lagged one year. (c) For Negative Binomial models, the exposure variable is set to annual state-level sex-specific population size. 
Table S5. Sensitivity Analyses, including Detailed Age Structure Controls, Percentage of the Population Born Outside of the U.S., and State-by-Year Linear Time Trends

\begin{tabular}{|c|c|c|c|}
\hline & $\begin{array}{c}\text { Detailed Age } \\
\text { Structure } \\
\text { Controls }\end{array}$ & $\begin{array}{l}\text { Percentage of } \\
\text { Population } \\
\text { Born Outside } \\
\text { of the U.S. }\end{array}$ & $\begin{array}{c}\text { State-by- } \\
\text { Year Linear } \\
\text { Time Trends }\end{array}$ \\
\hline \multicolumn{4}{|l|}{ A. Logged Drug Overdose Deaths } \\
\hline \multicolumn{4}{|l|}{ Manufacturing Measure } \\
\hline \multicolumn{4}{|l|}{ Female } \\
\hline \% Employees in Manufacturing & $\begin{array}{l}-0.030 \\
(0.016)\end{array}$ & $\begin{array}{l}-0.033 * * \\
(0.012)\end{array}$ & $\begin{array}{l}0.021 \\
(0.032)\end{array}$ \\
\hline$\%$ Annual Payroll in Manufacturing & $\begin{array}{l}-0.023^{*} \\
(0.012)\end{array}$ & $\begin{array}{l}-0.030 * * \\
(0.010)\end{array}$ & $\begin{array}{l}0.012 \\
(0.022)\end{array}$ \\
\hline \multicolumn{4}{|l|}{ Male } \\
\hline \% Employees in Manufacturing & $\begin{array}{l}-0.044 * * \\
(0.014)\end{array}$ & $\begin{array}{l}-0.051 * * * \\
(0.014)\end{array}$ & $\begin{array}{l}0.013 \\
(0.026)\end{array}$ \\
\hline$\%$ Annual Payroll in Manufacturing & $\begin{array}{l}-0.027 * \\
(0.011) \\
\end{array}$ & $\begin{array}{l}-0.039 * * * \\
(0.011) \\
\end{array}$ & $\begin{array}{l}0.014 \\
(0.016) \\
\end{array}$ \\
\hline \multicolumn{4}{|l|}{ B. Logged Opioid Overdose Deaths } \\
\hline \multicolumn{4}{|l|}{ Manufacturing Measure } \\
\hline \multicolumn{4}{|l|}{ Female } \\
\hline$\%$ Employees in Manufacturing & $\begin{array}{l}-0.058 * \\
(0.026)\end{array}$ & $\begin{array}{l}-0.056^{*} \\
(0.023)\end{array}$ & $\begin{array}{l}0.041 \\
(0.045)\end{array}$ \\
\hline$\%$ Annual Payroll in Manufacturing & $\begin{array}{l}-0.045^{*} \\
(0.021) \\
\end{array}$ & $\begin{array}{l}-0.050^{* *} \\
(0.018)\end{array}$ & $\begin{array}{l}0.015 \\
(0.033) \\
\end{array}$ \\
\hline \multicolumn{4}{|l|}{ Male } \\
\hline$\%$ Employees in Manufacturing & $\begin{array}{l}-0.084 * * * \\
(0.022)\end{array}$ & $\begin{array}{l}-0.072 * \\
(0.028)\end{array}$ & $\begin{array}{l}0.022 \\
(0.039)\end{array}$ \\
\hline$\%$ Annual Payroll in Manufacturing & $\begin{array}{l}-0.051 * * \\
(0.018) \\
\end{array}$ & $\begin{array}{l}-0.054^{*} \\
(0.021) \\
\end{array}$ & $\begin{array}{l}0.009 \\
(0.025) \\
\end{array}$ \\
\hline \multicolumn{4}{|c|}{ C. Logged Corrected Opioid Overdose Deaths } \\
\hline \multicolumn{4}{|l|}{ Manufacturing Measure } \\
\hline \multicolumn{4}{|l|}{ Female } \\
\hline$\%$ Employees in Manufacturing & $\begin{array}{l}-0.069 * \\
(0.026)\end{array}$ & $\begin{array}{l}-0.064 * * \\
(0.021)\end{array}$ & $\begin{array}{l}0.017 \\
(0.045)\end{array}$ \\
\hline$\%$ Annual Payroll in Manufacturing & $\begin{array}{l}-0.047^{*} \\
(0.020)\end{array}$ & $\begin{array}{l}-0.051 * * \\
(0.016)\end{array}$ & $\begin{array}{l}-0.004 \\
(0.032)\end{array}$ \\
\hline \multicolumn{4}{|l|}{ Male } \\
\hline$\%$ Employees in Manufacturing & $\begin{array}{l}-0.087 * * * \\
(0.021)\end{array}$ & $\begin{array}{l}-0.080 * * * \\
(0.019)\end{array}$ & $\begin{array}{l}-0.002 \\
(0.037)\end{array}$ \\
\hline$\%$ Annual Payroll in Manufacturing & $\begin{array}{l}-0.054 * * \\
(0.016)\end{array}$ & $\begin{array}{l}-0.058 * * * \\
(0.015)\end{array}$ & $\begin{array}{l}-0.005 \\
(0.025)\end{array}$ \\
\hline State and Year Fixed Effects & Yes & Yes & Yes \\
\hline Compositional and Economic Covariates & Yes & Yes & Yes \\
\hline Labor and Drug Policy Covariates & Yes & Yes & Yes \\
\hline
\end{tabular}

$* \mathrm{p}<.05, * * \mathrm{p}<.01, * * * \mathrm{p}<.001$ (two tailed tests)

Notes: (a) All models are equivalent to Model 2 specifications for covariates (unless otherwise indicated in Section 4.6 Additional Sensitivity Analyses), which include state and year fixed effects, compositional and economic covariates, and labor and drug policy covariates. (b) All 
covariates are lagged one year. (c) Detailed age structure controls include the percentage of the state population who are within 5-year age bin categories $(0-4,5-9, \ldots 85+)$. 
Table S6. Regression Analyses Predicting Rates of Emergency Department Visits and Inpatient Stays (2005-2017)

\begin{tabular}{|c|c|c|}
\hline \multicolumn{3}{|c|}{ A. Logged Emergency Department Visits Per 100,000 Population } \\
\hline Manufacturing Measure & Model 1 & Model 2 \\
\hline \multicolumn{3}{|l|}{ Female } \\
\hline$\%$ Employees in Manufacturing & $\begin{array}{l}-0.017 \\
(0.026)\end{array}$ & $\begin{array}{l}-0.017 \\
(0.026)\end{array}$ \\
\hline$\%$ Annual Payroll in Manufacturing & $\begin{array}{l}-0.007 \\
(0.022)\end{array}$ & $\begin{array}{l}-0.003 \\
(0.022)\end{array}$ \\
\hline $\mathrm{N}$ & 381 & 381 \\
\hline \multicolumn{3}{|l|}{ Male } \\
\hline$\%$ Employees in Manufacturing & $\begin{array}{l}-0.025 \\
(0.028)\end{array}$ & $\begin{array}{l}-0.023 \\
(0.030)\end{array}$ \\
\hline$\%$ Annual Payroll in Manufacturing & $\begin{array}{l}-0.021 \\
(0.023)\end{array}$ & $\begin{array}{l}-0.016 \\
(0.023)\end{array}$ \\
\hline $\mathrm{N}$ & 381 & 381 \\
\hline \multicolumn{3}{|c|}{ B. Logged Hospital Stays Per 100,000 Population } \\
\hline Manufacturing Measure & Model 1 & Model 2 \\
\hline \multicolumn{3}{|l|}{ Female } \\
\hline \% Employees in Manufacturing & $\begin{array}{l}-0.008 \\
(0.020)\end{array}$ & $\begin{array}{l}-0.007 \\
(0.019)\end{array}$ \\
\hline$\%$ Annual Payroll in Manufacturing & $\begin{array}{l}-0.005 \\
(0.013)\end{array}$ & $\begin{array}{l}-0.003 \\
(0.013)\end{array}$ \\
\hline $\mathrm{N}$ & 553 & 553 \\
\hline \multicolumn{3}{|l|}{ Male } \\
\hline$\%$ Employees in Manufacturing & $\begin{array}{l}-0.005 \\
(0.020)\end{array}$ & $\begin{array}{l}-0.005 \\
(0.019)\end{array}$ \\
\hline$\%$ Annual Payroll in Manufacturing & $\begin{array}{l}-0.000 \\
(0.014)\end{array}$ & $\begin{array}{l}0.001 \\
(0.013)\end{array}$ \\
\hline $\mathrm{N}$ & 553 & 553 \\
\hline State and Year Fixed Effects & Yes & Yes \\
\hline Compositional and Economic Covariates & Yes & Yes \\
\hline Labor and Drug Policy Covariates & No & Yes \\
\hline
\end{tabular}

$* \mathrm{p}<.05, * * \mathrm{p}<.01, * * * \mathrm{p}<.001$ (two tailed tests)

Notes: (a) All covariates are lagged one year. (b) State-clustered standard errors are in parentheses. (c) Data are available between 2005-2017 and most states do not have observations spanning those entire 13 years. (d) Compositional and economic covariates include state-level measures of the labor force participation rate, the percentage with a college degree, the percentage who have ever been married, the percentage who are Hispanic, the percentage who are Black, the percentage who are ages 18-64, the percentage who are ages 65 or above, the percentage living in metropolitan counties, and the average self-reported health score. (e) Labor and drug policy covariates include state-level measures of the percent of workers covered or represented by labor unions, and binary indicators of whether states have implemented three types of drug policies: PDMPs, naloxone access laws, and Good Samaritan laws for reporting drug overdoses. 